Aus dem Institut für Neuropathologie

(Prof. Dr. med. W. Brück)

im Zentrum Pathologie und Rechtsmedizin

der Medizinischen Fakultät der Universität Göttingen

\title{
Die Rolle der
}

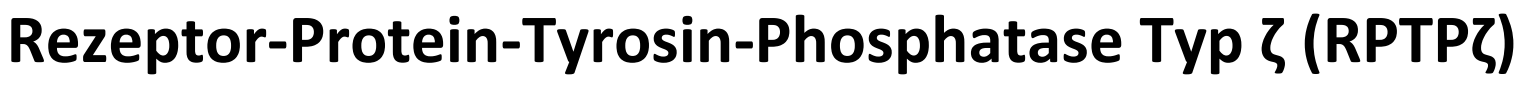
bei der

\section{De- und Remyelinisierung}

\author{
INAUGURAL-DISSERTATION \\ zur Erlangung des Doktorgrades \\ der medizinischen Fakultät \\ der Georg-August-Universität zu Göttingen
}

vorgelegt von
Gero Lockstaedt

aus

Bremen

Göttingen 2013 
Dekan:

I. Berichterstatterin: Prof. Dr. med. C. Stadelmann-Nessler

II. Berichterstatter: Prof. Dr. med. M. W. Sereda

III. Berichterstatter: Prof. Dr. med. dent. R. F. Mausberg

Tag der mündlichen Prüfung: 28. 10. 2013 


\section{Inhaltsverzeichnis}

Verzeichnis der Abbildungen im Text ..................................................... IV

Verzeichnis der Tabellen im Text................................................................ V

Verzeichnis der Abkürzungen ..................................................................... VI

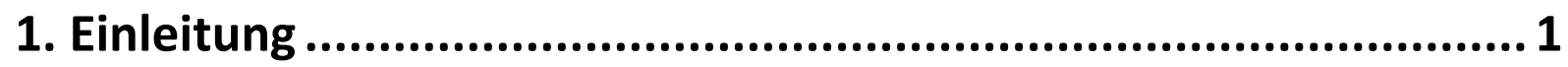

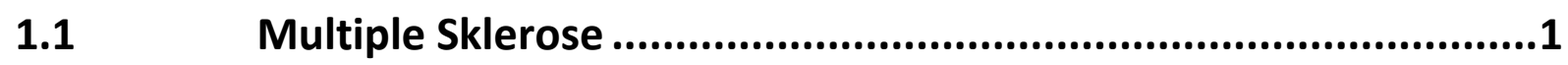

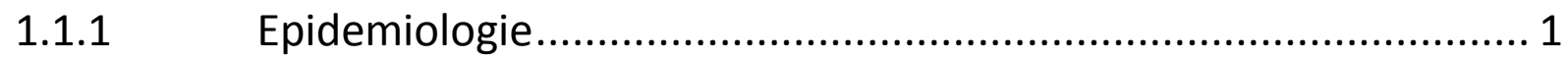

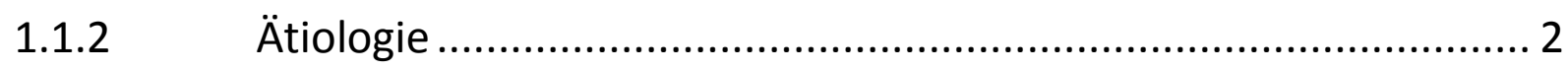

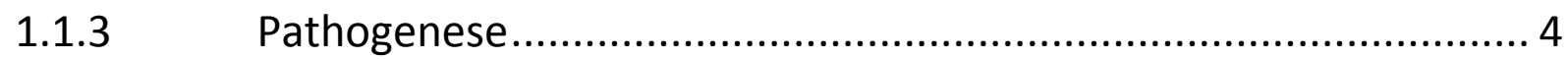

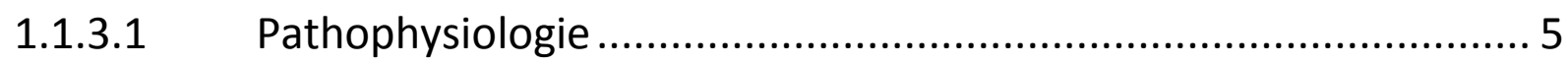

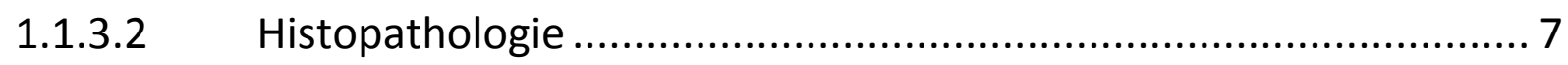

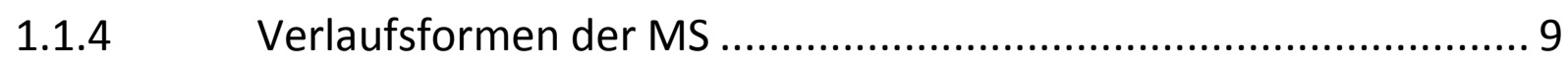

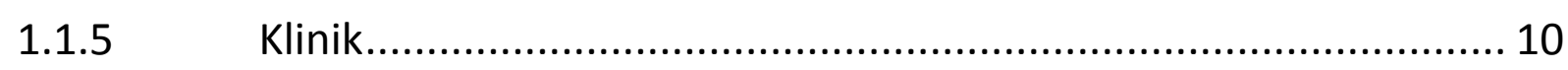

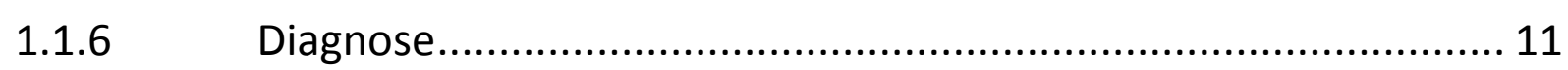

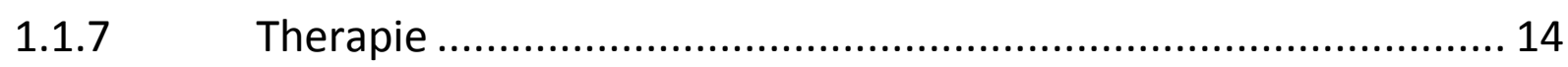

1.2 Tiermodelle der Multiplen Sklerose .........................................16

1.2.1 Toxisch induzierte Demyelinisierung per Cuprizon ...................... 16

1.2.2 Viral induzierte Demyelinisierung........................................... 20

1.2.3 Experimentelle autoimmune Enzephalomyelitis (EAE) ............... 21

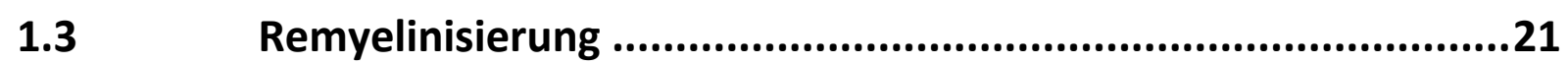

1.4 Protein-Tyrosin-Phosphatasen (PTPasen) ................................24

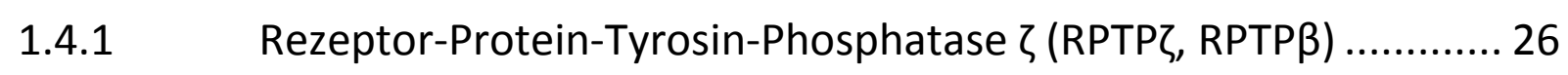

1.4.2 Rezeptor-Protein-Tyrosin-Phosphatase $\zeta$ bei der MS.................. 28

1.5 Fragestellung der vorliegenden Arbeit .................................30 
$2.1 \quad$ Material .31

2.1.1

Versuchstiere 31

2.1.2

Verfütterung von Cuprizon 31

2.1 .3 Verwendete Chemikalien 32

2.1 .4 Histologische Färbungen 34

2.1.5 Antikörper und spezielle Chemikalien zur immunhistochemischen Färbung 35

2.2 Methoden .37

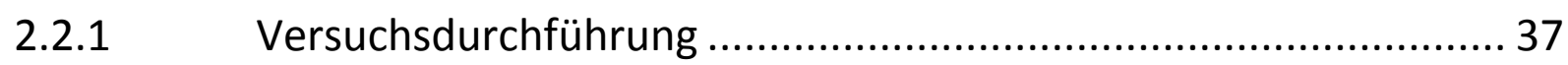

2.2.2 Perfusion und Präparation der Mäuse ........................................ 37

2.2.3 Histologische Färbemethoden .................................................. 38

2.2.4 Immunhistochemische Färbungen ........................................ 40

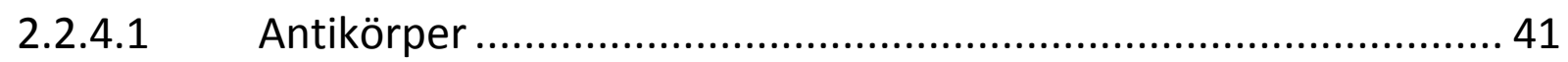

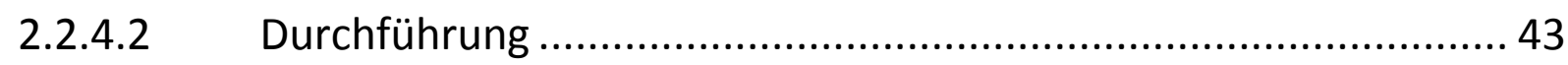

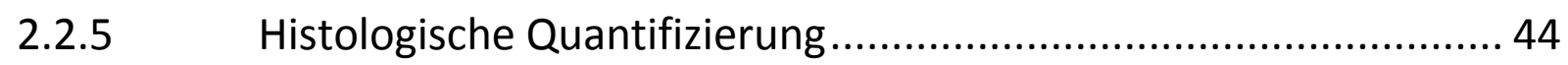

2.2.5.1 Zell-, Myelin- und Axonquantifizierung..................................... 45

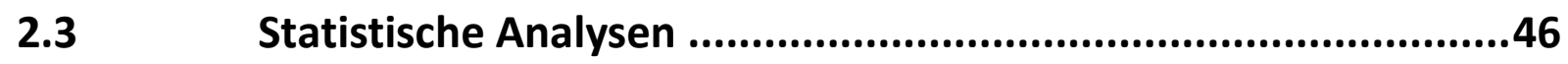

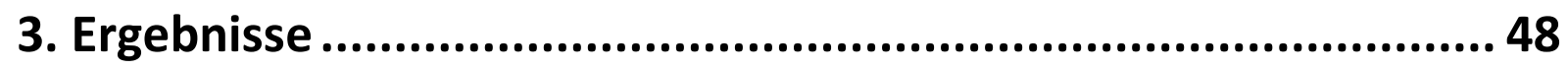

3.1 Morphometrische Analyse der Wildtyp-, RPTPל-heterozygoten und RPTPל-Knockout-Mäuse nach 6-wöchiger Verfütterung von Cuprizon.

3.1.1 Ausmaß der Entmarkung in Wildtyp-, RPTPל-heterozygoten und

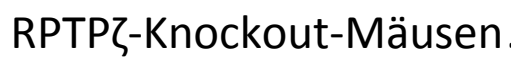
48

3.1.2 Dichte reifer Oligodendrozyten in Wildtyp-, RPTPל-heterozygoten

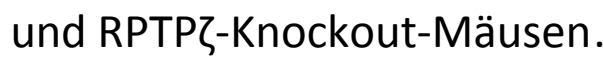

3.1.3 Dichte der Oligodendrozyten bzw. OligodendrozytenProgenitorzellen in Wildtyp- und RPTP $\zeta$-Knockout-Mäusen 53 
3.1.4 Axonale Schädigung in Wildtyp- und RPTPל-Knockout-Mäusen .... 55

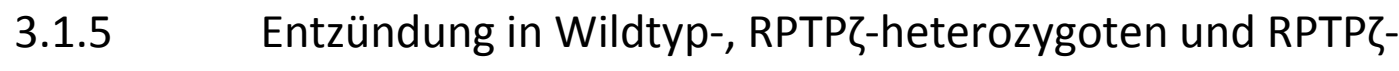

Knockout-Mäusen

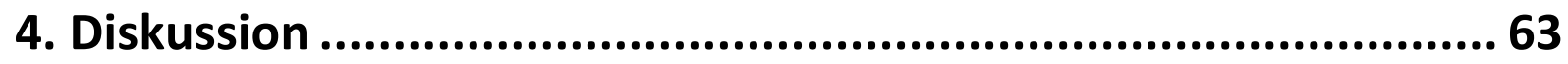

4.1 Die Bedeutung von RPTP für das Ausmaß der Entmarkung unter Cuprizon-Verfütterung ..............................................................64

4.2 Die Bedeutung von RPTP\ für das Ausmaß Cuprizon-induzierter Apoptosen von Oligodendrozyten .............................................65

4.3 Die Bedeutung von RPTP für das Ausmaß der Rekrutierung und Differenzierung von Oligodendrozyten-Progenitorzellen bei Cuprizon-induzierter Entmarkung

4.4 Die Bedeutung von RPTP für das Ausmaß der axonalen Schädigung bei Cuprizon-induzierter Entmarkung ......................69

4.5 Die Bedeutung von RPTP für das Ausmaß der Entzündung bei Cuprizon-induzierter Entmarkung ............................................71

5. Zusammenfassung ..................................................... 73

6. Anhang: Übersichtstabelle der Ergebnisse der statistischen Auswertung75 


\section{Verzeichnis der Abbildungen im Text}

Abbildung 1: $\quad$ Aufbau von Phosphacan und der RPTP $\beta$ Isoformen ............... 28

Abbildung 2: Überblick über die ausgewerteten Areale des ZNS mit

Markierung des Corpus callosum (Färbung)

Abbildung 3: Histopathologie der Cuprizon-induzierten Demyelinisierung (Färbung)

Abbildung 4: Ausmaß des Myelinverlustes in den medialen Arealen des

Corpus callosum nach Cuprizon-induzierter Entmarkung (graphische Darstellung) 50

Abbildung 5: Ausmaß des Myelinverlustes in den lateralen Arealen des

Corpus callosum nach Cuprizon-induzierter Entmarkung (graphische Darstellung)

Abbildung 6: Morphologie und Verteilung reifer Oligodendrozyten (Färbung)

Abbildung 7: Dichte der Nogo-A-positiven reifen Oligodendrozyten (graphische Darstellung)

Abbildung 8: Morphologie und Verteilung der Oligodendrozyten und ihrer Progenitorzellen (Färbung).

Abbildung 9: $\quad$ Dichte der Olig-2-positiven Oligodendrozyten bzw.

Oligodendrozyten-Progenitorzellen (graphische

Darstellung)

Abbildung 10: Morphologie und Verteilung axonaler Schädigung (Färbung) 56

Abbildung 11: Dichte der APP-positiven axonalen Sphäroide (graphische Darstellung)

Abbildung 12: Morphologie und Verteilung der T-Lymphozyten (Färbung) 59

Abbildung 13: Dichte der CD3-positiven T-Lymphozyten (graphische

Darstellung) 60

Abbildung 14: Morphologie und Verteilung aktivierter Mikroglia (Färbung) 61

Abbildung 15: Dichte der Mac-3-positiven aktivierten Mikroglia (graphische Darstellung) 


\section{Verzeichnis der Tabellen im Text}

Tabelle 1: Diagnostische Kriterien der MS nach McDonald, revidiert nach Polman et al. (2011) ............................................................. 12

Tabelle 2: Verwendete Chemikalien .................................................. 32

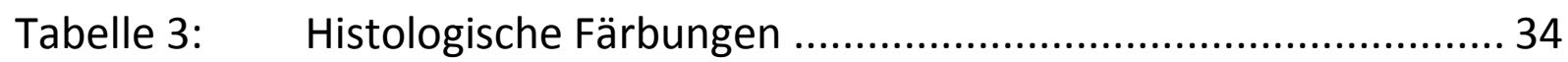

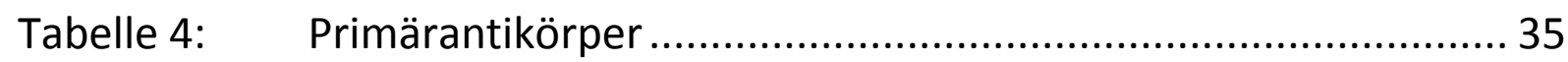

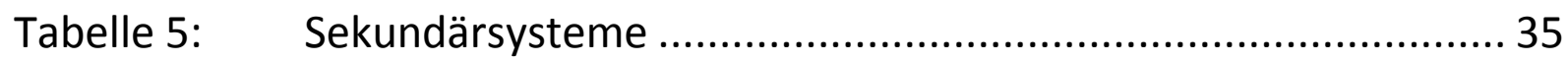

Tabelle 6: Semiquantitativer Score zur Bestimmung des Myelinverlustes bei Cuprizon-induzierter Entmarkung des Corpus callosum nach Hiremath et al. (1998) .......................................................... 45

Tabelle 7: Übersicht der Ergebnisse der statistischen Auswertung ........... 75 


\section{Verzeichnis der Abkürzungen}

Abb.:

Abbildung

ADEM:

akute disseminierte Enzephalomyelitis

ANOVA:

analysis of variance

(Varianzanalyse)

APC:

antigen presenting cell

(Antigen-präsentierende Zelle)

APP:

amyloid precursor protein

(Amyloid-Vorläuferprotein)

Aqua bidest.: $\quad$ zweifach destilliertes Wasser

Aqua dest.: destilliertes Wasser

BDNF:

brain-derived neurotrophic factor

(aus Hirngewebe stammender neurotropher Faktor)

BHS: Blut-Hirn-Schranke

bzgl.: bezüglich

bzw.: beziehungsweise

${ }^{\circ} \mathrm{C}$ : $\quad$ Grad Celsius

CA: $\quad$ carbonic anhydrase

(Carboanhydrase)

CA II: $\quad$ carbonic anhydrase II

(Carboanhydrase II)

ca.: $\quad$ circa

(ungefähr, etwa)

$\mathrm{Ca}^{2+}: \quad$ Calcium

CAM: cell adhesion molecule

(Zelladhäsionsmolekül)

Caspr: contactin-associated protein

(Contactin-assoziiertes Protein)

CD3: $\quad$ cluster of differentiation 3

(Differenzierungsmuster 3)

CD4: $\quad$ cluster of differentiation 4

(Differenzierungsmuster 4) 
CD8: $\quad$ cluster of differentiation 8

(Differenzierungsmuster 8)

CD45: $\quad$ cluster of differentiation 45

(Differenzierungsmuster 45)

CEC: cerebral endothelial cell

(zerebrale Endothelzelle)

CIS: $\quad$ clinically isolated syndrome

(klinisch isoliertes Syndrom)

CNTF: ciliary neurotrophic factor

(ziliarer neurotropher Faktor)

CSF: cerebrospinal fluid

(Liquor)

CS GAG: $\quad$ chondroitin sulphate glycosaminoglycan chain

(Chondroitin-Sulfat-Glykosaminoglykan-Kette)

Cuprizon: Biscyclohexanon Oxalyldihydrazon

D1: $\quad$ phosphatase domain 1

(Phosphatasedomäne 1)

D2: $\quad$ phosphatase domain 2

(Phosphatasedomäne 2)

DAB:

3,3`-Diaminobenzidin-Tetrahydrochlorid

DEP-1:

density-enhanced protein-tyrosine-phosphatase-1

(Protein-Tyrosin-Phosphatase-1; ihre Expression steigt in verschiedenen Zelltypen mit der Zelldichte an)

d. h.: das heißt

DIS: dissemination in space

(räumliche Dissemination)

DIT: dissemination in time

(zeitliche Dissemination)

DNA: desoxyribonucleic acid

(Desoxyribonukleinsäure)

DSP: dual-specific phosphatase

(dualspezifische Phosphatase)

EAE: $\quad$ experimentelle autoimmune Enzephalomyelitis 
EDSS: $\quad$ expanded disability status scale

(Skala der Schwere der Behinderung bei der MS nach

Kurtzke (1983)

et al.: et alii

(und andere)

FCS: $\quad$ fetal calf serum

(fetales Kälberserum)

FN: fibronectin

(Fibronektin)

g:

Gramm

GLEPP-1: $\quad$ glomerular epithelial protein-1

(glomeruläres epitheliales Protein-1)

h: hours

(Stunden)

$\mathrm{HCl}: \quad$ Chlorwasserstoff

HE: Hämatoxylin-Eosin

HLA: human leukozyte antigen

(humanes Leukozytenantigen)

$\mathrm{H}_{2} \mathrm{O}_{2}: \quad$ Wasserstoffperoxid

ICAM: intercellular adhesion molecule

(interzelluläres Adhäsionsmolekül)

IFN- $\beta$ : $\quad$ Interferon- $\beta$

IFN- $\gamma$ : Interferon- $\gamma$

Ig: Immunglobulin

IGF-1: insulin-like growth factor-1

(Insulin-artiger Wachstumsfaktor-1)

IgG: Immunglobulin G

IL: Interleukin

IL2RA: Interleukin-2-Rezeptor $\alpha$

IL7RA: Interleukin-7-Rezeptor $\alpha$

i. p.: intraperitoneal

IS: $\quad$ intervening sequence

(dazwischenliegende Sequenz)

IVIG: intravenöse Verabreichung von Immunglobulinen 
I:

Kat.:

LAR:

LFA-1:

LFB:

Mac-3:

MAG:

MAM:

MBP:

$\mathrm{mg}$ :

$\mathrm{Mg}^{2+}:$

MHC:

$\mathrm{ml}:$

$\mu l:$

$\mathrm{mm}$ :

$\mathrm{mM}$ :

$\mu \mathrm{m}$ :

$\mathrm{mm}^{2}$ :

MMP:

MOG:

mRNA:

MRT:

MS:

MTX:

MW:
Liter

Katalog

leukocyte antigen-related protein

lymphocyte function-associated antigen

(lymphozytäres Funktions-assoziiertes Antigen-1)

$$
\text { Luxol-fast-blue }
$$

Mikroglia-/Makrophagenmarker

myelin-associated glycoprotein

(Myelin-assoziiertes Glykoprotein)

meprin-A5 antigen-PTP-mu

(Meprin-A5 Antigen-PTP- $\mu$ )

myelin-basic protein

(basisches Myelinprotein)

Milligramm

Magnesium

major histocompatibility complex

(Haupthistokompatibilitätskomplex)

Milliliter

Mikroliter

Millimeter

Millimol

Mikrometer

Quadratmillimeter

matrix-metalloproteinase

(Matrix-Metalloproteinase)

myelin oligodendrocyte glycoprotein

(Myelin-Oligodendrozyten-Glykoprotein)

messenger ribonucleic acid

(Boten-Ribonukleinsäure)

Magnetresonanztomographie

Multiple Sklerose

Methotrexat

Mittelwert 
N-CAM: $\quad$ neural cell adhesion molecule (neurales Zelladhäsionsmolekül)

Ng-CAM: $\quad$ neuron-glia cell adhesion molecule (Neuron-Glia-Zelladhäsionsmolekül)

NO:

Stickstoffmonoxid

Nogo-A:

neurite outgrowth inhibitory protein A

(Neuritenwachstum-hemmendes Protein A)

Nr-CAM: $\quad$ neuronal cell adhesion molecule (neuronales Zelladhäsionsmolekül)

NRPTP: $\quad$ non receptor-protein-tyrosine-phosphatase (intrazelluläre Protein-Tyrosin-Phosphatase)

Olig-2: oligodendrocyte transcription factor 2 (Oligodendrozyten-Transkriptionsfaktor 2)

$\pm:$ plus minus

PAS: periodic acid-Schiff (Periodsäure-Schiff)

PBS: $\quad$ phosphate buffered saline (Phosphat-gepufferte Salzlösung)

PCP-2: $\quad$ purkinje cell protein-2

(Purkinjezellprotein 2)

PDGF: $\quad$ plateled-derived growth factor (aus Blutplättchen stammender Wachstumsfaktor)

PFA: $\quad$ Paraformaldehyd

PLP: $\quad$ proteolipid protein

(Proteolipidprotein)

PP-MS: $\quad$ primary-progressive multiple sclerosis (primär chronisch-progrediente Multiple Sklerose)

PR-MS: $\quad$ progressive-relapsing multiple sclerosis (progredient-schubförmige Multiple Sklerose)

PSD-95: $\quad$ postsynaptic density protein-95 (postsynaptisches Dichte-Protein-95)

PTK: $\quad$ protein-tyrosine-kinase

(Protein-Tyrosin-Kinase) 
PTP: $\quad$ protein-tyrosine-phosphatase

(Protein-Tyrosin-Phosphatase)

PTPase: $\quad$ Protein-Tyrosin-Phosphatase

Ptprz1: $\quad$ protein-tyrosine-phosphatase receptor-type zeta 1

(Protein-Tyrosin-Phosphatase-Rezeptor-Typ zeta 1)

RPTP: $\quad$ receptor-like protein-tyrosine-phosphatase

(Rezeptor-Protein-Tyrosin-Phosphatase)

RPTPase: Rezeptor-Protein-Tyrosin-Phosphatase

RPTP弓:

receptor-like protein-tyrosine-phosphatase type $\zeta$

(Rezeptor-Protein-Tyrosin-Phosphatase Typ $\zeta$ )

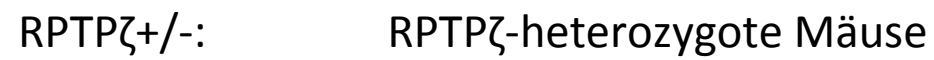

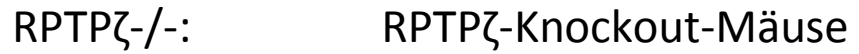

RR-MS: $\quad$ relapsing-remitting multiple sclerosis

(schubförmige Multiple Sklerose)

S: $\quad$ spacer region

(Spacer Region)

SAP-1: $\quad$ stomach cancer-associated protein-tyrosine-phosphatase-1

(Magenkarzinom-assoziierte Protein-Tyrosin-Phosphatase-1)

SAP90: $\quad$ synapse-associated protein 90

(Synapsen-assoziiertes Protein 90)

SD: $\quad$ standard deviation

(Standardabweichung)

SP-MS: $\quad$ secondary-progressive multiple sclerosis

(sekundär chronisch-progrediente Multiple Sklerose)

Tab.: Tabelle

TCR: $\quad T$ cell receptor

(T-Zell-Rezeptor)

TMEV: $\quad$ Theiler's murine encephalomyelitis virus

(Theiler`s Murine Encephalomyelitis Virus der Maus)

TNF- $\alpha$ : Tumornekrosefaktor- $\alpha$

u. a.: unter anderem

VCAM: vascular cell adhesion molecule

(vaskuläres Zelladhäsionsmolekül)

v. a.: $\quad$ vor allem 
VEP:

vgl.:

VLA-4:

wt:

z. B.:

ZNS: visuell evoziertes Potenzial

$$
\text { vergleiche }
$$

very late antigen-4

Wildtyp-Mäuse

$$
\text { zum Beispiel }
$$

zentrales Nervensystem 


\section{$1 \quad$ Einleitung}

\subsection{Multiple Sklerose}

\subsubsection{Epidemiologie}

Bei der Multiplen Sklerose (MS) handelt es sich um eine chronisch entzündliche Erkrankung des zentralen Nervensystems (ZNS). Die Anzahl der MS-Patienten in Deutschland beläuft sich auf ca. 122.000, was einer Prävalenzrate von 149,1 auf 100.000 Einwohner entspricht (Hein und Hopfenmüller 2000).

Die MS stellt die häufigste Ursache für eine dauerhafte Behinderung im jungen Erwachsenenalter dar. Der Gipfel des Erstmanifestationsalters liegt zwischen dem 20. und 40. Lebensjahr. Es hat sich ebenfalls gezeigt, dass Frauen mit einem Verhältnis von ca. 2,5: 1 häufiger von der Erkrankung MS betroffen sind als Männer (Flachenecker et al. 2008).

Auch bei der globalen Verteilung der Erkrankungshäufigkeit gibt es deutliche Unterschiede:

Während die MS am häufigsten bei der weißen Bevölkerung Nordeuropas und Nordamerikas auftritt, so erkranken z. B. die schwarze Bevölkerung Afrikas oder die Menschen in Japan oder China nur selten (Acheson 1977). Gleichzeitig fällt auf, dass die Erkrankung MS besonders häufig in Regionen auftritt, in denen Menschen mit skandinavischer Abstammung leben und dass unabhängig davon auch innerhalb eines Landes bzw. einer Region die MS-Prävalenz bei den Einwohnern mit unterschiedlicher ethnischer Abstammung stark variieren kann (Poser 1994). Dieses gehäufte Auftreten von MS innerhalb bestimmter geographischer Gebiete wird auch als Cluster bezeichnet (Hogancamp et al. 1997). 


\subsection{2 Ätiologie}

Die MS ist eine Autoimmunerkrankung (Lutton et al. 2004) mit bislang ungeklärter Ätiologie (Hogancamp et al. 1997).

Als Ursache für die Erkrankung werden sowohl eine genetische Veranlagung als auch der Einfluss der Umweltbedingungen in den verschiedenen Regionen der Erde diskutiert.

Es gibt Hinweise dafür, dass eine genetische Prädisposition für die Erkrankung an MS mitverantwortlich ist. So z. B. die Tatsache, dass die MS unabhängig vom jeweiligen Kontinent am häufigsten bei der weißen Bevölkerung vorkommt, insbesondere im Falle nordeuropäischer Abstammung, während andere ethnische Gruppen, wie die schwarze Bevölkerung Afrikas (Poser 1994) oder die Bevölkerung des Orients, deutlich seltener betroffen sind (Hogancamp et al. 1997).

Ebenso zeigt sich, dass Verwandte von MS-Erkrankten in Abhängigkeit vom Verwandtschaftsgrad ein erhöhtes Erkrankungsrisiko haben. Im Vergleich zur Normalbevölkerung ist das Erkrankungsrisiko bei Verwandten ersten Grades 15- bis 25-fach, bei zweieiigen Zwillingen ebenfalls 15 - bis 25-fach und bei eineiigen Zwillingen 190-fach erhöht. Im Gegensatz dazu haben Adoptivkinder erkrankter Menschen ein Erkrankungsrisiko, das dem der Normalbevölkerung entspricht (Sadovnick 2002). Aufgrund dieser Zahlen und der Tatsache, dass bisher keine MS-spezifischen Gene identifiziert werden konnten, wird von einer polygenetischen Vererbung ausgegangen, die im Gegensatz zu klassischen Erbkrankheiten nicht den Mendelschen Regeln folgt (Ebers und Sadovnick 1994). Allerdings ist eine Assoziation mit HLA DR2 sowie mit Polymorphismen in nicht-HLA-Genen wie dem Interleukin-2-Rezeptor- $\alpha$-Gen (IL2RA) und dem Interleukin-7-Rezeptor- $\alpha$-Gen (IL7RA) (Hafler et al. 2007) belegt. Hingegen ist eine X-chromosomale Vererbung ausgeschlossen, da die Erkrankungsrate bei väterlichen und mütterlichen Onkeln von MS-Erkrankten gleich hoch ausfällt (Hogancamp et al. 1997).

Auf der anderen Seite gibt es Daten, die die Bedeutung der Umweltbedingungen betonen. So zum Beispiel die Konkordanz von MS bei 
eineiigen Zwillingen, welche mit 26\% zu gering für eine rein genetische Genese ausfällt (Hogancamp et al. 1997).

Auch Migrationsstudien belegen den Einfluss der Umwelt auf das Erkrankungsrisiko, da sie zeigen, dass sich das Erkrankungsrisiko von Migranten dem der neuen Heimat anzugleichen scheint. Hierbei fällt allerdings auf, dass das Ausmaß der Risikoänderung augenscheinlich sowohl vom Lebensalter zum Zeitpunkt der Migration als auch von der ethnischen Abstammung abhängig ist. So hat es den Anschein, dass sich das Risiko v. a. bei unter 15-jährigen Migranten an das des neuen Heimatlandes angleicht, während es bei über 15jährigen Migranten weiterhin dem der Herkunftsregion zu entsprechen scheint. Die Erkrankungshäufigkeit für MS bei den im neuen Heimatland geborenen Kindern von Migranten entspricht der der dort lebenden Normalbevölkerung, wie Elian et al. 1990 z. B. für die Kinder von Migranten aus Asien, Afrika und Westindien in England belegen konnten. Detels et al. konnten 1977 allerdings zeigen, dass sich das ursprünglich geringe Erkrankungsrisiko von Japanern nach Auswanderung in die USA nur in unerwartet geringem Ausmaß dem der USBürger angleicht.

Dies lässt darauf schließen, dass die Ätiologie für eine Erkrankung an MS in einer genetischen Prädisposition in Kombination mit unter anderem geographisch bedingten Umwelteinflüssen insbesondere während der ersten 15 Lebensjahre zu sehen ist.

Vor diesem Hintergrund haben sich zahlreiche Untersuchungen damit beschäftigt, inwiefern früh im Leben durchgemachte Infektionen mit Viren, wie dem Epstein-Barr-Virus oder dem humanen Herpesvirus 6, an der Entstehung von MS mitbeteiligt sein könnten. Bisher konnte allerdings nicht belegt werden, dass tatsächlich ein bestimmtes Virus spezifisch für die Erkrankung MS ist (Cermelli und Jacobson 2000). Gleiches gilt für die Infektion mit Chlamydia pneumoniae (Gieffers et al. 2001).

Dennoch scheint ein Zusammenhang von MS mit diversen Viruserkrankungen, bzw. einer Infektion mit Chlamydia pneumoniae, denkbar. Dies wäre auch mit dem Umstand vereinbar (Cermelli und Jacobson 2000), dass sich die MS durch eine sowohl klinische als auch pathologische Heterogenität auszeichnet (Lucchinetti et al. 2000). 


\subsubsection{Pathogenese}

Die MS ist eine komplexe Autoimmunerkrankung des ZNS und gekennzeichnet durch Entzündung, eine vermutlich dadurch bedingte Zerstörung der Markscheiden (Demyelinisierung) sowie durch Schädigung bis hin zu völligem Funktionsverlust von Axonen, welche sowohl mit dem Ausmaß der entzündlichen Aktivität als auch der Schwere der chronischen Behinderung einhergeht. Eine Störung der Blut-Hirn-Schranke (BHS) sowie der Untergang von Oligodendrozyten und die reaktive Gliose sind weitere Wesensmerkmale der MS (Dutta und Trapp 2007).

Zurzeit wird davon ausgegangen, dass es hierzu durch Aktivierung autoreaktiver T-Zellen im Rahmen einer Autoimmunität kommt (Lucchinetti et al. 2000), womöglich aber auch ausgelöst durch den Kontakt mit einem bisher noch unbekannten infektiösen Agens (Cermelli und Jacobson 2000).

Aufgrund der Tatsache, dass bei der MS sehr unterschiedliche klinische Verläufe ebenso wie eine unterschiedliche Darstellung der Läsionen in neuroradiologischen Untersuchungen und z. B. auch ein sehr unterschiedliches Ansprechen auf verschiedene Therapieformen beobachtet werden können, entsteht der Eindruck, dass dieser Erkrankung von Patient zu Patient jeweils unterschiedliche pathophysiologische Mechanismen zugrunde liegen (Lucchinetti et al. 2000).

Prädilektionsstellen der MS sind der optische Nerv, die unmittelbar subpial gelegenen Cortexareale ( $\mathrm{B} \varnothing$ et al. 2003), die periventrikulären Areale, der Hirnstamm, das Kleinhirn und die Kleinhirnstiele sowie das Rückenmark (Gleixner 2007/2008).

Folge der Demyelinisierung ist das Ausbleiben einer schnellen saltatorischen Erregungsleitung. Stattdessen kommt es zu einer langsamen Ausbreitung der Erregung, bei der auch Verlustströme auftreten. Eine vollständige Leitungsunterbrechung resultiert aus einer axonalen Schädigung. 


\subsubsection{Pathophysiologie}

Die der MS zugrundeliegende Pathophysiologie ist bis heute größtenteils ungeklärt (Trebst et al. 2006). Allem Anschein nach kommt es bei der MS zu einer Aktivierung autoreaktiver T-Zellen durch Präsentation von Myelinbestandteilen durch Antigen-präsentierende Zellen (APC) in peripheren lymphatischen Organen wie z. B. den Lymphknoten (de Vos et al. 2002).

Daneben wird auch eine Aktivierung im Rahmen einer Kreuzreaktivität mit viralen oder bakteriellen Antigenen in Betracht gezogen (Molekulares Mimikry; dies beschreibt die Ähnlichkeit von Antigenen menschlicher und mikrobieller Herkunft) (Oldstone 1998; Benoist und Mathis 2001).

Nach Wingerchuk et al. (2001) gelingt es den autoreaktiven T-Zellen im weiteren Verlauf auf bisher noch nicht vollständig geklärte Art und Weise, die Blut-Hirn-Schranke (BHS) zu überwinden, welche aus zerebralen Endothelzellen (CEC), Perizyten, deren Basalmembran, sowie aus Astrozyten und perivaskulären Makrophagen/Mikroglia besteht (Minagar und Alexander 2003) und normalerweise eine immunologische Barriere darstellt (Risau et al. 1990). Es scheint jedoch, dass es hierbei durch von aktivierten T-Zellen und Makrophagen/Mikroglia ausgeschüttete, proinflammatorisch wirkende Zytokine und Chemokine zur Aktivierung zerebraler Endothelzellen (CEC) und dadurch zur Expression von u. a. vaskulären Zelladhäsionsmolekülen (vascular cell adhesion molecule, VCAM), interzellulären Adhäsionsmolekülen (intercellular adhesion molecule, ICAM) und MHC-Klasse-II-Molekülen, sowie zur Beeinflussung der endothelialen Tight Junctions kommt. Auf der anderen Seite exprimieren aktivierte T-Zellen selbst Integrine wie das very late antigen (VLA-4, auch als a4-Integrin bezeichnet), das lymphozytäre Funktionsassoziierte Antigen-1 (LFA-1) und CD4 und binden dann über diese an die Adhäsionsmoleküle der Endothelzellen, bevor es zur Diapedese der T-Zellen durch die Endothelzellen kommt. Im Anschluss hieran müssen die T-Zellen noch die extrazelluläre Matrix der BHS durchdringen. Hierzu sezernieren sie sogenannte Matrix-Metalloproteinasen (MMPs), welche Kollagen IV, einen Bestandteil der extrazellulären Matrix, abbauen (Steinman 2001). 
Nach der Migration ins ZNS werden die T-Helfer-Zellen reaktiviert, wodurch es letztlich zur Entzündung kommt. Die Reaktivierung der T-Helfer-Zellen erfolgt durch Kontakt mit Autoantigenen, wobei es sich mutmaßlich u. a. um das $\alpha \mathrm{B}-$ Crystallin (heat shock-protein) (van Noort et al. 1995), das Myelin-assoziierte Glykoprotein (MAG), das basische Myelinprotein (MBP), das MyelinOligodendrozyten-Glykoprotein (MOG) bzw. das Proteolipidprotein (PLP) handelt (de Rosbo et al. 1993). Dies geschieht im Rahmen einer Interaktion von T-Helferzellen mit Antigen-präsentierenden Zellen (APC) (z. B. dendritische Zellen, Makrophagen, Mikroglia, Astrozyten) über deren MHC-II-Komplex mit dem präsentierten Antigen und dem T-Zell-Rezeptor (TCR). Im Anschluss hieran produzieren die aktivierten T-Helferzellen proinflammatorische Zytokine (Abbas et al. 1996).

Typ1-Helferzellen produzieren typischerweise Interferon- $\gamma$ (IFN- $\gamma$ ), Interleukin2 (IL-2) und Tumornekrosefaktor- $\alpha$ (TNF- $\alpha$ ). Diese wirken direkt toxisch auf Myelin und Oligodendrozyten. Sie aktivieren aber auch Makrophagen/Mikroglia, welche dann mittels Phagozytose wesentlich zur Demyelinisierung beitragen (Lassmann et al. 2001). Die genannten Zytokine bewirken aber auch, dass Makrophagen, Mikroglia und Astrozyten u. a. Stickstoffmonoxid (NO) freisetzen, welches ebenfalls zytotoxisch wirkt (Steinman 2001).

Typ2-Helferzellen hingegen produzieren u. a. die Interleukine (IL) 4, 5, 6, 10 und 13, welche die Differenzierung von B-Lymphozyten zu Antikörpersezernierenden Plasmazellen bewirken. Diese Antikörper binden im weiteren Verlauf an diverse Epitope der Myelinscheiden und Oligodendrozyten und können dann über verschiedene Mechanismen die Demyelinisierung vorantreiben, z. B. mittels Veranlassung von Phagozytose oder Aktivierung des Komplementsystems.

Zytotoxische, CD8-positive T-Zellen werden einerseits durch AntigenPräsentation über den MHC-I-Komplex auf Myelinscheiden und Oligodendrozyten aktiviert, andererseits aber auch durch IFN- $\gamma$ und entfalten daraufhin direkt ihre zytotoxische Wirkung. 
Aus dem Zusammenspiel der hier genannten Mechanismen resultiert allem Anschein nach schließlich die Zerstörung der Myelinscheiden und Phagozytose durch Makrophagen/Mikroglia (Steinmann 2001). Zusätzlich wird diskutiert, inwieweit z. B. auch Sauerstoffradikale (Toshniwal und Zarling 1992) oder ein gestörter Glutamat-Stoffwechsel (Pitt et al. 2000) am Untergang von Myelin und Oligodendrozyten beteiligt sein können.

Bei der MS kommt es auch zu Axonschäden bis hin zum Verlust von Axonen. Dieser Vorgang kann bereits zu Beginn der Erkrankung beobachtet werden und geht wahrscheinlich mit dem Ausmaß der Entzündung einher. Der Untergang der Myelinscheiden aber auch eine Störung der axonalen lonenkonzentrationen oder des Energiehaushaltes sowie eine $\mathrm{Ca}^{2+}$ Akkumulation scheinen u. a. ursächlich zu sein (Dutta und Trapp 2007).

Die Entzündung bzw. die beteiligten Immunzellen können augenscheinlich neben destruktiven Effekten auch eine neuroprotektive Wirkung entfalten und zur Remyelinisierung beitragen. Es wird davon ausgegangen, dass dies beispielsweise durch Sekretion neuronaler Wachstumsfaktoren, wie BDNF (brain-derived neurotrophic factor), durch T-Zellen und andere Immunzellen erfolgt (Hohlfeld et al. 2000).

Im Rahmen der hier dargestellten Hirnschädigung kommt es auch zu einer Astrozytenproliferation, aus der letztlich eine Gliose, also eine Narbenbildung, resultiert (Norton et al. 1992).

\subsubsection{Histopathologie}

Lucchinetti et al. konnten im Jahr 2000 durch die histopathologische Untersuchung von Biopsien und Autopsien unterschiedlicher Patienten zeigen, dass bei der MS vier unterschiedliche histopathologische Läsionsmuster vorkommen. Diese können anhand diverser Kriterien voneinander abgegrenzt werden. Hierzu gehören das Ausmaß des Myelinverlustes, die Lokalisation und Ausdehnung der Plaques, das Muster der Oligodendrozytenzerstörung, sowie die Aktivierung des Komplementsystems: 
Typ 1: Es zeigen sich entzündliche, aktiv demyelinisierende, scharf begrenzte und hauptsächlich neben Venen und Venolen lokalisierte Areale mit einer Präsenz von v. a. T-Lymphozyten und Makrophagen.

Typ 2: $\quad$ Dieses Schädigungsmuster weist die gleichen Merkmale wie Typ 1 auf. Zusätzlich fällt allerdings eine ausgeprägte Ablagerung von Antikörpern und Komplementfaktoren im Randbereich der Läsionen auf.

Typ 3: Hier zeigen sich entzündliche, aktiv demyelinisierende Läsionen, die aber unscharf begrenzt sind. Es dominieren T-Lymphozyten, Makrophagen und aktivierte Mikroglia, während eine Ablagerung von Antikörpern oder Komplementfaktoren nicht beobachtet werden kann. Innerhalb demyelinisierter Plaques zeigt sich am Rand entzündlich veränderter Gefäße ein Erhalt von Myelin. Typisch ist das Vorkommen zahlreicher apoptotischer Oligodendrozyten. Außerdem ist ein selektiver, früher Verlust von Myelin-assoziiertem Glykoprotein (MAG) zu beobachten.

Typ 4: Entzündliche, aktiv demyelinisierende, scharf begrenzte Läsionen, dominiert von T-Lymphozyten und Makrophagen aber ohne Ablagerung von Antikörpern oder Komplementfaktoren. Es zeigt sich ein Oligodendrozytenuntergang in der die Läsion umgebenden weißen Substanz.

Am häufigsten kann das Läsionsmuster Nr. 2 beobachtet werden, gefolgt von Nr. 3, Nr. 1 und Nr. 4.

Außerdem fällt auf, dass bei jedem Patienten zu einem bestimmten Zeitpunkt immer nur eines der verschiedenen Läsionsmuster gefunden werden kann. 


\subsubsection{Verlaufsformen der MS}

Die Einteilung der MS erfolgt nach Lublin und Reingold (1996) anhand der Verlaufsformen. Maßgebende Kriterien sind hierbei zeitlicher Verlauf und Merkmale der Symptome.

Die schubförmige MS (relapsing-remitting multiple sclerosis, RR-MS) ist mit 85\% die häufigste Form. Hier kommt es nach Auftreten von Symptomen jeweils zu einer vollständigen oder unvollständigen Remission, gefolgt von einem Intervall vollständiger oder teilweiser Beschwerdefreiheit, bevor sich ein neuer Schub ereignet.

Bei dem sekundär chronisch-progredienten Verlauf (secondary-progressive multiple sclerosis, SP-MS) kommt es nach einem anfänglich schubförmigen Krankheitsverlauf zu einem Übergang in einen chronisch-progredienten Verlauf. Dabei kann es auch zu Schüben und leichten Remissionen kommen. Ca. $50 \%$ der Patienten mit RR-MS entwickeln im Verlauf eine SP-MS.

Ca. $15 \%$ der MS-Erkrankten zeigen einen primär chronisch-progredienten Krankheitsverlauf (primary-progressive multiple sclerosis, PP-MS). Bei dieser Form der MS kommt es von Beginn an zu einem steten Voranschreiten der Erkrankung ohne Schübe und Remissionen. Phasen, in denen keine neuen Beschwerden hinzu kommen bzw. Symptome vorübergehend weniger werden, sind dabei möglich.

Bei dem progredient-schubförmigen Verlauf (progressive-relapsing multiple sclerosis, PR-MS) kommt es ebenfalls von Beginn an zu einem steten Voranschreiten der Erkrankung, hier allerdings mit Schüben und - bezogen auf den vorangegangenen Schub - kompletter oder teilweiser Remission.

Zwei weitere Varianten der MS sind der Marburg-Typ und die konzentrische Sklerose Baló. Hierbei handelt es sich um schwere akute Verläufe, die innerhalb von Wochen oder Monaten zum Tode führen (Capello und Mancardi 2004). Darüber hinaus zählt man auch die Neuromyelitis optica Devic (Cree et al. 2002), die myelinoklastische Sklerose Schilder (Poser et al. 1986) und die akute disseminierte Enzephalomyelitis (ADEM) (Hartung und Grossman 2001) zum Formenkreis der MS. Durch die Identifizierung von Aquaporin 4 als Zielantigen 
der humoralen Immunantwort konnte kürzlich die Neuromyelitis optica als eigenständiges Krankheitsbild definiert werden (Lennon et al. 2005). Liegt nach über 10 Jahren Krankheitsdauer ein EDSS von $\leq 3$ vor, so spricht man von einem benignen Verlauf der MS (Hawkins und McDonnell 1999).

Schübe neurologischer Beeinträchtigungen sind vor allem verursacht durch die Entzündung und die Demyelinisierung, während permanente neurologische Beeinträchtigung durch Schädigung und Verlust von Axonen verursacht wird (Lassmann et al. 2001).

\subsubsection{Klinik}

Da die MS das gesamte Zentralnervensystem befallen kann, ist eine große Bandbreite sowohl neurologischer als auch psychiatrischer Symptome möglich. So werden je nach Lokalisation der Läsionen beim jeweiligen MS-Patienten z. B. psychische Störungen, Sehstörungen, zerebelläre Symptome, wie eine Ataxie und Dysarthrie, vegetative Störungen, wie eine Blasenentleerungs- oder Darmstörung, schlaffe Paresen oder auch Sensibilitätsstörungen beobachtet (Gleixner 2007/2008).

Grundsätzlich ist jede Symptomkombination möglich. Es gibt allerdings einige Symptomkombinationen, die häufiger beobachtet werden als andere:

Die Marburg-Trias beschreibt die Kombination aus Paraspastik, Erlöschen der Bauchhautreflexe und temporaler Papillenabblassung.

Bei dem Nackenbeugezeichen nach Lhermitte kommt es bei Nackenbeugung zu Parästhesien im Bereich der Wirbelsäule, welche in Arme und Beine ausstrahlen. Die von Marburg und Lhermitte beschriebenen Symptome treten häufig schon im Anfangsstadium der MS auf, ebenso wie Augenmotilitätsstörungen und eine Retrobulbärneuritis.

Eher selten ist hingegen die Charcot-Trias mit Nystagmus, Intentionstremor und skandierender Sprache. 
Kommt es infolge einer Nackenbeugung zu einem verstärkten spastischen Schwächegefühl in den Beinen zusammen mit einer gesteigerten Gangstörung, so wird dies als McArdle-Zeichen bezeichnet.

Ein Symptom, unter dem ein Großteil der MS-Patienten leidet, ist ein ausgeprägtes Empfinden von Erschöpfung. Dies wird als Fatigue-Syndrom bezeichnet (Krupp und Christodoulou 2001).

Ein weiteres charakteristisches Merkmal der MS ist das Uhthoff-Zeichen. Es beschreibt den Effekt, dass ein Anstieg der Körpertemperatur, beispielsweise durch körperliche Anstrengung, Fieber, ein heißes Bad oder einen Saunabesuch, zu einer Verschlechterung der Symptome führt.

Die Schwere der MS-bedingten Behinderung im Alltag lässt sich mittels der expanded disability status scale (EDSS) nach Kurtzke (1983) bewerten. Hierbei werden acht funktionelle Systeme des ZNS im Hinblick auf eine mögliche Beeinträchtigung hin untersucht. Bei den funktionellen Systemen handelt es sich um die pyramidale, die zerebelläre, die zerebrale, die sensorische, die visuelle, sowie die Hirnstamm-, die Darm- und die Blasenfunktion und eine Gruppe anderer Funktionen.

\subsubsection{Diagnose}

Die Diagnose der MS ist im Wesentlichen eine klinische Diagnose, $d$. h., dass bei der Diagnosestellung der zeitliche Verlauf sowie Art und Ausprägung neurologischer Störungen im Vordergrund stehen. Hierbei sind nach wie vor die im Jahr 1983 von Poser et al. veröffentlichten Diagnosekriterien von Bedeutung (Poser und Brinar 2000). Die 2001 von McDonald et al. veröffentlichten und 2005 sowie zuletzt 2010 (veröffentlicht im Jahr 2011) von Polman et al. revidierten Diagnosekriterien legen zusätzlich besonderes Augenmerk auf die radiologische Untersuchung der Patienten mittels Magnetresonanztomographie (MRT) sowie auf andere paraklinische Untersuchungsmethoden, wie die Untersuchung des Liquors (CSF) und die Ableitung visuell evozierter Potentiale (VEP). Diese revidierten 
Diagnosekriterien sollen unter Aufrechterhaltung einer angemessenen Sensitivität und Spezifität die Diagnosestellung erleichtern und beschleunigen.

\begin{tabular}{|c|c|}
\hline Klinische Präsentation & $\begin{array}{l}\text { Für die Diagnosestellung zusätzlich } \\
\text { erforderliche Kriterien }\end{array}$ \\
\hline $\begin{array}{l}\geq 2 \text { Schübe; } \\
\geq 2 \text { 2Läsionen (klinisch objektivierbar) oder } \\
1 \text { Läsion (klinisch objektivierbar) mit } \\
1 \text { früheren Schub (mit begründeter historischer } \\
\text { Evidenz) }\end{array}$ & keine \\
\hline $\begin{array}{l}\geq 2 \text { Schübe; } \\
1 \text { Läsion (klinisch objektivierbar) }\end{array}$ & $\mathrm{DIS}^{1}$ \\
\hline $\begin{array}{l}1 \text { Schub; } \\
\geq 2 \text { 2Läsionen (klinisch objektivierbar) }\end{array}$ & DIT \\
\hline $\begin{array}{l}1 \text { Schub; } \\
1 \text { Läsion (klinisch objektivierbar) } \\
\text { (klinisch isoliertes Syndrom (clinically isolated } \\
\text { syndrome, CIS) }\end{array}$ & $\begin{array}{l}\text { DIS }^{1} \\
\text { DIT }\end{array}$ \\
\hline $\begin{array}{l}\text { Schleichender, auf eine MS-Erkrankung } \\
\text { hindeutender neurologischer Verlauf (PP-MS) }\end{array}$ & $\begin{array}{l}\text { Krankheitsprogression für } 1 \text { Jahr (retrospektiv } \\
\text { oder prospektiv bestimmt) plus } 2 \text { der folgenden } \\
3 \text { Kriterien: } \\
\text { 1. DIS } \\
\text { 2. DIS } \\
\text { 3. positiver Liquorbefund (liegt vor, wenn } \\
\text { oligoklonale Banden und/oder ein erhöhter IgG- } \\
\text { Index festgestellt werden) }\end{array}$ \\
\hline
\end{tabular}

Tabelle 1: Diagnostische Kriterien der MS nach McDonald, revidiert nach Polman et al. (2011), S. 297

Das Vorliegen der hier genannten Kriterien setzt dabei u. a. Folgendes voraus:

Räumliche Dissemination (dissemination in space, DIS) wird demonstriert durch:

-DIS ${ }^{1}: \geq 1$ T2-Läsion in mindestens 2 von 4 MS-typischen ZNS-Regionen (periventrikulär, juxtakortikal, infratentoriell oder Rückenmark) oder 1 weiterer klinischer Schub (ein anderes Gebiet des ZNS einbeziehend) -DIS ${ }^{2}: \geq 1$ T2-Läsion in MS-charakteristischen Hirnarealen (periventrikulär, juxtakortikal oder infratentoriell)

-DIS ${ }^{3}$ : $\geq 2$ T2-Läsionen im Rückenmark 
Zeitliche Dissemination (dissemination in time, DIT) wird demonstriert durch:

-DIT: Gleichzeitiges Vorhandensein asymptomatischer Gadoliniumanreichernder und nicht anreichernder Läsionen oder eine neue T2 und/oder Gadolinium-anreichernde Läsion in der VerlaufsMRT (unabhängig vom zeitlichen Abstand zur Referenz-MRT) oder 1 weiterer klinischer Schub

Ein Schub beschreibt eine für einen akuten entzündlichen und demyelinisierenden Prozess im ZNS typische neurologische Störung (gegenwärtig vorliegend oder in der Vergangenheit) und muss vom Patienten berichtet oder durch objektive neurologische Untersuchungsmethoden festgestellt werden. Die Ursache darf hierbei nicht in einer Erhöhung der Körperkerntemperatur oder einer Infektion liegen. Außerdem muss die Dauer der Störung mindestens $24 \mathrm{~h}$ betragen. Um die Diagnose "MS“ definitiv stellen zu können, ist es notwendig, dass wenigstens 1 Schub durch entsprechende neurologische Untersuchungsergebnisse untermauert werden kann, beispielsweise durch einen pathologischer Befund bzgl. der visuell evozierten Potentiale eines Patienten mit vorausgegangenen Sehstörungen oder einen pathologischen MRT-Befund, der mit den vom jeweiligen Patienten in der Vergangenheit beschriebenen neurologischen Symptomen vereinbar ist.

Für die Diagnosestellung gilt allgemein, dass bei Zutreffen der oben aufgeführten Kriterien die Diagnose "MS“ gestellt werden kann, vorausgesetzt, es lässt sich keine bessere Erklärung für die klinische Präsentation finden. Treffen die Kriterien bei bestehendem Verdacht auf eine MS nur teilweise zu, so lautet die Diagnose "möglicherweise MS". Trifft hingegen keines der Kriterien zu oder ergibt sich während der Untersuchung eine Diagnose, welche die klinische Präsentation besser zu erklären scheint, so lautet die Diagnose „nicht MS“. 


\subsubsection{Therapie}

Eine kausale Therapie der MS ist bis heute nicht bekannt (Haas et al. 2005). Ziel der aktuell zur Verfügung stehenden Therapie ist es, Symptome der MS zu mindern oder zu beseitigen und dadurch eine möglichst hohe Lebensqualität und Selbständigkeit im Alltag zu gewährleisten und Folgeschäden zu verhindern. Bestandteile der Therapie sind zum einen eine Immunsuppression bzw. eine Immunmodulation und zum anderen eine symptomatische Therapie (Henze 2004).

Akute Schübe werden standardmäßig mit Glukokortikoiden, vorzugsweise Methylprednisolon oder Dexamethason hochdosiert und intravenös verabreicht, behandelt (Grauer et al. 2001). Diese wirken entzündungshemmend und scheinen protektive Effekte auf die Blut-HirnSchranke zu haben (Gaillard et al. 2001). Melcangi et al. (2000) konnten zeigen, dass Glukokortikoide in der Lage sind, Oligodendrozyten vor einer TNF $\alpha$ - und IFNy-induzierter Apoptose zu schützen. Außerdem scheinen Glukokortikoide die Produktion von Stickstoffmonoxid (NO) durch Mikroglia zu senken (Golde et al. 2003).

Die Therapie mit Glukokortikoiden sollte möglichst innerhalb von 3-5 Tagen nach dem Auftreten der ersten neurologischen Symptome begonnen werden. Üblicherweise erhalten die Patienten je $1 \mathrm{~g}$ an 3 aufeinander folgenden Tagen. Wenn keine ausreichende Besserung eintritt, kann die Therapie auf insgesamt 5 Tage verlängert werden.

Bei unzureichendem Therapieerfolg durch Glukokortikoide kann als Therapie der 2. Wahl eine Plasmapherese durchgeführt werden.

Vor dem Hintergrund, dass es bei der MS bereits sehr früh zu axonalen Schäden kommen kann (Ferguson et al. 1997), wird deutlich, dass die Behandlung von Schüben einen wichtigen Bestandteil der MS-Therapie darstellt (Rieckmann und Toyka 2002).

Neben dieser Therapie im akuten Schub erhalten MS-Patienten eine immunmodulierende bzw. immunsupprimierende Basistherapie, die der Schubprophylaxe dienen und das Voranschreiten der Erkrankung bremsen soll. 
Zur Gruppe der immunmodulierenden Medikamente gehören Interferon (IFN) $\beta$ (Comi et al. 2001; The IFNB Multiple Sclerosis Study Group 1993) und Glatirameracetat (Johnson et al. 1995). Eine deutliche Verminderung der Krankheitsaktivität und ein Hinauszögern körperlicher Behinderung durch diese beiden Medikamente gilt für Patienten mit einer RR-MS als gesichert. In welchem Ausmaß dies auch für Patienten mit einer SP-MS gilt, konnte noch nicht abschließend geklärt werden. Therapeutische Effekte von IFN- $\beta$ bei Patienten mit einer SP-MS sind allerdings beschrieben worden (European Study Group on Interferon $\beta$-1b in Secondary Progressive MS 1998). Auch der genaue Wirkmechanismus beider Medikamente ist nicht bzw. nur teilweise bekannt. Es gibt Hinweise, dass IFN- $\beta$ u. a. die Proliferation von T-Zellen, die Produktion von IFN- $\gamma$ (Noronha et al. 1993) sowie von TNF- $\alpha$ (Brod et al. 1996) hemmen könnte, ebenso wie die Sekretion von MMP-9 durch T-Lymphozyten und infolgedessen ihre Passage über die BHS (Stüve et al. 1996). IFN- $\beta$ scheint außerdem die Sekretion von Interleukin-10 steigern zu können (Rudick et al. 1996).

Ist eine Therapie mit Interferon- $\beta$ oder Glatirameracetat kontraindiziert, so wird für die RR-MS als Therapie der 2. Wahl eine intravenöse Verabreichung hochdosierter Immunglobuline (IVIG) empfohlen (Rieckmann und Toyka 2002). Verläuft die Basistherapie einer RR-MS oder SP-MS mit IFN- $\beta$, Glatirameracetat bzw. IVIG frustran, so erfolgt eine Therapie-Eskalation durch Verabreichung immunsupprimierender Medikamente. Hierzu gehören Mitoxantron (Hartung et al. 2002), Azathioprin (Yudkin und Ellison 1991), Cyclophosphamid (Weiner und Cohen 2002) und Methotrexat (MTX) (Currier et al. 1993).

Ein weiteres für die Eskalationstherapie der schubförmigen MS zur Verfügung stehendes Medikament ist Natalizumab. Hierbei handelt es sich um einen monoklonalen Antikörper gegen a4-Integrin, der die Adhäsion aktivierter TZellen an Endothelzellen der BHS blockiert (Ropper 2006). Eine Therapie der primär progressiven MS steht bislang noch nicht zur Verfügung (Leary und Thompson 2005; Thompson et al. 1997).

Gegenstand der symptomatischen Therapie ist z. B. die Behandlung von Spastiken, Fatigue, Schmerzen oder einer Dysphagie. Dabei kommen ebenfalls 
Medikamente zum Einsatz, darüber hinaus aber u. a. auch Physiotherapie, funktionelle Therapie oder palliative Therapie (Henze 2004).

Neue Therapieansätze, die sich aktuell noch in der Entwicklung befinden, zukünftig aber eine Rolle in der Therapie der MS spielen könnten, sind beispielsweise weiterentwickelte immunmodulatorische Wirkstoffe, der Einsatz weiterer monoklonaler Antikörper gegen verschiedene Moleküle, DNAVakzinierungen oder zelltherapeutische Ansätze. Auch neuroprotektive und -reparative Therapieansätze könnten in der Zukunft zum Einsatz kommen (Martin et al. 2008).

\subsection{Tiermodelle der Multiplen Sklerose}

Durch experimentelle Tiermodelle der MS ist es möglich, Demyelinisierung im ZNS hervorzurufen und Remyelinisierung bzw. die an ihr beteiligten zellulären und molekularen Prozesse zu erforschen. Dabei wird auch zu ergründen versucht, warum Remyelinisierung bei der MS offensichtlich nicht vollständig gelingt und welche Möglichkeiten existieren, sie zu stimulieren (Miller und Rodriguez 1995). Hierzu kann Demyelinisierung auf toxischem (Cuprizon (Blakemore 1973), Ethidium-Bromid (Yajima und Suzuki 1979), Lysolecithin (Hall 1972)), autoimmunem (Kabat et al. 1947; Lublin 1992) oder viralem (Theiler 1937) Wege hervorgerufen werden.

\subsubsection{Toxisch induzierte Demyelinisierung per Cuprizon}

Kupfer ist ein Spurenelement und essenzieller Bestandteil diverser Metalloenzyme (Simić und Budić 2003). Cuprizon (Biscyclohexanon Oxalyldihydrazon) ist ein Kupferchelator, der zur quantitativen Bestimmung von Kupfer verwendet werden kann (Peterson und Bollier 1955). Cuprizon wurde erstmals in den 1960er Jahren als toxisches Agens im Rahmen von Tierexperimenten an Mäusen genutzt (Carlton 1966). Durch Verfütterung von Cuprizon an die Versuchstiere entwickelten diese in Abhängigkeit von der 
jeweiligen Dosierung u. a. mikroskopische Läsionen in Form von Ödemen und einer nichtentzündlichen Demyelinisierung im ZNS und darüber hinaus auch eine verminderte Körpergröße, Schwäche und Paresen. Außerdem verstarben auch Tiere.

Das Cuprizon-Tiermodell eignet sich sehr gut zur Untersuchung der direkt an der De- und Remyelinisierung beteiligten zellulären Prozesse (Ludwin 1978). Gegenüber anderen Tiermodellen besitzt es den Vorteil, dass das Muster des Oligodendrozytenunterganges und der Demyelinisierung, welche u. a. im Corpus callosum - in diesem Teil des ZNS kann das Ausmaß der Demyelinisierung auch am einfachsten bestimmt werden (Hiremath et al. 1998) - besonders ausgeprägt ist, innerhalb bestimmter Mausstämme ein hohes Maß an Reproduzierbarkeit aufweist. Es kommt weder zu einer Schädigung der BlutHirn-Schranke (Bakker und Ludwin 1987) noch zu einer wesentlichen Infiltration von Lymphozyten (Komoly 2005). Das Immunsystem wird in den Läsionen lediglich durch aktivierte Mikroglia repräsentiert (Hiremath et al. 1998; Remington et al. 2007).

Anscheinend ist die Demyelinisierung eher durch das Zugrundegehen der Oligodendrozyten als durch eine direkte Zerstörung der Myelinscheiden bedingt. Außerdem scheint sich die Schädigung von Zellen im ZNS auf Oligodendrozyten zu beschränken (Blakemore 1972).

Welche Mechanismen dem Cuprizon-bedingten Untergang der Oligodendrozyten zugrunde liegen, ist nicht abschließend geklärt. Es ist aber bekannt, dass sich während der Verfütterung von Cuprizon enorm große Mitochondrien, sogenannte Megamitochondrien, in den Hepatozyten bilden (Wakabayashi und Green 1974). Dies könnte die Folge des veränderten Stoffwechsels der Mitochondrien sein (Hoppel und Tandler 1973). Tatsächlich hat sich gezeigt, dass Cuprizon zu einer verminderten Aktivität der mitochondrialen Metalloenzyme Monoaminooxidase und Cytochromoxidase im Gehirn und der Leber und darüber hinaus auch zu einem verminderten Kupfergehalt im Gehirn führt. Wird Kupfer-gebundenes Cuprizon verfüttert, so bleiben diese Effekte aus (Venturini 1973). Wird Kupfer den Tieren hingegen gesondert verabreicht, so hat dies keinen Einfluss auf die Toxizität von Cuprizon (Carlton 1967). 
Die Toxizität von Cuprizon scheint also durch die Bindung von Kupfer an Cuprizon mit nachfolgendem Kupfermangel im Gehirn und einer daraus resultierenden Funktionsstörung von Mitochondrien mit konsekutivem Energiemangel glialer Zellen bedingt zu sein (Venturini 1973).

Der Cuprizon-bedingten Demyelinisierung scheinen neben der Bindung von Kupfer jedoch noch andere Mechanismen zugrunde zu liegen. So hat sich gezeigt, dass unter Cuprizon auch die enzymatische Aktivität des zinkabhängigen (Coleman 1984) Metalloenzyms Carboanhydrase II (CA II) von Oligodendrozyten abfällt, bevor es zur Demyelinisierung kommt (Komoly et al. 1987). Dieses Enzym scheint an der Bildung und dem Erhalt von Myelin im ZNS beteiligt zu sein (Kida et al. 2006). Die Ursache für den ausschließlichen Untergang von Oligodendrozyten könnte darin liegen, dass Oligodendrozyten große Mengen von Myelin aufrechterhalten müssen und dies mit einem entsprechend hohen Energiebedarf verbunden ist, was wiederum dazu führen könnte, dass gerade Oligodendrozyten besonders empfindlich auf einen gestörten Energiehaushalt reagieren und in Apoptose gehen, sobald nicht mehr genug Energie zur Aufrechterhaltung der Zellfunktionen verfügbar ist (Matsushima und Morell 2001). Hierfür spricht der Befund, dass sich bei der Verfütterung von Cuprizon an 8 Wochen alte C57BL/6J Mäuse schon nach einer Woche ein deutlicher Rückgang der Expression myelinspezifischer Gene in den Oligodendrozyten zeigt und diese nach 3 Wochen lediglich noch $10 \%$ des Ausgangswertes beträgt. In der 2. Woche der Cuprizon-Verfütterung ist dann bereits ein beträchtlicher Anteil der reifen Oligodendrozyten apoptotisch (Mason JL et al. 2000 b), und nach 3 Wochen zeigt sich schließlich eine umfangreiche Demyelinisierung im Corpus callosum (Morell et al. 1998).

Acht Wochen alte C57BL/6J Mäuse, die 6 Wochen lang 0,2\% Cuprizon erhalten, entwickeln eine komplette Demyelinisierung des Corpus callosum und weisen in diesem Bereich des ZNS bestimmte Muster bzgl. der quantitativen Entwicklung diverser Zellpopulationen sowie von Wachstumsfaktoren auf: Innerhalb der ersten 2 Wochen nach Beginn der Cuprizon-Verfütterung kommt es zu keiner bemerkenswerten Demyelinisierung. Diese zeigt sich erst ab der 3. Woche und schreitet ab diesem Zeitpunkt schnell voran, bis sie etwa in der 5 . Woche ihr Maximum erreicht hat (Hiremath et al. 1998). Wird die Cuprizon- 
Verfütterung nach 6 Wochen beendet, so kommt es innerhalb von 6 Wochen zu einer nahezu vollständigen Remyelinisierung (Armstrong et al. 2006).

Die Anzahl der reifen Oligodendrozyten beginnt ab der 2. Woche nach Beginn der Cuprizon-Verfütterung zu sinken, bis sie etwa in der 5 . Woche nahezu vollständig verschwunden sind. Diese Verkleinerung der Oligodendrozytenpopulation ist zu einem erheblichen Anteil auf Apoptose zurückzuführen. Ab der 6 . Woche steigt die Anzahl dann wieder an, bis die Dichte der reifen Oligodendrozyten etwa in der 10. Woche wieder den gleichen Wert erreicht hat wie vor der Cuprizon-Verfütterung.

$A b$ der 2. Woche scheinen auch Oligodendrozyten-Progenitorzellen benachbarter Hirnregionen zu proliferieren und in das Corpus callosum einzuwandern. In der 3. Woche zeigt sich dann ein starker Anstieg der Akkumulation der Oligodendrozyten-Progenitorzellen im Corpus callosum, welche etwa in der 4. Woche ihr Maximum erreicht. Diese Zellen beginnen zu differenzieren, kurz bevor die Population der reifen Oligodendrozyten wieder deutlich ansteigt. Diese Beobachtung erhärtet den Verdacht, dass die eingewanderten Progenitorzellen die Quelle der neuen reifen Oligodendrozyten bilden (Mason JL et al. 2000 b).

Die Demyelinisierung des Corpus callosum geht mit einer Akkumulation von Mikroglia sowie mit einer Astrogliose einher. Die Anzahl der Mikroglia sowie die der Astrozyten zeigt ab der 3. Woche einen deutlichen Anstieg im Corpus callosum und erreicht ihr Maximum etwa um die 4. bis 5. Woche. Während der ersten 2 Wochen bleibt die Anzahl der Astrozyten unverändert klein. Im Gegensatz dazu akkumulieren Mikroglia bereits in der 1. und 2. Woche, also schon bevor Demyelinisierung festgestellt werden kann. Dies erweckt den Eindruck, dass Mikroglia nicht nur als Reaktion auf die Demyelinisierung akkumulieren, etwa zur Phagozytose von Myelinbestandteilen (Smith 1999), sondern auch ursächlich an diesem Prozess mitbeteiligt sein könnten (Hiremath et al. 1998).

Mikroglia scheinen aber auch am Prozess der Remyelinisierung beteiligt zu sein. Es gibt Hinweise, dass dieser Mechanismus durch die Aktivierung einer Oligodendrozytenproliferation und -differenzierung mittels Zytokinen und/oder Wachstumsfaktoren vermittelt wird (Diemel et al. 1998). So zeigt sich zwischen der 3. und 6. Woche nach Beginn der Cuprizon-Verfütterung ein massiver 
Anstieg von IL-1, einem aus Makrophagen (Scheibenbogen und Andreesen 1991) und Mikroglia (Giulian et al. 1986) stammenden Zytokin und kurz danach von IGF-1 (insulin-like growth factor-1), welcher sowohl von Mikroglia als auch von Astrozyten sezerniert wird. Dabei erweckt die leichte Verzögerung des IGF1-Anstiegs gegenüber dem von IL-1 den Eindruck, dass die Sekretion von IL-1 durch Mikroglia die Sekretion von IGF-1 initiieren könnte. Da der massive Anstieg der IGF-1-Spiegel in der 3. Woche zeitlich mit der ausgeprägten Akkumulation der Oligodendrozyten-Progenitorzellen (Mason JL et al. 2000 b) und der Regeneration der Expression myelinspezifischer Gene, wohl ein Indikator für remyelinisierende Oligodendrozyten (Morell et al. 1998), zusammenfällt, und auch gezeigt werden konnte, dass erhöhte IGF-1-Spiegel Oligodendrozyten vor Cuprizon-bedingter Apoptose schützen können (Mason JL et al. 2000 a), erscheint es als wahrscheinlich, dass IGF-1 sich begünstigend auf die Differenzierung bzw. das Überleben von Oligodendrozyten und damit auch den Prozess der Remyelinisierung auswirkt (Matsushima und Morell 2001).

Diese Darstellung beschreibt die Initiierung einer "akuten" Demyelinisierung. Wird die Cuprizon-Verfütterung nicht nach 6 Wochen gestoppt, sondern auf insgesamt 16 Wochen ausgeweitet, so kommt es zu einer "chronischen" Demyelinisierung (Matsushima und Morell 2001). Bei der "chronischen" Demyelinisierung zeigt sich nach Absetzen des Cuprizon allerdings nur eine sehr geringfügige Remyelinisierung (Armstrong et al. 2006).

\subsubsection{Viral induzierte Demyelinisierung}

In den 1930er Jahren gelang es Max Theiler, den Theiler's Murine Encephalomyelitis Virus (TMEV) aus dem ZNS von Mäusen mit schlaffer Parese der Hinterbeine zu isolieren (Theiler 1937). 1952 berichteten Daniels et al. von Demyelinisierung bei mit TMEV infizierten Mäusen. Circa 20 Jahre später berichtete dann Lipton (1975) von einer zu einer Demyelinisierung führenden Erkrankung des ZNS bei Mäusen, die zuvor eine intrazerebrale Injektion von 
TMEV erhalten hatten. Seither ist die viral induzierte Demyelinisierung durch TMEV ein gängiges Tiermodell zur Untersuchung der MS.

\subsubsection{Experimentelle autoimmune Enzephalomyelitis (EAE)}

Die EAE ist eine entzündliche und demyelinisierende Erkrankung des ZNS, die durch eine Immunisierung mit Myelinantigenen hervorgerufen werden kann. Bei den bisher verwendeten Tierspezies handelt es sich vorwiegend um Affen, Ratten und Mäuse (Martin und McFarland 1995).

Historisch geht die EAE u. a. auf Thomas Rivers zurück, der bereits im Jahr 1933 zeigen konnte, dass es bei Affen zu einer Demyelinisierung im ZNS kommt, wenn ihnen Hirngewebe von Kaninchen injiziert wird (Rivers et al. 1933).

Bisher im Rahmen der EAE untersuchte Faktoren, die mutmaßlich auch bei der MS eine Rolle spielen, sind z. B. die Beteiligung von T-Zellen und Myelinbestandteilen.

Vor dem Hintergrund, dass sich nicht nur die MS, sondern auch die EAE sehr heterogen darstellt, je nach verwendeter Tierspezies und Antigenen, muss kritisch beurteilt werden, inwieweit die jeweiligen Untersuchungsergebnisse der EAE auf die MS übertragen werden können. Dennoch scheint die EAE grundsätzlich von großem Nutzen zu sein, wenn es darum geht, bestimmte Einzelaspekte der MS zu untersuchen (Gold et al. 2006).

\subsection{Remyelinisierung}

Bereits vor über 100 Jahren wies Marburg (1906) darauf hin, dass es im ZNS von MS-Patienten zu Remyelinisierung kommen könnte. Als morphologisches Korrelat hierfür vermutete er von ihm beobachtete Nervenfasern mit sehr dünnen Myelinscheiden in MS-Plaques. Spätere Untersuchungen mittels Elektronenmikroskopie in den 1960er Jahren bestätigten und ergänzten Marburgs Beobachtungen (Périer und Grégoire 1965; Suzuki et al. 1969). 1909 
beschrieb Schlesinger als erster Markschattenherde (Shadow-Plaques) als Ausdruck von Remyelinisierung.

Es wurde lange davon ausgegangen, dass Remyelinisierung im ZNS vernachlässigbar ist. Inzwischen ist bekannt, dass Remyelinisierung in einigen Fällen nur in sehr geringem Ausmaß stattfindet, während es in anderen Fällen durchaus $\mathrm{zu}$ einer umfangreichen Remyelinisierung kommen kann. Augenscheinlich korreliert das Ausmaß der Remyelinisierung mit verschiedenen Faktoren. Untersuchungen hierzu weisen allerdings uneinheitliche bzw. widersprüchliche Ergebnisse auf.

Patrikios et al. konnten in einer neueren Untersuchung von Hirngewebsproben von 51 MS-Patienten im Jahr 2006 zeigen, dass das Alter zum Todeszeitpunkt und die Erkrankungsdauer Einfluss auf den Umfang der Remyelinisierung zu haben scheinen. Je älter die MS-Patienten gestorben waren bzw. je länger die MS-Erkrankung bestanden hatte, desto höher war das vorgefundene Maß an Remyelinisierung. Das Geschlecht oder das Erkrankungsalter hingegen schienen keinen Einfluss zu haben. Remyelinisierung in akuten MS-Plaques wurde kaum beobachtet. Desweiteren haben sie festgestellt, dass Remyelinisierung bei allen Formen der MS stattfindet, tendenziell aber häufiger bei der RR-MS und der PP-MS als bei der SP-MS. Ein statistisch signifikanter Unterschied ergab sich hier allerdings nicht.

Die Mehrzahl der bisherigen Studien ergab allerdings, dass Remyelinisierung vor allem in frühen Krankheitsstadien der MS stattfindet und mit zunehmender Erkrankungsdauer deutlich abnimmt. Beispielsweise haben Raine und Wu (1993) bei der Untersuchung von Hirngewebsproben von vier MS-Patienten Remyelinisierung in allen akuten MS-Läsionen festgestellt und Périer und Grégoire (1965) sowie Suzuki et al. (1969) haben Anzeichen von Remyelinisierung in späten Stadien progressiver Krankheitsverläufe nur in geringem Ausmaß und v. a. im Randbereich inaktiver Läsionen beobachtet.

Offensichtlich korreliert das Ausmaß der Remyelinisierung mit der Anzahl der vorhandenen Oligodendrozyten in den jeweiligen Plaques (Brück et al. 1994; Ozawa et al. 1994). 
Es ist weitestgehend anerkannt, dass die Anzahl der Oligodendrozyten in chronischen MS-Läsionen in der Regel ausgesprochen gering ist (Mews et al. 1998). Auch die Dichte der Oligodendrozyten-Progenitorzellen ist in chronischen MS-Läsionen deutlich geringer als in akuten MS-Läsionen (Kuhlmann et al. 2008).

Lucchinetti et al. (1999) konnten zeigen, dass akute MS-Läsionen hingegen ein hohes Maß an Heterogenität bzgl. der Anzahl der in ihnen enthaltenen Oligodendrozyten aufweisen (siehe auch 1.1.3.2. Histopathologie). Dabei reicht die Bandbreite von einem nahezu völligen Verlust der Oligodendrozyten bis hin zu einer Dichte, die höher ist als die der angrenzenden weißen Substanz.

In aktiv demyelinisierenden Läsionen kommt es zu einer deutlichen Reduzierung der Oligodendrozyten. Da aber selbst nach Tagen und Wochen demyelinisierender Aktivität teilweise noch funktionell intakte Oligodendrozyten zu finden sind, ist davon auszugehen, dass innerhalb demyelinisierender Läsionen auch Faktoren vorhanden sind, die Oligodendrozyten stimulieren bzw. schützen (Raine und Wu 1993). In inaktiven bzw. remyelinisierenden Plaques steigt die Anzahl der Oligodendrozyten wieder an. Ca. $1 / 3$ der MS-Patienten weist allerdings auch inaktive Plaques ohne Oligodendrozyten und ohne Anzeichen von Remyelinisierung auf.

Es fällt auf, dass das Ausmaß des Oligodendrozytenverlustes von Patient zu Patient stark variiert, während es beim einzelnen Patienten konstant ist. Es fällt ebenfalls auf, dass sich die Anzahl der Oligodendrozyten und die von Makrophagen/Mikroglia in den Plaques umgekehrt proportional zueinander verhalten. Dementsprechend zeigt sich die höchste Dichte an Makrophagen/Mikroglia in aktiv demyelinisierenden Plaques, während inaktive, demyelinisierte und remyelinisierte Plaques weniger Makrophagen/Mikroglia enthalten (Brück et al. 1995; Schönrock et al. 1998). Ein signifikanter Zusammenhang zwischen Oligodendrozytendichte und der Anzahl der T-Zellen, Plasmazellen oder der Dichte der Axone in den einzelnen Läsionen zeigt sich hingegen nicht. Makrophagen/Mikroglia sind offensichtlich entscheidend am Untergang von Oligodendrozyten und der Demyelinisierung beteiligt (Sriram und Rodriguez 1997). Andere Untersuchungen wiederum haben ergeben, dass Makrophagen/Mikroglia augenscheinlich auch dazu in der Lage sind, einen Beitrag zur Remyelinisierung zu leisten, indem sie 
wahrscheinlich über Zytokine oder Wachstumsfaktoren Oligodendrozyten zur Proliferation und Differenzierung anregen (Diemel et al. 1998).

Bisher konnte noch nicht abschließend geklärt werden, was genau mit den verschwindenden Oligodendrozyten in den demyelinisierenden Plaques geschieht und woher die wieder zunehmende Anzahl von Oligodendrozyten stammt. Gensert und Goldman (1997) konnten beobachten, dass Progenitorzellen in demyelinisierten Plaques zu myelinisierenden Oligodendrozyten differenzieren. Andere Studien wiederum konnten zeigen, dass auch ausgereifte Oligodendrozyten, die nicht im Rahmen der Demyelinisierung zerstört wurden, durchaus in der Lage sein können, zu proliferieren und zur Remyelinisierung beizutragen (Ludwin 1984; Ludwin und Bakker 1988).

Ein Grund dafür, dass Remyelinisierung in den meisten Fällen letztlich doch fehlschlägt, könnte u. a. eine mehrfach wiederkehrende Demyelinisierung derselben Areale sein (Prineas et al. 1993). Als weitere Gründe werden beispielsweise ein progredienter Verlust von Oligodendrozyten und Progenitorzellen (Pöhlau et al. 1998), eine Abnahme der Axondichte (Wood und Bunge 1986) oder eine Störung der Progenitorzellen-Rekrutierung bzw.

-Differenzierung (Franklin 2002) in den Läsionen diskutiert.

Eine Stimulation der Remyelinisierung in MS-Läsionen kommt als möglicher Therapieansatz der MS infrage (Lassmann et al. 1997). Vor diesem Hintergrund wurde bereits untersucht, inwieweit sich z. B. der Einsatz von Wachstumsfaktoren (D'Souza et al. 1996), die Transplantation Myelinbildender Zellen (Blakemore und Franklin 1991) oder die intravenöse Applikation von Immunglobulinen (IVIG) (Rodriguez et al. 1996) positiv auf den Krankheitsverlauf auswirken können.

\subsection{Protein-Tyrosin-Phosphatasen (PTPasen)}

Tyrosin-Phosphorylierung ist eine posttranslationale Modifikation, die für die Regulation fundamentaler Zellprozesse wie Signaltransduktion, Stoffwechsel, Wachstum und Differenzierung von grundlegender Bedeutung ist. TyrosinPhosphorylierung ist ein reversibler Prozess und wird durch das Gegenspiel von 
Protein-Tyrosin-Kinasen (PTKs) und Protein-Tyrosin-Phosphatasen (PTPs) gesteuert. Dabei bewirkt die enzymatische Aktivität der Protein-TyrosinKinasen die Tyrosin-Phosphorylierung, während die Protein-TyrosinPhosphatasen eine Tyrosin-Dephosphorylierung katalysieren (Hunter 1995; Denu und Dixon 1998).

Kommt es infolge von Funktionsstörungen von Protein-Tyrosin-Kinasen bzw. Protein-Tyrosin-Phosphatasen zu einer dauerhaften Störung des Phosphorylierungsgleichgewichtes, so können schwere Erkrankungen entstehen wie z. B. Morbus Alzheimer (Shapiro et al. 1991), Insulinresistenz (Ahmad et al. 1995) bzw. Diabetes (Hotamisligil et al. 1994) oder Krebs (Seo et al. 1997).

Die Superfamilie der PTPasen setzt sich aus mehreren Untergruppen zusammen. Man unterscheidet zwischen den Tyrosin-spezifischen Phosphatasen (phosphotyrosin (pTyr)-specific phosphatases) und den dualspezifischen Phosphatasen (DSPs). Tyrosin-spezifische Phosphatasen dephosphorylieren ausschließlich Tyrosinreste. Dualspezifische Phosphatasen dephosphorylieren hingegen sowohl Tyrosin- als auch Threonin- und Serinreste. Tyrosin-spezifische Phosphatasen lassen sich in zwei Untergruppen unterteilen. Bei diesen handelt es sich zum einen um die membranständigen Rezeptor-Protein-Tyrosin-Phosphatasen (RPTPasen, receptor-like PTPS, RPTPs) und zum anderen um die intrazellulären PTPasen (non rezeptor-proteintyrosine-phosphatases, NRPTPs).

Membranständige Rezeptor-Protein-Tyrosin-Phosphatasen weisen eine extrazelluläre rezeptorartige Domäne, eine transmembrane Region und einen intrazellulären Teil mit zwei (D1 bzw. D2), in einigen wenigen Fällen aber auch nur einer Phosphatasedomäne auf (Li und Dixon 2000). Die enzymatische Aktivität scheint ausschließlich von der membranseitigen Phosphatasedomäne (D1) geleistet zu werden, während die zweite Phosphatasedomäne (D2) wohl eher nur regulatorisch aktiv ist (Streuli et al. 1989, 1990).

Die extrazellulären Domänen weisen unterschiedliche Größen und Strukturelemente - namentlich Carboanhydrase(CA)-Domäne, Immunglobulin(Ig)-ähnliche Domäne, Fibronektin(FN)III-ähnliche Domäne und Meprin-A5 Antigen-PTP- $\mu(M A M)$-Domäne - auf, anhand derer die Rezeptor- 
Protein-Tyrosin-Phosphatasen in fünf verschiedene Klassen unterteilt werden können (Mourey und Dixon 1994).

Vertreter der Klasse I der RPTPasen ist CD45 (Charbonneau et al. 1988) und wird ausschließlich in hämatopoetischen Zellen exprimiert (Hermiston et al. 2003). Die Klasse II wird u. a. repräsentiert durch LAR (leukocyte antigenrelated protein) (Streuli et al. 1992), RPTPS (Mizuno et al. 1993) und RPTPo (Yan et al. 1993) sowie RPTP $\mu$ (Gebbink et al. 1991), RPTPK (Jiang et al. 1993) und PCP-2 (Wang et al. 1996). RPTPß (Krueger et al. 1990), DEP-1 (Östman et al. 1994), SAP-1 (Matozaki et al. 1994) und GLEPP-1 (Wiggins et al. 1995) werden zur Klasse III der RPTPasen gezählt. RPTPa (Pallen 1993) und RPTP $\varepsilon$ bilden die Klasse IV und die RPTPasen RPTP $\gamma$ und RPTP $\zeta$ die Klasse V (Krueger et al. 1990).

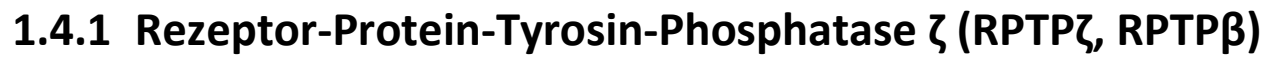

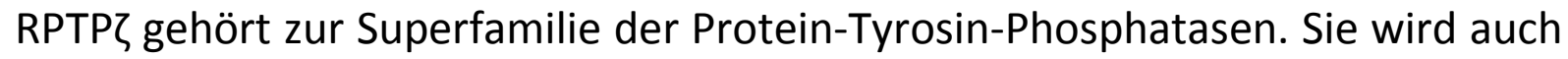
als RPTP $\beta$ bezeichnet (Krueger et al. 1990; Krueger und Saito 1992). Der extrazelluläre Teil von RPTP $\zeta$ besteht aus einer Carboanhydrase(CA)-ähnlichen Domäne, gefolgt von einer Fibronektin(FN)III-ähnlichen Domäne und einer langen Spacer Region (S) (Barnea et al. 1993). Der intrazellulär gelegene Teil besteht aus ein oder zwei PTPase-Domänen (D1 bzw. D2). Durch alternatives mRNA-Spleißen entstehen drei Isoformen von RPTPל. Dabei handelt es sich um eine membrangebundene Ausführung in vollständiger Länge, um eine membrangebundene verkürzte Ausführung und um eine lösliche, ausschließlich aus dem extrazellulären Abschnitt bestehende Form, welche als Phosphacan bezeichnet wird (Levy et al. 1993; Maurel et al. 1994; Krueger und Saito 1992). RPTP\ wird hauptsächlich im ZNS aber auch im peripheren Nervensystem exprimiert (Krueger und Saito 1992; Snyder et al. 1996). Zu den Zellen, die

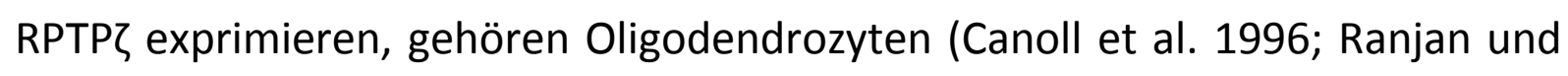
Hudson 1996), Astrozyten und Neurone (Snyder et al. 1996; Shintani et al. 1998).

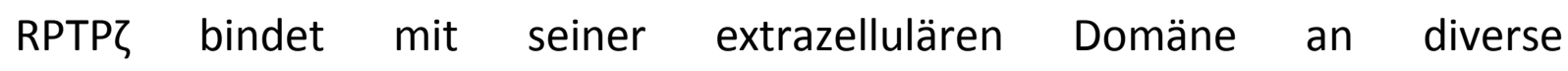
Zelladhäsionsmoleküle (cell adhesion molecules, CAMs), Matrixmoleküle und Wachstumsfaktoren. Als Beispiele sind hier Tenascin (Barnea et al. 1994), 
Midkine (Maeda et al. 1999), Pleiotropin (Maeda et al. 1996), L1 (Ohyama et al. 1998), Contactin (Peles et al. 1995), Nr-CAM (Sakurai et al. 1997), N-CAM, NgCAM (Grumet et al. 1993) und Caspr(contactin-associated protein) (Peles et al. 1997) zu nennen. Es gibt Hinweise, dass hierdurch Prozesse wie Wachstum, Migration und Differenzierung von Nervenzellen reguliert werden, die für die Entwicklung des Nervensystems von großer Bedeutung sind. Mit welchen intrazellulären Proteinen RPTP $\zeta$ interagiert und auf welche Art und Weise diese Prozesse vermittelt werden, ist bisher nicht bekannt. Allerdings wurde festgestellt, dass die intrazelluläre Domäne von RPTP $\zeta$ mit Proteinen der PSD95/SAP90 Familie interagiert, sodass wohl davon ausgegangen werden kann, dass RPTP $\zeta$ u. a. an der Regulation von Funktionen im Bereich von Synapsen beteiligt ist (Kawachi et al. 1999).

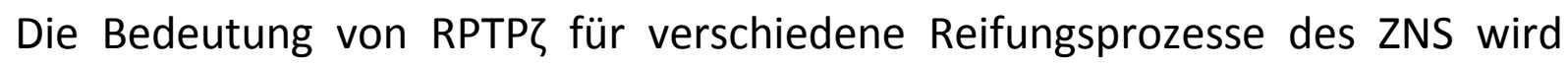
darüber hinaus auch durch die Beobachtung hervorgehoben, dass das Ausmaß der Expression insbesondere im embryonalen ZNS relativ hoch ist (Levy et al. 1993) und dass sie darüber hinaus anscheinend vom Differenzierungsgrad der Gliazellen abhängig ist (Canoll et al. 1996). Gleichzeitig fällt auf, dass sich die drei Isoformen von RPTP $\zeta$ während der Entwicklung des ZNS im Hinblick auf das Ausmaß ihrer Expression teilweise unterscheiden (Nishiwaki et al. 1998).

Diesen Daten steht eine Studie von Harroch et al. (2000) gegenüber, in welcher sich gezeigt hat, dass RPTP $\zeta$ allem Anschein nach dennoch nicht essenziell für die Entwicklung des ZNS ist: Bei der Untersuchung von Mäusen, welche aufgrund von Genmanipulation kein RPTP besaßen, zeigte sich eine weitestgehend normale Entwicklung des Nervensystems. Bei der ultrastrukturellen Untersuchung der Sehnerven mittels Elektronenmikroskopie fiel jedoch eine Fragmentierung das Myelins auf, womöglich als Ausdruck einer verminderten Stabilität das Myelins. Dies legt die Vermutung nahe, dass RPTP\} für die Myelinsynthese und/oder Prozesse der Remyelinisierung von Bedeutung ist. 


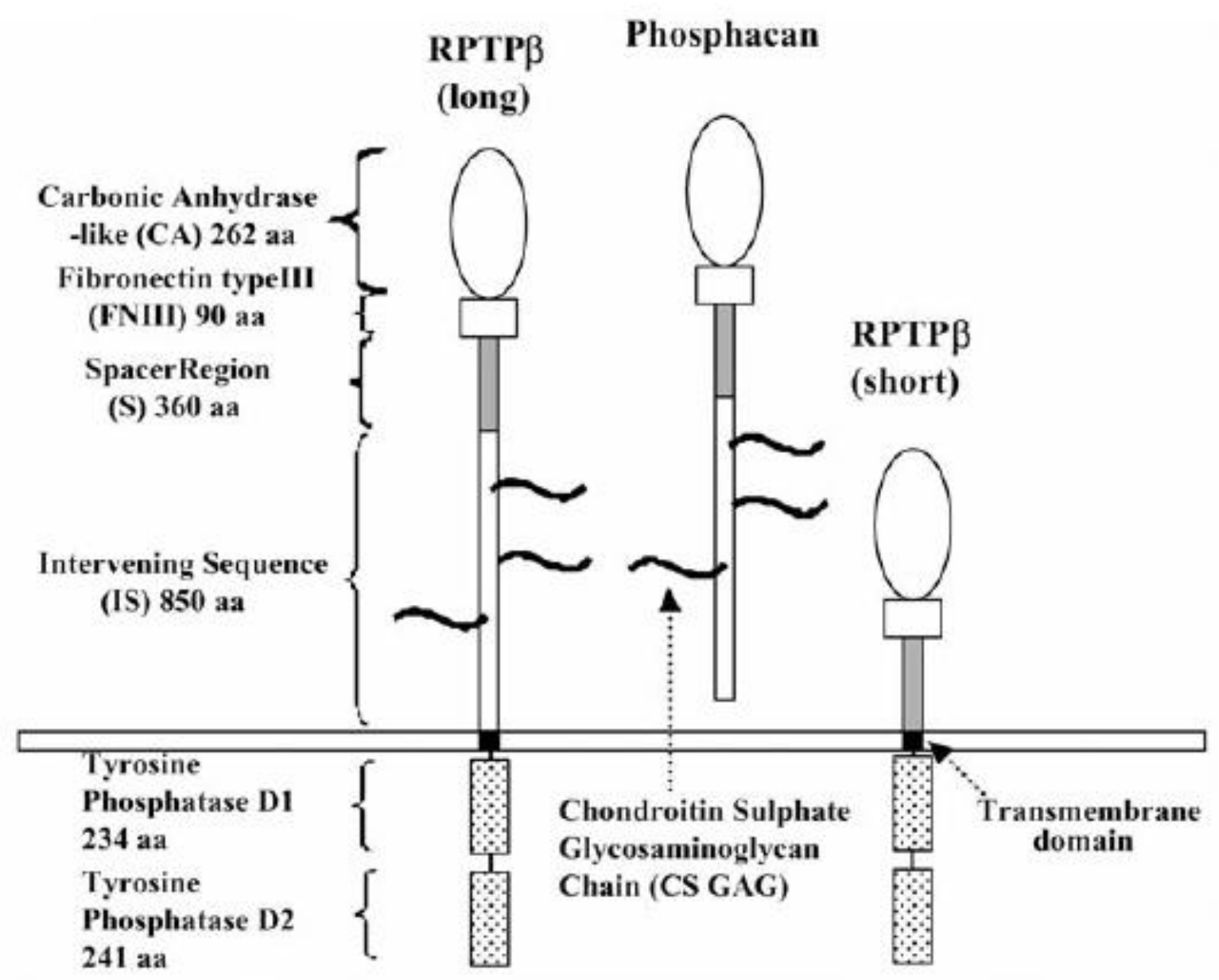

Abbildung 1: Der Aufbau von Phosphacan und den RPTP $\beta$ Isoformen (Faissner et al. 2006, S. 28)

\subsubsection{Rezeptor-Protein-Tyrosin-Phosphatase $\zeta$ bei der MS}

Es hat sich herausgestellt, dass die lokale Neubildung (Keirstead und Blakemore 1997) und/oder die Migration bzw. Reifung (Sim et al. 2002) neuer Oligodendrozyten wohl als Voraussetzungen für Remyelinisierung betrachtet werden müssen. Demzufolge könnte das Scheitern der Remyelinisierung bei der MS u. a. durch eine Beeinträchtigung einer oder mehrerer dieser Prozesse bedingt sein.

Darüber hinaus konnte anhand von Untersuchungen an Mäusen und MSPatienten gezeigt werden, dass RPTP $\zeta$ allem Anschein nach sowohl für das 
Überleben von Oligodendrozyten als auch für die Erholung von demyelinisierenden Erkrankungen von Bedeutung ist (Harroch et al. 2002):

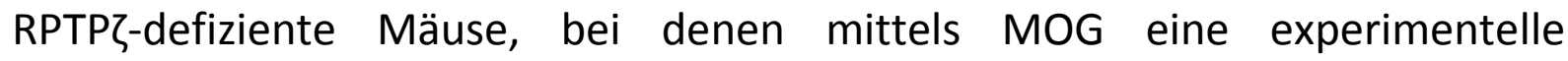
autoimmune Enzephalomyelitis (EAE) induziert wurde, zeigten im Wesentlichen den gleichen zeitlichen Verlauf und das gleiche klinische Erscheinungsbild wie

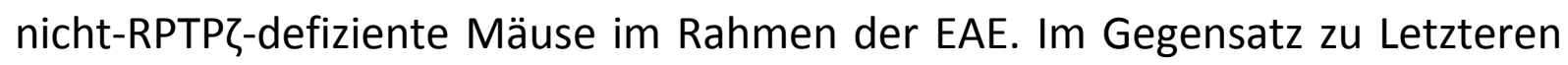
erholten sich die RPTPל-defizienten Mäuse aber nicht wieder von der EAE. Außerdem zeigte sich bei ihnen im Rahmen der Entzündung auch ein verstärkter Untergang ausgereifter Oligodendrozyten.

Bei der Untersuchung von mittels Biopsie gewonnenem Hirngewebe von MSPatienten stellte sich heraus, dass in den MS-Läsionen, und hier besonders in den remyelinisierenden Oligodendrozyten, Ptprz1, das humane Homolog von

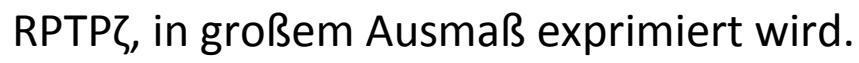




\subsection{Fragestellung der vorliegenden Arbeit}

RPTP $\zeta$ wird vor allem im ZNS aber auch im peripheren Nervensystem

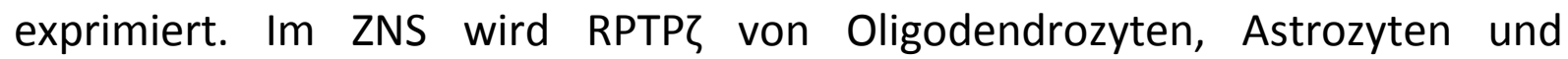
Neuronen exprimiert. In der wissenschaftlichen Literatur kristallisiert es sich heraus, dass durch RPTP $\zeta$ vermittelte zelluläre Prozesse eine Rolle bei der Entwicklung des Nervensystems spielen. Darüber hinaus legen Untersuchungen an Mäusen und Menschen nahe, dass RPTPל bzw. sein humanes Homolog Ptprz1 Einfluss auf die Reparatur von demyelinisierenden Erkrankungen nehmen.

Ziel der vorliegenden Arbeit ist es, die Rolle von RPTP Remyelinisierung während Cuprizon-induzierter toxischer Entmarkung im ZNS von Mäusen zu untersuchen. Zu diesem Zweck untersuchten wir das Corpus callosum von Wildtyp- und RPTPל-defizienten Mäusen nach 6-wöchiger Verfütterung von 0,25\%-igem Cuprizon und analysierten, inwiefern RPTP $\zeta$ die folgenden Prozesse zu beeinflussen vermochte:

- Das Ausmaß der Entmarkung

- Den Verlust reifer Oligodendrozyten

- Die Rekrutierung bzw. Differenzierung von OligodendrozytenProgenitorzellen

- Die Schädigung von Axonen

- Die Entzündung bzw. die Infiltration von Immunzellen (Unser Interesse galt hierbei den T-Lymphozyten und Mikroglia.) 


\section{Material und Methoden}

\subsection{Material}

\subsubsection{Versuchstiere}

Für die Versuche wurden 46 6-8 Wochen alte, männliche Wildtyp-Mäuse (13

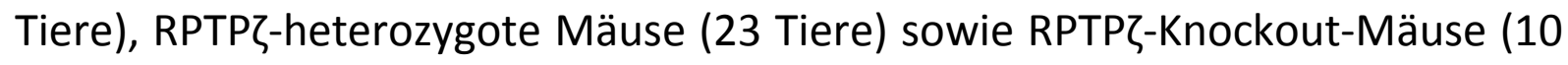
Tiere) verwendet. Der Stamm war für mehr als 10 Generationen auf C57BL/6 rückgekreuzt worden. Die Tiere wurden von Dr. Sheila Harroch, Institut Pasteur, Paris, gezüchtet und uns zur Verfügung gestellt. Bei unseren Untersuchungen unterteilten wir die Tiere auf zwei Experimente. Im ersten

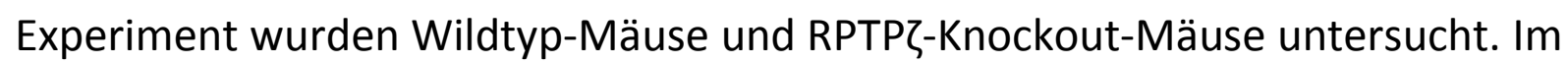

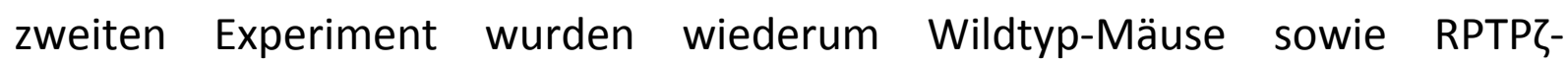
heterozygote Mäuse untersucht. Bei der statistischen Auswertung fassten wir die Wildtyp-Mäuse - da die Ergebnisse aus beiden Experimenten nicht signifikant unterschiedlich waren - zu einer Gruppe zusammen und verglichen

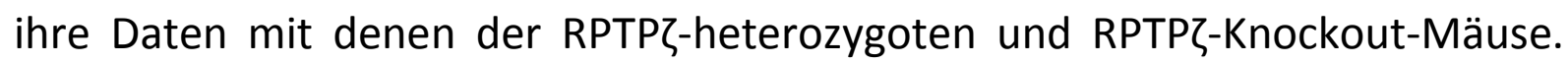
Bei der Auswertung der immunhistochemischen Färbungen Olig-2 und APP wurden nur die Wildtyp- und RPTPZ-Knockout-Mäuse des ersten Experiments verwendet.

Sowohl die Tierhaltung als auch die Durchführung aller Versuche erfolgte nach den Richtlinien der tierexperimentellen Einrichtung der Universität Göttingen. Die hierfür notwendigen Genehmigungen wurden durch die Bezirksregierung Braunschweig erteilt, Genehmigungsnummer G79/08.

\subsubsection{Verfütterung von Cuprizon}

Cuprizon (Biscyclohexanon Oxalyldihydrazon) (Sigma-Aldrich Chemie $\mathrm{GmbH}$, Steinheim, Deutschland) wurde gemahlenem Futter in einer Konzentration von $0,25 \%$ beigemengt und an die Versuchstiere verfüttert. Die Mäuse wurden wöchentlich gewogen und untersucht. 


\subsubsection{Verwendete Chemikalien}

\begin{tabular}{|c|c|c|}
\hline Substanz & Hersteller & Bearbeitung \\
\hline $\begin{array}{l}\text { 3,3'-Diaminobenzidin- } \\
\text { Tetrahydrochlorid (DAB) }\end{array}$ & Sigma-Aldrich $^{1}$ & siehe unten \\
\hline Ammoniak & Merck $^{2}$ & \\
\hline Avidin-Biotin-Block & $\mathrm{DAKO}^{3}$ & \\
\hline Chloralhydrat & Merck & $14 \%$ in Aqua dest. \\
\hline $\begin{array}{l}\text { Chlorwasserstoff(HCl)- } \\
\text { Alkohol }\end{array}$ & $\mathrm{CVH}^{4}$ & $1 \%$ in Aqua dest. \\
\hline Citratpuffer (10 mM) & Merck & $\begin{array}{l}-2,1014 \mathrm{~g} \\
\text { Zitronensäure- } \\
\text { Monohydrat } \\
\text {-1 I Aqua dest. } \\
\text {-auf pH } 6 \text { einstellen }\end{array}$ \\
\hline $\begin{array}{l}\text { Cuprizon } \\
\text { (Biscyclohexanon } \\
\text { Oxalyldihydrazon) }\end{array}$ & Sigma-Aldrich & $\begin{array}{l}0,25 \% \text { im gemahlenen } \\
\text { Pressfutter }\end{array}$ \\
\hline DAB-Entwicklerlösung & & $\begin{array}{l}-50 \mathrm{ml} \mathrm{PBS} \\
-1 \mathrm{ml} \mathrm{DAB}-\text { Stocklösung } \\
-20 \mu \mathrm{l} \mathrm{H}_{2} \mathrm{O}_{2}(30 \%)\end{array}$ \\
\hline DAB-Stocklösung & & $\begin{array}{l}1 \mathrm{~g} \text { DAB gelöst in } 40 \mathrm{ml} \\
\text { PBS }\end{array}$ \\
\hline $\begin{array}{l}\text { DePeX mounting } \\
\text { medium }\end{array}$ & $\mathrm{BDH}^{5}$ & \\
\hline Diethylether & Sigma-Aldrich & per inhalationem \\
\hline Eosin-G Certistain ${ }^{\circledR}$ & Merck & \\
\hline Essigsäure (100\%) & Merck & $10 \%$ in Aqua dest. \\
\hline Ethanol & Merck & $\begin{array}{l}\text { 100\%, 96\%, 95\%, 90\%, } \\
70 \%, 50 \% \text { in Aqua dest. }\end{array}$ \\
\hline ExtrAvidin $^{\circledR}$ & Sigma-Aldrich & \\
\hline $\begin{array}{l}\text { fetales Kälberserum } \\
\text { (FCS) }\end{array}$ & Biochrom $A^{6}{ }^{6}$ & \\
\hline Formalin (37\%) & Merck & \\
\hline
\end{tabular}




\begin{tabular}{|c|c|c|}
\hline Isoxylol & Merck & $\begin{array}{l}\text { Ethanol und Xylol zu } \\
\text { gleichen Teilen }\end{array}$ \\
\hline $\begin{array}{l}\text { Hämalaunlösung nach } \\
\text { Mayer }\end{array}$ & Merk & \\
\hline Lithiumcarbonat & Merck & \\
\hline Luxol-fast-blue (LFB) & $\mathrm{BDH}$ & \\
\hline Natriumthiosulfat & Merck & \\
\hline Paraffin, Paraplast plus & Tyco $^{7}$ & \\
\hline Paraformaldehyd (PFA) & Merck & $4 \%$ in Aqua dest. \\
\hline $\begin{array}{l}\text { PBS (phosphate buffered } \\
\text { saline, Phosphat- } \\
\text { gepufferte Salzlösung) } \\
\text { DULBECCO Instamed } \\
9,55 \mathrm{~g} / \mathrm{I} \mathrm{w} / \mathrm{o} \mathrm{Ca}{ }^{2+}, \mathrm{Mg}^{2+}\end{array}$ & Biochrom AG & $\begin{array}{l}30 \text { Minuten bei } 120^{\circ} \mathrm{C} \\
\text { autoklaviert }\end{array}$ \\
\hline Periodsäure & Merck & $1 \%$ in Aqua dest. \\
\hline Salpetersäure & Merck & $65 \%$ in Aqua dest. \\
\hline Schiff'sches Reagenz & Merck & \\
\hline Silbernitrat & $\operatorname{Roth}^{8}$ & \\
\hline $\begin{array}{l}\text { Wasserstoffperoxid } \\
(30 \%)\left(\mathrm{H}_{2} \mathrm{O}_{2}\right)\end{array}$ & Merck & \\
\hline Xylol & Merck & \\
\hline $\begin{array}{l}\text { Zitronensäure- } \\
\text { Monohydrat }\end{array}$ & Merck & \\
\hline
\end{tabular}

Tabelle 2: Verwendete Chemikalien

1) Sigma-Aldrich Chemie GmbH, Steinheim, Deutschland; 2) Merck KGaA, Darmstadt, Deutschland;

3) DAKO, Glostrup, Dänemark; 4) CVH Chemievertrieb GmbH \& Co., Hannover, Deutschland;

5) BDH Laboratory Supplies, VWR, International Ltd., Poole, UK; 6) Biochrom AG, Berlin, Deutschland;

7) Tyco Healthcare GmbH, Neustadt a. d. Donau, Deutschland; 8) Roth, Karlsruhe, Deutschland 


\subsubsection{Histologische Färbungen}

\begin{tabular}{|l|l|}
\hline Hämatoxylin-Eosin-Färbung & Bearbeitung \\
\hline Mayers Hämalaunlösung (Merck ${ }^{1}$ ) & \\
\hline Eosin Stammlösung (1\%) & $2 \mathrm{~g}$ Eosin-G Certistain ${ }^{\circledR}$ (Merck) \\
& $40 \mathrm{ml}$ Aqua bidest. \\
$160 \mathrm{ml}$ Ethanol (95\%) (Merck)
\end{tabular}

\begin{tabular}{|l|l|}
\hline LFB/PAS Färbung & Bearbeitung \\
\hline LFB: & \\
\hline Luxol-fast-blue(LFB)-Lösung & $\begin{array}{l}\text { g L Luxol-fast-blue (LFB) } \\
\text { (BDH Laboratory Supplies }\end{array}{ }^{2}$ ) \\
& $\begin{array}{l}1000 \mathrm{ml} \text { Ethanol (96\%) (Merck) } \\
5 \mathrm{ml} \text { Essigsäure (10\%) }\end{array}$ \\
\hline Lithiumcarbonat (Merck) & $0,05 \%$ in Aqua bidest. \\
\hline Aqua bidest. & \\
\hline PAS: & \\
\hline Periodsäure (Merck) & $1 \%$ in Aqua bidest. \\
\hline Schiff'sches Reagenz (Sigma Aldrich ${ }^{3}$ ) & \\
\hline Mayers Hämalaunlösung (Merck) & siehe oben \\
\hline
\end{tabular}

\begin{tabular}{|l|l|}
\hline Bielschowsky Färbung & Bearbeitung \\
\hline Silbernitrat (Roth ${ }^{4}$ ) & $20 \%$ in Aqua dest. \\
\hline Ammoniak (Merck) & $32 \%$ in Aqua dest. \\
\hline Entwicklerlösung & $20 \mathrm{ml}$ Formalin (37\%) (Merck) \\
& $100 \mathrm{ml}$ Aqua bidest. \\
& $0,5 \mathrm{~g}$ Zitronensäure (Merck) \\
& 2 Tropfen Salpetersäure (65\%) \\
& (Merck) \\
\hline Natriumthiosulfat (Merck) & $2 \%$ in Aqua dest. \\
\hline
\end{tabular}

Tabelle 3: Histologische Färbungen

1) Merck KGaA, Darmstadt, Deutschland; 2) BDH Laboratory Supplies, VWR International Ltd., Poole, UK; 3) Sigma-Aldrich Chemie GmbH, Steinheim, Deutschland; 4) Roth, Karlsruhe, Deutschland 
2.1.5 Antikörper und spezielle Chemikalien zur immunhistochemischen Färbung

Primärantikörper

\begin{tabular}{|l|l|l|l|l|l|}
\hline $\begin{array}{c}\text { humanes } \\
\text { Antigen }\end{array}$ & Herkunftsspezies & \multicolumn{1}{|c|}{ Klon } & \multicolumn{1}{|c|}{$\begin{array}{c}\text { Kat.- } \\
\text { Nr. }\end{array}$} & Hersteller & $\begin{array}{c}\text { Verdünnung } \\
\text { in 10\% } \\
\text { FCS/PBS }\end{array}$ \\
\hline APP & Maus & 22 C11 & $\begin{array}{l}\text { MAB } \\
348\end{array}$ & Chemicon $^{1}$ & $1: 3000$ \\
\hline CD3 & Ratte & CD3-12 & $\begin{array}{l}\text { MCA } \\
1477\end{array}$ & Serotec $^{2}$ & $1: 200$ \\
\hline Mac-3 & Ratte & M3/84 & 553322 & Biosciences $^{3}$ & $1: 200$ \\
\hline Nogo-A & Maus & 11 C7 & & M. Schwab $^{4}$ & $1: 20000$ \\
\hline Olig-2 & Kaninchen & polyklonal & 18953 & IBL $^{5}$ & $1: 200$ \\
\hline
\end{tabular}

Tabelle 4: Primärantikörper

1) Chemicon International, Temecula, CA, USA; 2) Serotec Ltd., Kidlington, Oxford, UK; 3) Biosciences Clontech, Heidelberg, Deutschland; 4) M. Schwab, ETH Zürich, Schweiz; 5) IBL, Gunma, Japan

Sekundärsysteme

\begin{tabular}{|c|c|c|c|c|}
\hline Bezeichnung & $\begin{array}{c}\text { konjugiert } \\
\text { mit }\end{array}$ & Kat.-Nr. & Hersteller & Verdünnung \\
\hline $\begin{array}{l}\text { Schaf-anti- } \\
\text { Maus-IgG }\end{array}$ & Biotin & RPN 1001 & Amersham $^{1}$ & $\begin{array}{l}1: 200 \text { mit } \\
10 \% \text { FCS/PBS }\end{array}$ \\
\hline $\begin{array}{l}\text { Ziege-anti- } \\
\text { Ratte-IgG }\end{array}$ & Biotin & RPN 1005 & Amersham & $\begin{array}{l}1: 200 \text { mit } \\
10 \% \text { FCS/PBS }\end{array}$ \\
\hline $\begin{array}{l}\text { Esel-anti- } \\
\text { Kaninchen- } \\
\text { IgG }\end{array}$ & Biotin & RPN 1004 & Amersham & $\begin{array}{l}1: 200 \text { mit } \\
10 \% \text { FSC/PBS }\end{array}$ \\
\hline ExtrAvidin $^{\circledR}$ & Peroxidase & E 2886 & $\begin{array}{l}\text { Sigma- } \\
\text { Aldrich }^{2}\end{array}$ & $\begin{array}{l}1: 1000 \text { mit } \\
10 \% \text { FCS/PBS }\end{array}$ \\
\hline
\end{tabular}




\begin{tabular}{|l|l|l|l|l|}
\hline DAB & - & D-5637 & Sigma-Aldrich & $\begin{array}{l}25 \mathrm{mg} / 50 \mathrm{ml} \\
\text { PBS }\end{array}$ \\
\hline
\end{tabular}

Tabelle 5: Sekundärsysteme

1) Amersham Pharmacia Biotech Europe $\mathrm{GmbH}$, Freiburg, Deutschland; 2) Sigma-Aldrich Chemie $\mathrm{GmbH}$, Steinheim, Deutschland 


\subsection{Methoden}

\subsubsection{Versuchsdurchführung}

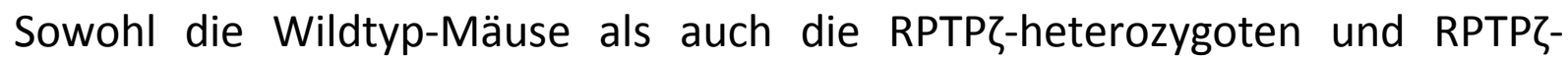
Knockout-Mäuse erhielten über einen Zeitraum von 6 Wochen gemahlenes Futter, welchem Cuprizon (Biscyclohexanon Oxalyldihydrazon) in einer Konzentration von 0,25\% beigemengt war. Dies entspricht 2,5 g Cuprizon pro Kilogramm Trockenfutter.

Anschließend wurden die Mäuse zwecks histopathologischer Untersuchung des ZNS mittels Inhalation von Diethylether (Sigma-Aldrich Chemie $\mathrm{GmbH}$, Steinheim, Deutschland) betäubt, dann durch Injektion von $1 \mathrm{ml}$ 14\%-iger Chloralhydratlösung (Merck KgaA, Darmstadt, Deutschland) i. p. anästhesiert und nach dem Erlöschen der Schmerzreflexe durch transkardiale Perfusion mit Paraformaldehyd (PFA) fixiert. Dann erfolgte die Entnahme des Gewebes.

Die Perfusion und Präparation der Mäuse (2.2.2) sowie die Herstellung der histologischen (2.2.3) bzw. immunhistochemischen (2.2.4) Präparate wurden von technischen Mitarbeitern der neuropathologischen Abteilung der Universitätsmedizin Göttingen durchgeführt.

\subsubsection{Perfusion und Präparation der Mäuse}

Bei der transkardialen Perfusion wurde zunächst das Blut mit PBS aus dem Körper der Mäuse herausgespült und danach das Gewebe mit 4\%-iger PFALösung fixiert. Dann wurde das Gehirn der Mäuse behutsam aus der knöchernen Hülle herauspräpariert, mithilfe einer Rasierklinge in ca. $3 \mathrm{~mm}$ dicke Scheiben geschnitten, in einer aufsteigenden Alkoholreihe $(50 \%, 70 \%$, $90 \%, 100 \%, 100 \%)$ dehydriert und in Paraffin eingebettet. Hieraus wurden mittels Mikrotom (Leica, Wetzlar, Deutschland) 2-4 $\mu \mathrm{m}$ dicke Schnitte hergestellt und auf Objektträger (Menzel-Gläser, Braunschweig, Deutschland) aufgebracht. 
Vor der Anwendung der verschiedenen histologischen Färbemethoden erfolgte zunächst die Entparaffinierung der Gewebeschnitte mit Xylol ( 3 x 5 Minuten) und Isoxylol ( $1 \times 1$ Minute) sowie eine Rehydrierung in einer absteigenden Alkoholreihe (jeweils 3 Minuten in Ethanol 100\%, 100\%, 90\%, 70\%, 50\%, dann Spülen in Aqua dest.).

Nach Durchführung der Färbemethoden wurden die Gewebeschnitte zwecks Konservierung einer Dehydrierung in einer aufsteigenden Alkoholreihe (Spülen in Aqua dest., dann jeweils 3 Minuten 50\%, 70\%, 90\%, $100 \%, 100 \%$ Ethanol) unterzogen, dann mit Isoxylol ( $1 \times 1$ Minute) und Xylol ( $3 \times 5$ Minuten) behandelt und mit DePeX eingedeckelt.

\subsubsection{Histologische Färbemethoden:}

\section{$\underline{\text { Hämatoxylin-Eosin (HE) }}$}

Bei der HE-Färbung handelt es sich um eine häufig durchgeführte Übersichtsfärbung. Zweck dieser Färbung ist es, einen Gesamtüberblick über das gefärbte Gewebe zu erhalten. Hierzu gehören auch Kriterien wie die allgemeine Anordnung von Strukturen, die Zellverteilung und die Kern-PlasmaRelationen. Zellkerne werden dabei blau-violett, das Parenchym hingegen rötlich gefärbt (Lang 2006).

Nach der Entparaffinierung und der Rehydrierung in der absteigenden Alkoholreihe wurden die Gewebeschnitte für 5 Minuten in die HämalaunLösung nach Meyer eingebracht, wodurch eine Färbung der Zellkerne erreicht wurde. Im Anschluß wurden die Schnitte mit Aqua dest. abgespült. Danach erfolgte die Differenzierung der Schnitte durch Eintauchen in 1\%-igen Chlorwasserstoff $(\mathrm{HCl})$-Alkohol und anschließend das Bläuen unter fließendem Leitungswasser über 10 Minuten. Dann wurden die Gewebeschnitte 5 Minuten lang in 1\%-ige Eosinlösung eingetaucht, wodurch das Parenchym seine Rotfärbung erhielt. Nach diesem Arbeitsschritt wurden die Schnitte erneut mit Aqua dest. gespült. Bei der sich anschließenden Dehydrierung wurden die Gewebeschnitte in der aufsteigenden Alkoholreihe bis zum 100\%-igen Ethanol 
jeweils nur kurz eingetaucht, um ein zu starkes Auswaschen des Eosins zu verhindern. Die folgenden Arbeitsschritte wurden wie unter 2.2.2 angegeben durchgeführt.

\section{$\underline{\text { LUXOL-FAST-BLUE/Perjodsäure-Schiff (LFB/PAS) }}$}

Bei dieser Färbemethode wird mittels Luxol-fast-blue phospholipidhaltiges Myelin blau bis grün und Zellkerne sowie Nisslsubstanz pink bis violett gefärbt. Durch die Inkubation im Schiff'schen Reagenz kommt es zu einer rot-violetten Färbung von Parenchym und entmarkten Arealen (Lang 2006).

Nach der Entparaffinierung und der Rehydrierung in der absteigenden Alkoholreihe - hier nur bis zum 90\%-igen Ethanol - wurden die Gewebeschnitte zunächst bei $60^{\circ} \mathrm{C}$ in der Luxol-fast-blue(LFB)-Lösung über Nacht inkubiert. Am folgenden Tag wurden sie in 90\%-igen Alkohol eingestellt. Als nächster Schritt erfolgte die Differenzierung der Gewebeschnitte durch Eintauchen in 0,05\%-ige Lithiumcarbonatlösung, 70\%-iges Ethanol und in Aqua dest., bis die überschüssige Färbelösung ausgewaschen und schließlich nur noch das Myelin blau gefärbt war.

Hiernach wurden die Gewebeschnitte zuerst 5 Minuten lang in 1\%-ige Perjodsäure in Aqua dest. eingebracht und anschließend 5 Minuten lang mit Leitungswasser und dann dreimal mit Aqua dest. gespült. Es folgte die Inkubation im Schiff'schem Reagenz für 20 Minuten und erneutes Spülen mit Leitungswasser für 5 Minuten, wodurch eine Rosafärbung des Parenchyms erzielt wurde. Anschließend wurden die Gewebeschnitte 2 Minuten lang in Hämalaun-Lösung eingetaucht, mit Aqua dest. gespült, kurz in 1\%-igem Chlorwasserstoff( $\mathrm{HCl}$ )-Alkohol differenziert und unter fließendem Leitungswasser gebläut. Hierdurch erfolgte die Gegenfärbung der Zellkerne. 
Bielschowsky-Versilberung

Durch die Bielschowsky-Versilberung kommt es zur Schwarzfärbung von Axonen, Neurofibrillen und Dendriten (Lang 2006).

Nach der Entparaffinierung und der Rehydrierung in der absteigenden Alkoholreihe wurden die Gewebeschnitte für 20 Minuten in eine 20\%-ige Silbernitrat-Lösung eingebracht und anschließend mit Aqua dest. gespült. Im nächsten Arbeitsschritt wurde der 20\%-igen Silbernitrat-Lösung unter Rühren tropfenweise 32\%-ige Ammoniak-Lösung hinzugegeben, bis der entstandene Niederschlag verschwand. Dann wurden der Silbernitrat-Ammoniak-Lösung 2 weitere Tropfen der 32\%-igen Ammoniak-Lösung hinzugegeben und die Schnitte in dieser Lösung für 15 Minuten bei Dunkelheit inkubiert. Anschließend wurden einer Küvette mit Aqua dest. 3 Tropfen Ammoniak beigemengt und die Gewebeschnitte in dieser Lösung gespült. Dann wurden der Silbernitrat-Ammoniak-Lösung unter Rühren 10 Tropfen Entwickler-Lösung hinzugegeben und die Schnitte so lange in der Lösung belassen, bis die Nervenfasern schwarz und das Parenchym braun gefärbt waren. Dann wurden die Gewebeschnitte mit Aqua dest. gespült und die Reaktion auf diese Weise gestoppt. Anschließend wurden die Schnitte 2 Minuten lang in eine 2\%-ige Natriumthiosulfat-Lösung eingebracht und im Anschluß hieran kurz mit Leitungswasser gespült.

\subsubsection{Immunhistochemische Färbungen}

Das Ziel der immunhistochemischen Färbungen ist es, bestimmte Gewebestrukturen, sogenannte Epitope, welche kleine Bereiche von Antigenen darstellen, durch eine Antigen-Antikörper-Reaktion eindeutig zu identifizieren. Dabei liegt folgendes Prinzip zugrunde: Der jeweilige Antikörper bindet spezifisch an ein bestimmtes Epitop. Dieses wird dann im Rahmen der AntigenAntikörper-Reaktion durch mit an die Antikörper gekoppelte Stoffe indirekt sichtbar gemacht. Dies geschieht meist in Form einer Farbstoffentwicklung. Bei 
den gekoppelten Stoffen handelt es sich zum Beispiel um Enzyme, Farbstoffe, Fluorochrome, Biotin, Dextran-Polymere oder Radioisotope (Lang 2006).

\subsubsection{Antikörper}

\section{APP-Antikörper}

APP (amyloid precursor protein, Amyloid-Vorläuferprotein) wird in Neuronen synthetisiert und anschließend in den Axonen schnell anterograd transportiert (Koo et al. 1990). Da APP im Falle einer axonalen Schädigung im proximal der Verletzung gelegenen Bereich des Axons akkumuliert, können akute axonale Schädigungen mit gegen APP gerichteten Antikörpern dargestellt werden (Ferguson et al. 1997).

Die APP-positiven Axone im Corpus callosum von wt, RPTP $\zeta+/-$ und RPTP $\zeta /-$ Mäusen mit Cuprizon-induzierter Entmarkung wurden unter 400-facher Vergrößerung ausgezählt und hieraus die Dichte der akut geschädigten Axone pro $\mathrm{mm}^{2}$ berechnet.

\section{CD3-Antikörper}

Das CD3-Molekül wird von T-Lymphozyten exprimiert (Campana et al. 1987). Daher können Antikörper gegen CD3 dazu verwendet werden, T-Lymphozyten darzustellen (Mason DY et al. 1988).

Die CD3-positiven Zellen wurden ebenfalls im Balken unter 400-facher Vergrößerung ausgezählt und hieraus die Dichte der T-Lymphozyten pro $\mathrm{mm}^{2}$ berechnet. 


\section{Mac-3-Antikörper}

Das Mac-3-Antigen wird von mononukleären Phagozyten (z. B. Makrophagen und Mikroglia) exprimiert und kann mittels Antikörperbindung dargestellt werden (Ho und Springer 1983).

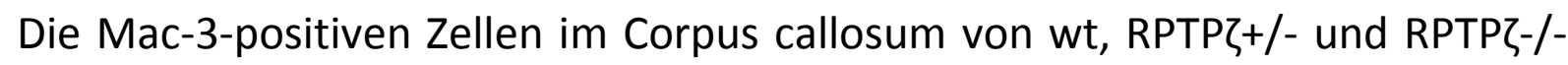
Mäusen nach Verfütterung von Cuprizon wurden unter 400-facher Vergrößerung ausgezählt und hieraus die Dichte der aktivierten Mikroglia pro $\mathrm{mm}^{2}$ berechnet.

\section{Nogo-A-Antikörper}

Nogo-A ist ein Protein, das sich in Oligodendrozyten sowie weniger stark exprimiert auch in Neuronen finden lässt. Es ist dafür bekannt, dass es durch die Bindung an den Nogo-Rezeptor auf Neuronen und Axonen das axonale Wachstum hemmt (Chen et al. 2000). Durch Markierung mit Antikörpern können Oligodendrozyten im Gehirn und in demyelinisierten Läsionen dargestellt werden (Kuhlmann et al. 2007).

Die Nogo-A-positiven Zellen wurden im Balken unter 400-facher Vergrößerung ausgezählt und hieraus die Dichte der reifen Oligodendrozyten pro $\mathrm{mm}^{2}$ berechnet.

\section{Olig-2-Antikörper}

Olig-2 (oligodendrocyte transcription factor 2, OligodendrozytenTranskriptionsfaktor 2) kodiert für Proteine, die in Oligodendrozyten und deren Progenitorzellen nachgewiesen wurden (Lu et al. 2000; Zhou et al. 2000). Olig-2 ist notwendig für die Entwicklung von Oligodendrozyten (Park et al. 2002). Die Darstellung von Olig-2 durch Olig-2-Antikörper diente zum Nachweis von Oligodendrozyten und ihrer Progenitorzellen. 
Diese wurden im Balken unter 400-facher Vergrößerung ausgezählt und hieraus die Dichte der Oligodendrozyten beziehungsweise ihrer Progenitorzellen pro $\mathrm{mm}^{2}$ errechnet.

\subsubsection{Durchführung}

\section{Bindung des primären Antikörpers}

Zuerst wurden die Gewebeschnitte entparaffiniert (Xylol 3 x 5 Minuten, dann Isoxylol $1 \times 1$ Minute) und in einer absteigenden Alkoholreihe bis Aqua dest. (Ethanol 100\%, 100\%, 90\%, 70\%, 50\% für jeweils 3 Minuten, dann Spülen in Aqua dest.) rehydriert. Dann erfolgte als Vorbehandlung die Demaskierung der Antigene (,epitope retrieval") durch Einstellen der Schnitte in kochenden Citratpuffer für 5 mal 3 Minuten. Dann wurden die Schnitte mit entionisiertem Wasser gespült und danach in eine mit PBS gefüllte Küvette eingestellt. Anschließend wurde das zu untersuchende Gewebe zwecks Blockierung der endogenen Peroxidase 10 Minuten lang mit 3\%-igem $\mathrm{H}_{2} \mathrm{O}_{2}$ /PBS (45 ml PBS und $5 \mathrm{ml} \mathrm{H} \mathrm{O}_{2} 30 \%$-ig) behandelt und unspezifische Bindungsstellen durch Zugabe von $120 \mu$ einer 10\%-igen FCS/PBS-Lösung abgesättigt. Zwischen diesen beiden Arbeitsschritten wurden die Schnitte mit PBS gespült und in ein ShandonCoverplate-System eingestellt. Schließlich wurden die jeweiligen PrimärAntikörper in entsprechender Verdünnung auf die Gewebeschnitte aufgebracht und diese dann bei $4^{\circ} \mathrm{C}$ über Nacht inkubiert. Am folgenden Tag wurden die Schnitte erneut mit PBS gespült.

\section{Sichtbarmachung der primären Antikörper}

Die Sichtbarmachung der primären Antikörper erfolgte durch Applikation der entsprechenden biotinylierten sekundären Antikörper. Hierfür erhielten die mit Primärantikörpern für APP bzw. Nogo-A behandelten Gewebeschnitte Schafanti-Maus-Antikörper, die mit Primärantikörpern für CD3 bzw. Mac-3 behandelten Gewebeschnitte Ziege-anti-Ratte-Antikörper und die mit 
Primärantikörpern für Olig-2 behandelten Schnitte Esel-anti-KaninchenAntikörper. Die Bindungsreaktion der sekundären Antikörper an die primären Antikörper erfolgte bei einstündiger Inkubation bei Raumtemperatur. Dann wurden die Gewebeschnitte mit PBS gespült und anschließend nach Aufbringen von ExtrAvidin ${ }^{\circledast}$, welches sich aufgrund seiner starken Affinität zu den Biotinmolekülen der sekundären Antikörper nur dort anlagert, wo eine Bindung der sekundären Antikörper stattgefunden hat, für 45 Minuten bei Raumtemperatur inkubiert. Die Schnitte wurden abermals mit PBS gespült und dann aus den Coverplates entnommen. Danach erfolgte die Zugabe des Entwicklungschromogens. Dabei wurde den Schnitten jeweils $50 \mathrm{ml}$ PBS und 1 $\mathrm{ml} \mathrm{DAB-Stocklösung} \mathrm{(1} \mathrm{g} \mathrm{DAB(3,3'-Diaminobenzidin-Tetrahydrochlorid)} \mathrm{gelöst}$ in $40 \mathrm{ml} \mathrm{PBS}$ ) hinzugegeben, welche mithilfe der an das ExtrAvidin ${ }^{\circledR}$ gebundenen Peroxidase unter Zugabe von $20 \mu \mathrm{H}_{2} \mathrm{O}_{2}$ (Wasserstoffperoxid) umgesetzt wurde, wodurch es zum Farbniederschlag kam. Anschließend wurden die Schnitte in entionisiertem Wasser gespült, 60 Sekunden lang in Hämalaun-Lösung gegengefärbt, 7 Minuten lang in Leitungswasser gebläut, dann in einer aufsteigenden Alkoholreihe bis Xylol (Spülen in Aqua dest, dann Ethanol 50\%, 70\%, 90\%, 100\%, 100\% für jeweils 3 Minuten, dann Isoxylol für $1 \mathrm{x}$ 1 Minute, dann Xylol $3 \times 5$ Minuten) dehydriert und schließlich mit DePeX eingedeckelt.

\subsubsection{Histologische Quantifizierung}

Die histologische Auswertung und Morphometrie erfolgte an einem Lichtmikroskop der Firma Olympus (Olympus, Deutschland GmbH, Hamburg, Germany), Modell BX41. Dieses war mit folgenden Objektiven ausgestaltet:

- Objektiv 2x/0,05 (20-fache Vergrößerung)

- Objektiv 4x/0,10 (40-fache Vergrößerung)

- Objektiv 10x/0,25 (100-fache Vergrößerung)

- Objektiv 20x/0,40 (200-fache Vergrößerung)

- Objektiv 40x/0,65 (400-fache Vergrößerung)

- Objektiv 100x/1,25 (1000-fache Vergrößerung) 
Die verwendeten Okulare mit 10-facher Vergrößerung stammten ebenfalls von der Firma Olympus und verfügten über ein standardisiertes Zellzählgitter, um Zellzählungen zu ermöglichen.

Die Fotodokumentation erfolgte mittels eines BX52 Lichtmikroskops der Firma Olympus mit integrierter DP71 Digitalkamera und der dazugehörigen Bildanalysesoftware cell^^.

\subsubsection{Zell-, Myelin- und Axonquantifizierung}

Die Quantifizierung der Nogo-A-positiven reifen Oligodendrozyten bzw. der Olig-2-positiven Oligodendrozyten und Oligodendrozyten-Progenitorzellen, der CD3-positiven T-Lymphozyten, der Mac-3-positiven aktivierten Mikroglia, der APP-positiven geschädigten Axone und des Ausmaßes der Demyelinisierung (LFB/PAS) erfolgte in der auf Abbildung 2 dargestellten Ebene bei 400-facher bzw. 40-facher (Ausmaß der Demyelinisierung) Vergrößerung. Dabei wurden die medial bzw. kranial der beiden Seitenventrikel gelegenen medialen Areale des Corpus callosum ausgewertet und bei der Bestimmung des Ausmaßes der Demyelinisierung zusätzlich auch die lateral der Seitenventrikeln gelegenen Areale des Corpus callosum. Der Schweregrad des Myelinverlustes wurde mithilfe des in Tabelle 6 dargestellten semiquantitativen Scores nach Hiremath et al. (1998) bestimmt.

\begin{tabular}{|c|c|}
\hline Score & $\begin{array}{c}\text { Schweregrad des Myelinverlustes des } \\
\text { Corpus callosum (LFB/PAS) }\end{array}$ \\
\hline 0 & kein Myelinverlust \\
\hline 1 & $<1 / 3$ des Balkens ohne Myelin \\
\hline 2 & $1 / 3-2 / 3$ des Balkens ohne Myelin \\
\hline 3 & $>2 / 3$ des Balkens ohne Myelin \\
\hline
\end{tabular}

Tabelle 6: Semiquantitativer Score zur Bestimmung des Myelinverlustes bei Cuprizoninduzierter Entmarkung des Corpus callosum (LFB/PAS) nach Hiremath et al. (1998) 


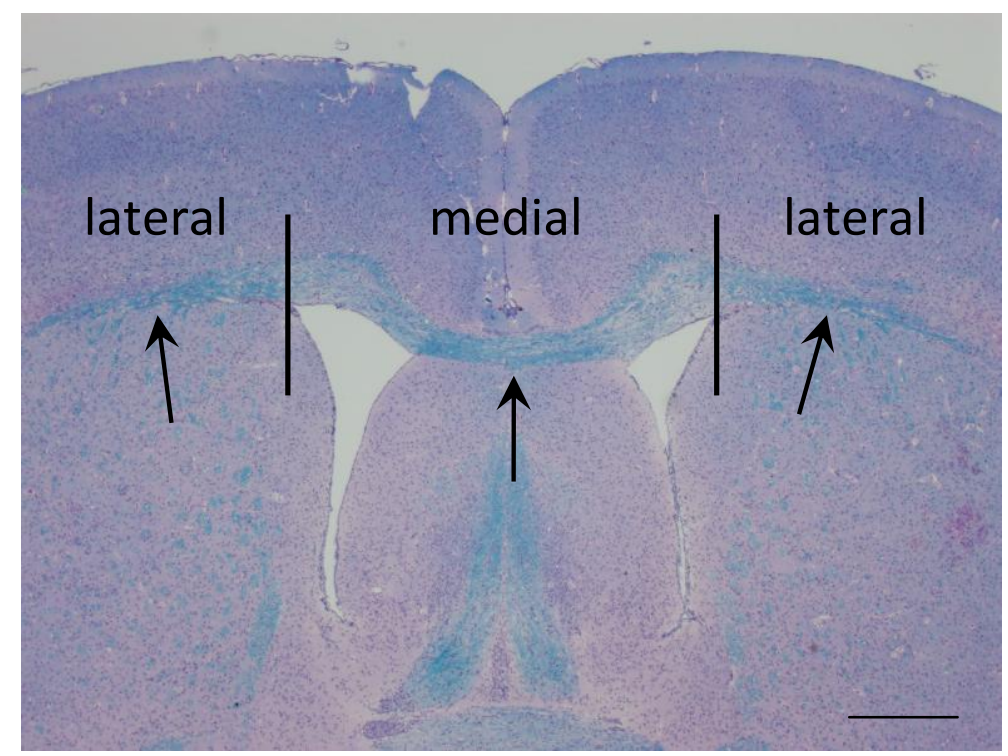

Abbildung 2: Überblick über die ausgewerteten Areale des ZNS mit Markierung des Corpus callosum (Pfeile) im LFB/PAS. Cuprizon-behandeltes Tier mit partieller Entmarkung. Originalvergrößerung: 20-fach. Balkengröße: $500 \mu \mathrm{m}$.

\subsection{Statistische Analysen}

Die Erfassung der Daten erfolgte mit dem Programm Microsoft Excel 2000 (Microsoft Deutschland $\mathrm{GmbH}$, Unterschleißheim) auf einem Personalcomputer. Die statistische Auswertung der Daten wurde mit dem Programm GraphPad PRISM ${ }^{\circledR} 5.01$ (GraphPad Software, San Diego, USA) durchgeführt.

Die durch die morphometrische Analyse gewonnenen Daten der verschiedenen experimentellen Gruppen wurden im Hinblick auf mögliche signifikante Unterschiede überprüft. Dazu wurden zunächst für jede Gruppe der Mittelwert (MW) und die Standardabweichung (standard deviation, SD) bestimmt und mittels Kolmogorov-Smirnov-Test überprüft, ob die jeweiligen Daten einer Gauß'schen Normalverteilung entsprechen.

Zum Vergleich der drei experimentellen Gruppen wt, RPTP $\zeta+/-$ und RPTP $\zeta / /-$ Mäuse zogen wir die Varianzanalyse nach ANOVA (analysis of variance) mit anschließender Tukey Post-Test-Analyse heran. Als statistisch signifikant wurde dabei jeweils ein $p$-Wert von $p \leq 0,05$ betrachtet. 
Der Vergleich zweier Gruppen erfolgte mittels ungepaartem t-Test. Auch hierbei wurde ein $p$-Wert von $p \leq 0,05$ als statistisch signifikant betrachtet. 


\section{Ergebnisse}

In der vorliegenden Arbeit wurde der Effekt einer RPTPS-Defizienz auf die Dichte oligodendroglialer Zellen, die Remyelinisierung, die axonale Schädigung sowie die Mikroglia- und T-Zell-Infiltration im Modell der Cuprizon-induzierten Entmarkung untersucht.

Eine tabellarische Aufstellung aller Ergebnisse findet sich im Anhang (s. Tab. 7).

\subsection{Morphometrische Analyse der Wildtyp-, RPTPY-heterozygoten und

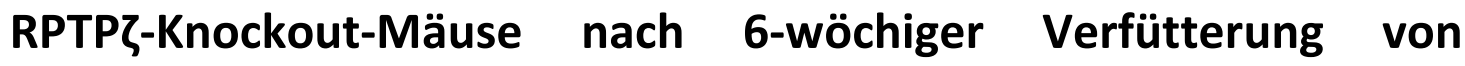 Cuprizon}

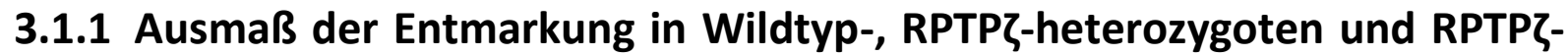 Knockout-Mäusen}

Das Ausmaß der Entmarkung im Corpus callosum wurde mittels des semiquantitativen Scores nach Hiremath et al. (1998) in der LFB/PAS-Färbung quantifiziert. Entmarkte Areale stellten sich rosa statt blau dar. Mediale und laterale Areale des Corpus callosum wurden getrennt untersucht.

Bei den medialen Arealen erreichten die Wildtyp-Mäuse (wt) einen Score von

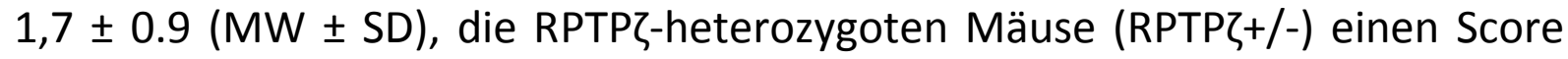

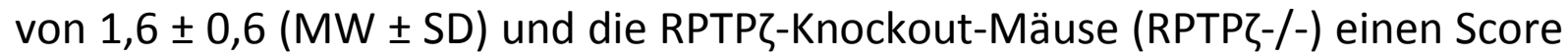
von $1,6 \pm 0,8$ (MW $\pm S D)$ (vgl. Abb. 4).

Bei den lateralen Arealen erreichten die Wildtyp-Mäuse einen Score von 2,8 \pm

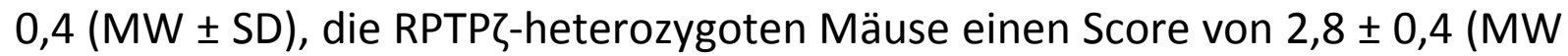

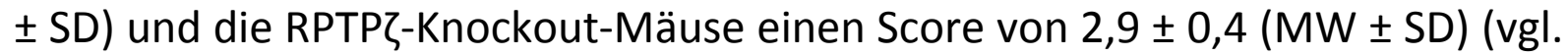
Abb. 5).

Die Varianzanalyse nach ANOVA ergab beim Vergleich der medialen Areale einen $p$-Wert von $p=0,9289$ und beim Vergleich der lateralen Areale einen $p$ Wert von $p=0,9653$ und zeigte somit keine signifikanten Unterschiede im Ausmaß des Myelinverlustes im Corpus callosum der drei untersuchten 
Genotypen an. Auch die Post-Test-Analyse nach Tukey ergab keine signifikanten Unterschiede.

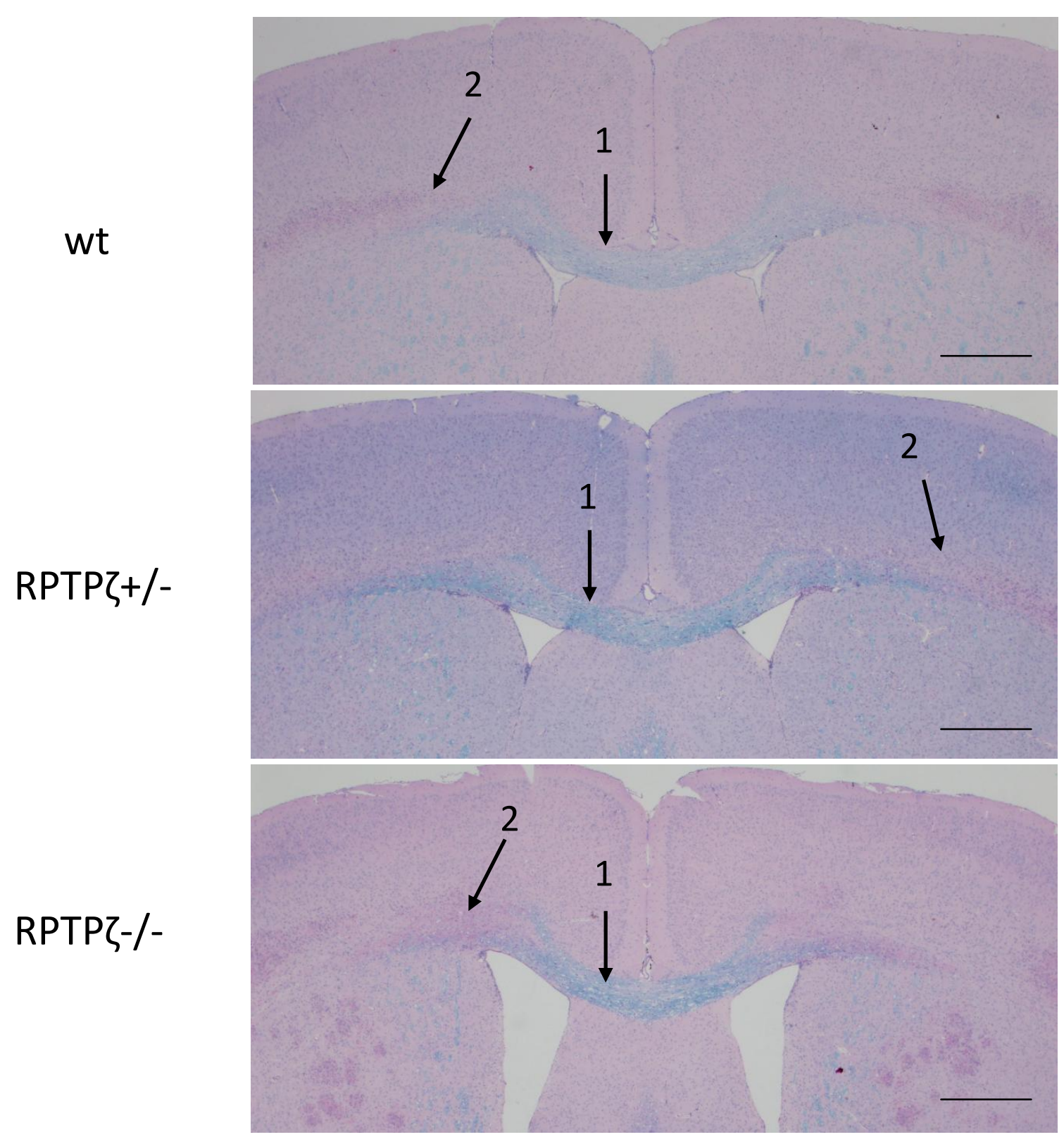

Abbildung 3: Histopathologie der Cuprizon-induzierten Demyelinisierung. In der LFB/PASFärbung stellten sich die Myelinscheiden im Corpus callosum blau (1), die entmarkten Areale rosa (2) dar. Bei den drei untersuchten Genotypen waren die lateralen Areale des Balkens stärker demyelinisiert als die medialen Areale. Dabei lag beim Ausmaß der Entmarkung der medialen und lateralen Areale kein signifikanter Unterschied zwischen den Wildtyp- und RPTPל-defizienten Mäusen vor. Originalvergrößerung: 20-fach. Balkengröße: $500 \mu \mathrm{m}$. 


\section{Entmarkung medial}

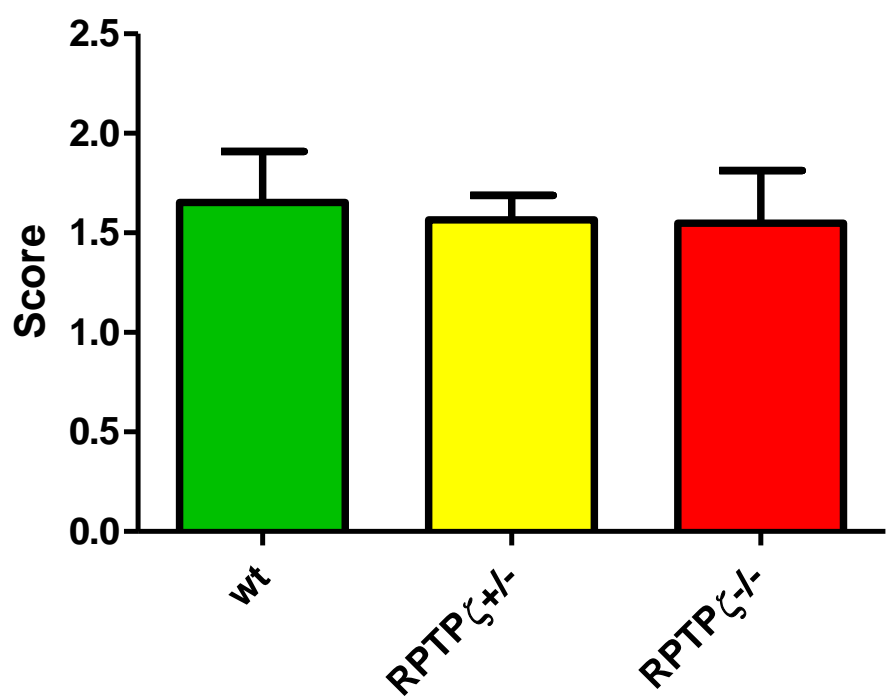

Abbildung 4: Semiquantitative Scores (MW $\pm \mathrm{SD}$ ) zur Bestimmung des Myelinverlustes nach Cuprizon-induzierter Entmarkung des Corpus callosum nach Hiremath et al. (1998) in der LFB/PAS-Färbung bei den drei untersuchten Genotypen (mediale Areale des Corpus callosum). Es zeigten sich keine signifikanten Unterschiede ( $p=0.9289)$ im Ausmaß des Myelinverlustes im Corpus callosum (ANOVA mit Tukey Post-Test-Analyse).

\section{Entmarkung lateral}

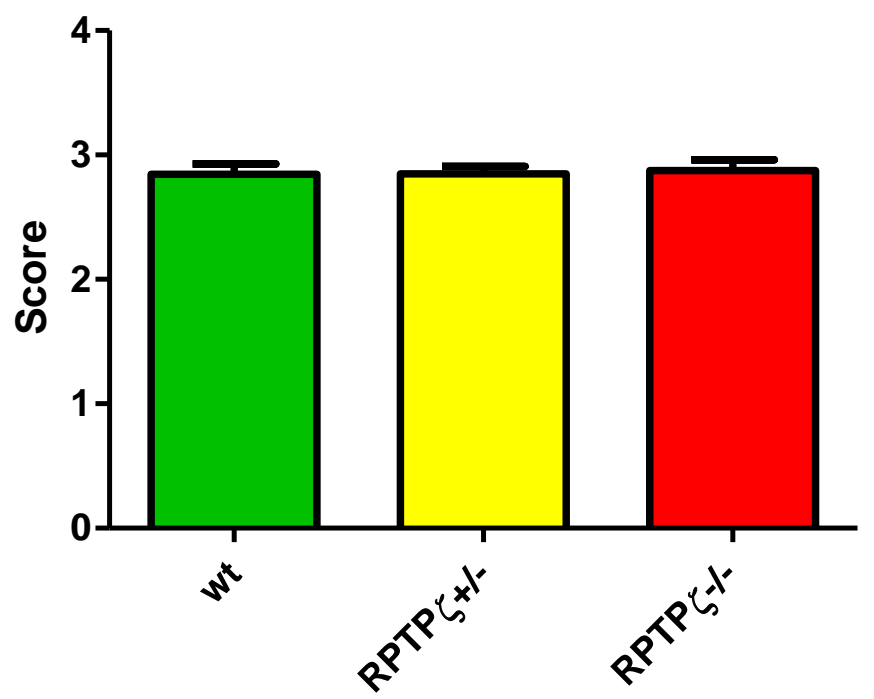

Abbildung 5: Semiquantitative Scores (MW $\pm \mathrm{SD}$ ) zur Bestimmung des Myelinverlustes nach Cuprizon-induzierter Entmarkung des Corpus callosum nach Hiremath et al. (1998) in der LFB/PAS-Färbung bei den drei untersuchten Genotypen (laterale Areale des Corpus callosum). Es zeigten sich keine signifikanten Unterschiede ( $p=0,9653$ ) im Ausmaß des Myelinverlustes im Corpus callosum (ANOVA mit Tukey Post-Test-Analyse). 


\subsubsection{Dichte reifer Oligodendrozyten in Wildtyp-, RPTPל-heterozygoten und

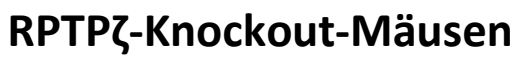

Die Dichte der reifen Oligodendrozyten in den medialen Arealen des Corpus callosum der drei Genotypen wurde immunhistochemisch mittels Antikörpern gegen Nogo-A quantifiziert. Die Nogo-A-positiven reifen Oligodendrozyten stellten sich als braun gefärbte Zellkörper dar. Die Quantifizierung ergab für die Wildtyp-Mäuse (wt) nach 6-wöchiger Cuprizon-Gabe einen Wert von $821 \pm 236$ $(\mathrm{MW} \pm \mathrm{SD})$ Nogo-A-positiven Zellen $/ \mathrm{mm}^{2}$, für die RPTP $\zeta$-heterozygoten Mäuse (RPTP $\zeta+/-)$ einen Wert von $825 \pm 152(\mathrm{MW} \pm \mathrm{SD})$ Nogo-A-positiven Zellen $/ \mathrm{mm}^{2}$

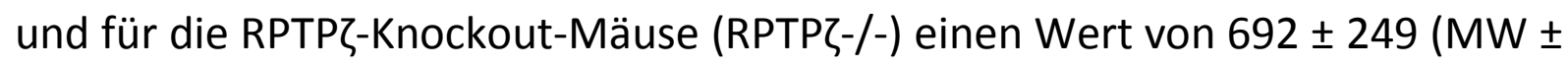
SD) Nogo-A-positiven Zellen/mm² (vgl. Abb. 7).

Bei der Durchführung der Varianzanalyse nach ANOVA ergab sich mit einem $\mathrm{p}$ Wert von $p=0,2096$ sowie bei der Post-Test-Analyse nach Tukey kein statistisch signifikanter Unterschied bei der Anzahl Nogo-A-positiver reifer Oligodendrozyten $/ \mathrm{mm}^{2}$ und somit auch kein Unterschied bezüglich der oligodendroglialen Schädigung bei den verschiedenen Genotypen. 

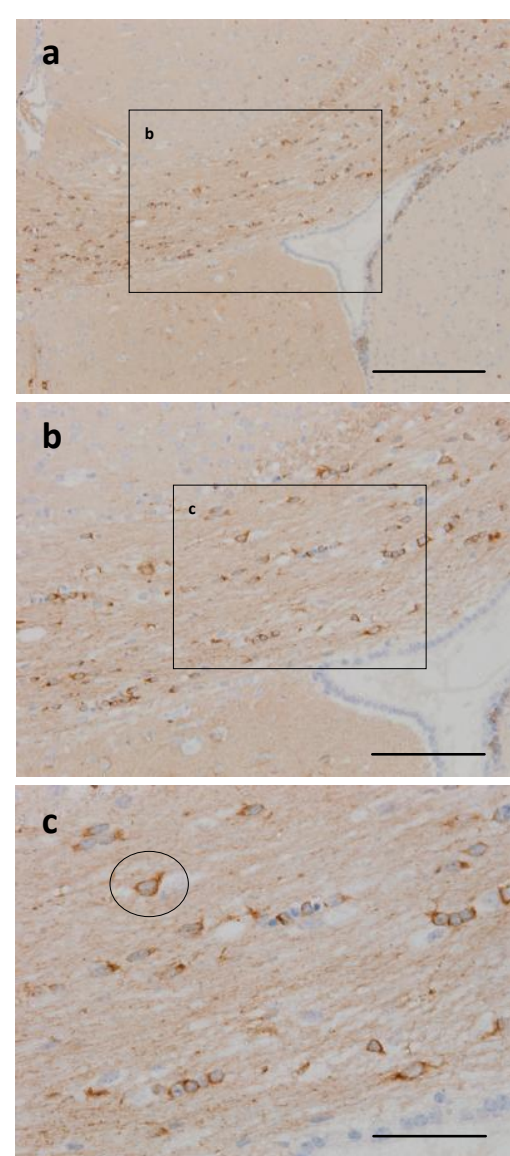

wt
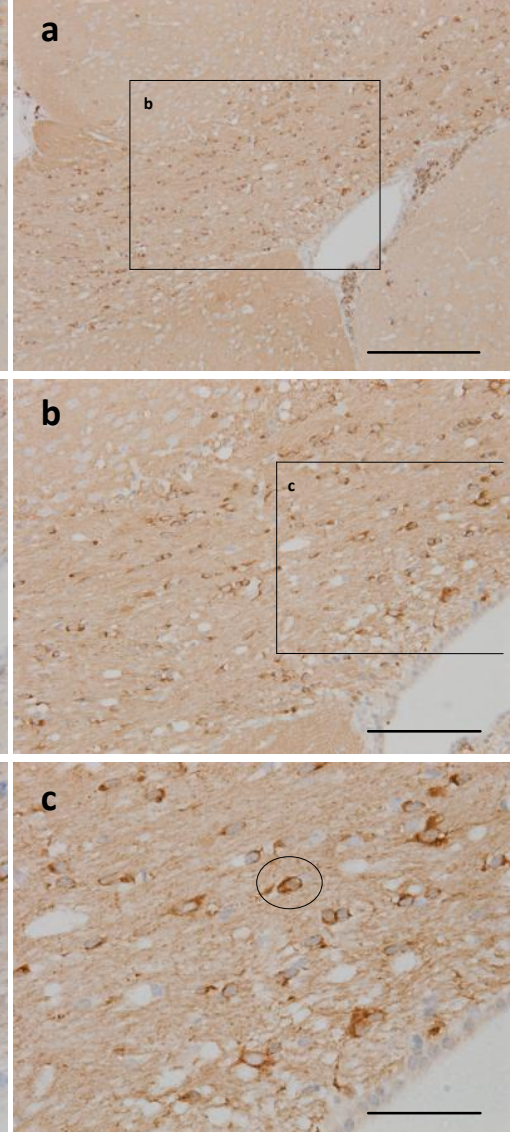

RPTP $+/-$

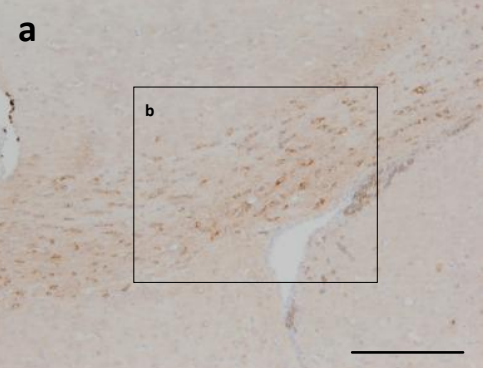

b
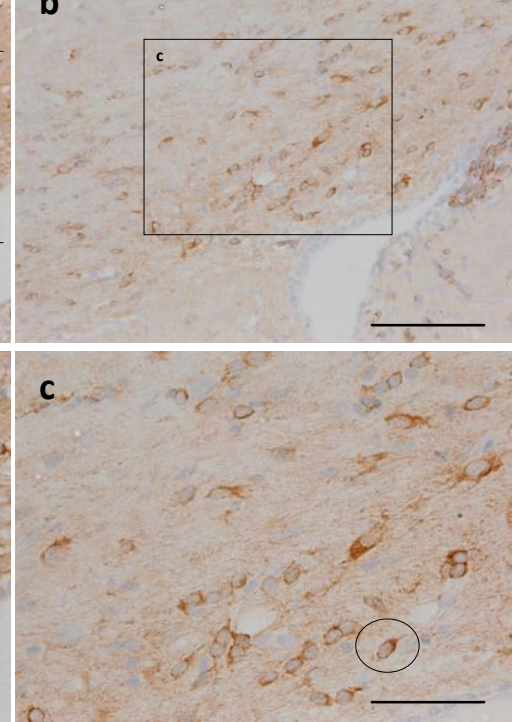

RPTPל-/-

Abbildung 6: Morphologie und Verteilung reifer Oligodendrozyten (schwarze Ellipsen) in der immunhistochemischen Färbung mit Antikörpern gegen Nogo-A nach Cuprizon-induzierter

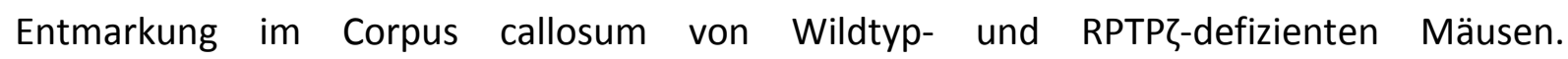
Originalvergrößerung und Balkengröße: 100-fach bzw. $200 \mu \mathrm{m}$ (obere Reihe), 200-fach bzw. $100 \mu \mathrm{m}$ (mittlere Reihe), 400-fach bzw. $50 \mu \mathrm{m}$ (untere Reihe). 


\section{Nogo-A}

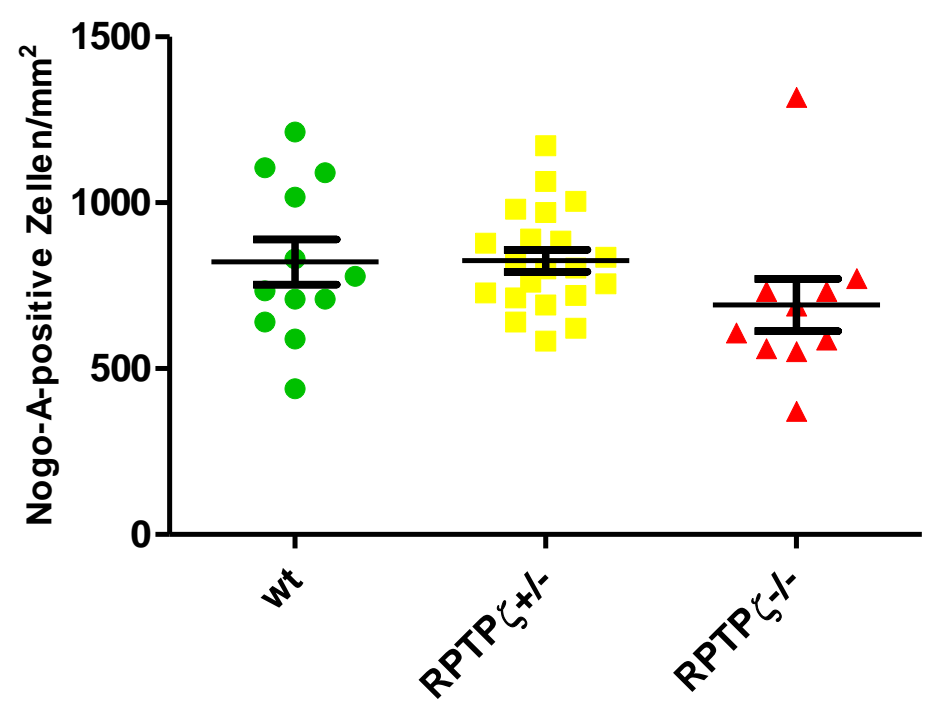

Abbildung 7: Nogo-A-positive reife Oligodendrozyten/ $/ \mathrm{mm}^{2}(\mathrm{MW} \pm \mathrm{SD})$ in den drei untersuchten Genotypen nach Cuprizon-induzierter Entmarkung. Immunhistochemische Färbung mit Antikörpern gegen Nogo-A. Bei den verschiedenen Genotypen lag kein signifikanter Unterschied ( $p=0,2096)$ bezüglich der Dichte reifer Oligodendrozyten vor (ANOVA mit Tukey Post-Test-Analyse).

\subsubsection{Dichte der Oligodendrozyten bzw. Oligodendrozyten-Progenitorzellen in Wildtyp- und RPTPZ-Knockout-Mäusen}

Die Dichte der Oligodendrozyten bzw. Oligodendrozyten-Progenitorzellen in den medialen Arealen des Balkens von wt und RPTP wöchiger Cuprizon-Gabe wurde immunhistochemisch mithilfe von Antikörpern gegen Olig-2 bestimmt. Die Olig-2-positiven Oligodendrozyten bzw. Oligodendrozyten-Progenitorzellen stellten sich als braun (reife Oligodendrozyten) bzw. stark braun (Oligodendrozyten-Progenitorzellen) gefärbte Zellkerne dar. Dabei ergab sich für die Wildtyp-Mäuse (wt) ein Wert von $1425 \pm 278$ (MW $\pm \mathrm{SD}$ ) Olig-2-positiven Zellen $/ \mathrm{mm}^{2}$ und für die RPTP弓-

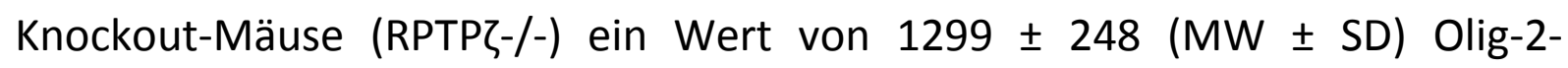
positiven Zellen $/ \mathrm{mm}^{2}$ (vgl. Abb. 9).

Wildtyp- und RPTPל-Knockout-Mäuse zeigten keinen signifikanten Unterschied bezüglich der Dichte der Oligodendrozyten und ihrer Progenitorzellen bzw. 
bezüglich des Ausmaßes der Rekrutierung bzw. Differenzierung der Oligodendrozyten-Progenitorzellen (ungepaarter t-Test).

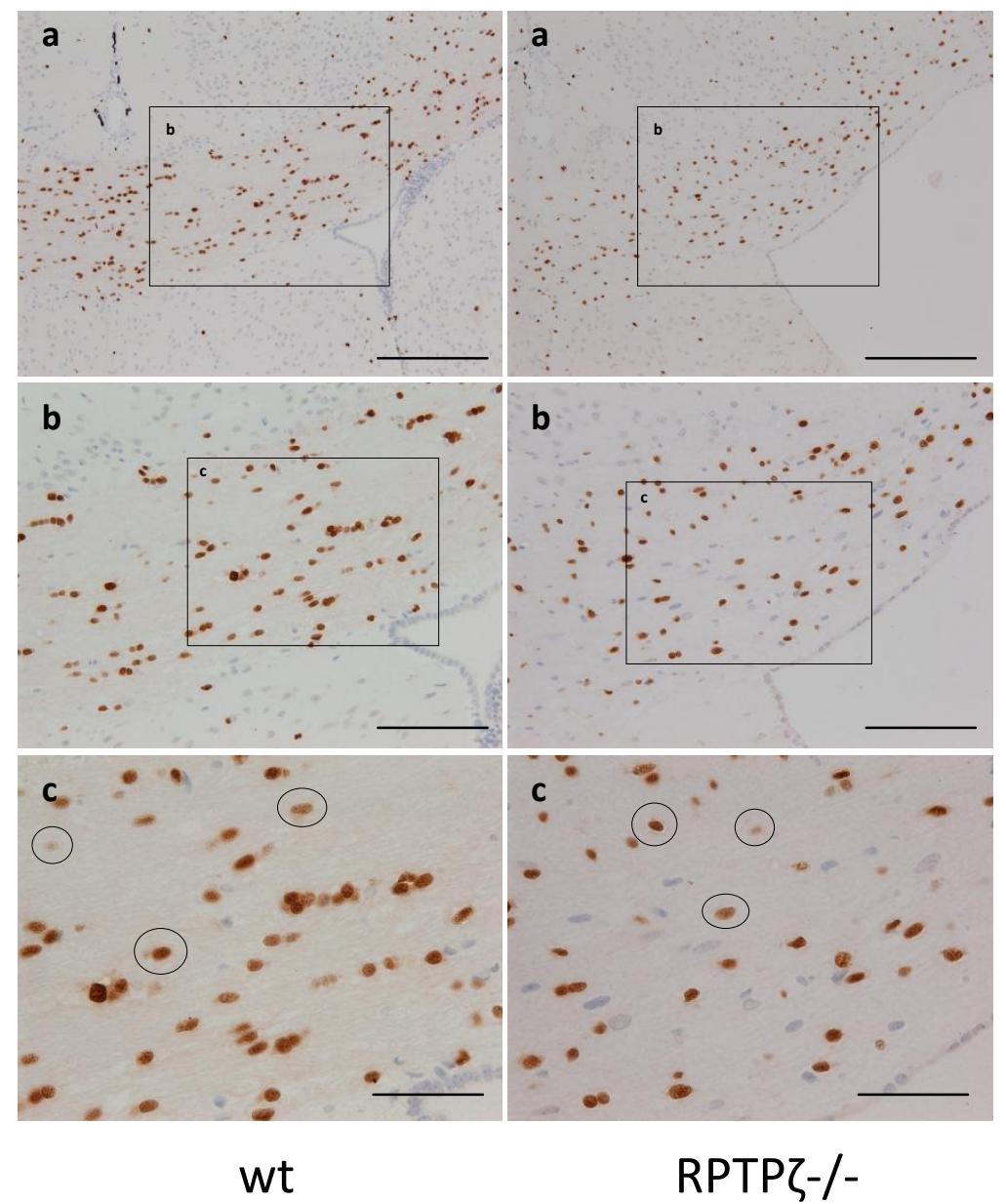

Abbildung 8: Morphologie und Verteilung der Oligodendrozyten und ihrer Progenitorzellen (schwarze Ellipsen) in der immunhistochemischen Färbung mit Antikörpern gegen Olig-2 nach Cuprizon-induzierter Entmarkung im Corpus callosum von Wildtyp- und RPTP\}Knockout-Mäusen. Originalvergrößerung und Balkengröße: 100-fach bzw. $200 \mu \mathrm{m}$ (obere Reihe), 200-fach bzw. $100 \mu \mathrm{m}$ (mittlere Reihe), 400-fach bzw. $50 \mu \mathrm{m}$ (untere Reihe). 
Olig-2

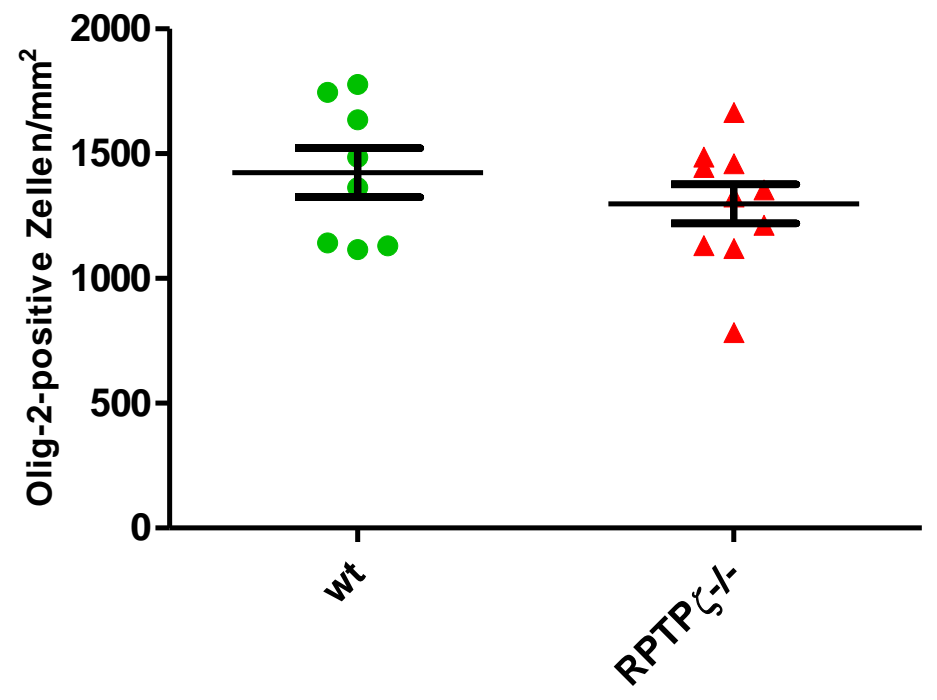

Abbildung 9: Olig-2-positive Oligodendrozyten bzw. Oligodendrozyten-

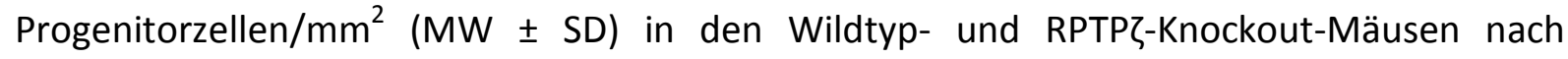
Cuprizon-induzierter Entmarkung. Immunhistochemische Färbung mit Antikörpern gegen Olig-2. Es stellte sich kein signifikanter Unterschied $(p=0,3269)$ bei der Dichte der Oligodendrozyten bzw. ihrer Progenitorzellen zwischen den beiden Genotypen dar (ungepaarter t-Test).

\subsubsection{Axonale Schädigung in Wildtyp- und RPTPל-Knockout-Mäusen}

Die akute axonale Schädigung in den medialen Arealen des Corpus callosum

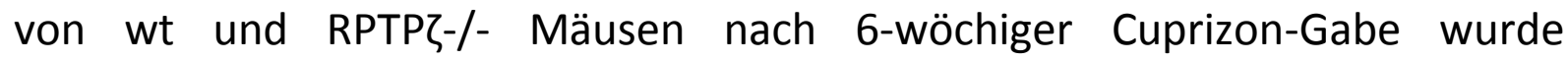
immunhistochemisch mittels Antikörpern gegen das sogenannte AmyloidVorläuferprotein (amyloid precursor protein, APP) quantifiziert. APP-positive axonale Sphäroide stellten sich dabei braun gefärbt dar. Es ergab sich für die Wildtyp-Mäuse (wt) ein Wert von $654 \pm 622$ (MW \pm SD) APP-positiven

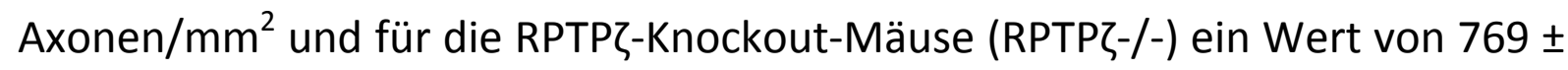
$322(\mathrm{MW} \pm \mathrm{SD}$ ) APP-positiven Axonen/mm (vgl. Abb. 11).

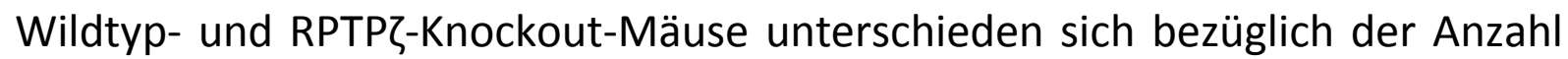
akut geschädigter Axone bzw. der Schwere des axonalen Verlustes nicht signifikant voneinander (ungepaarter t-Test). 

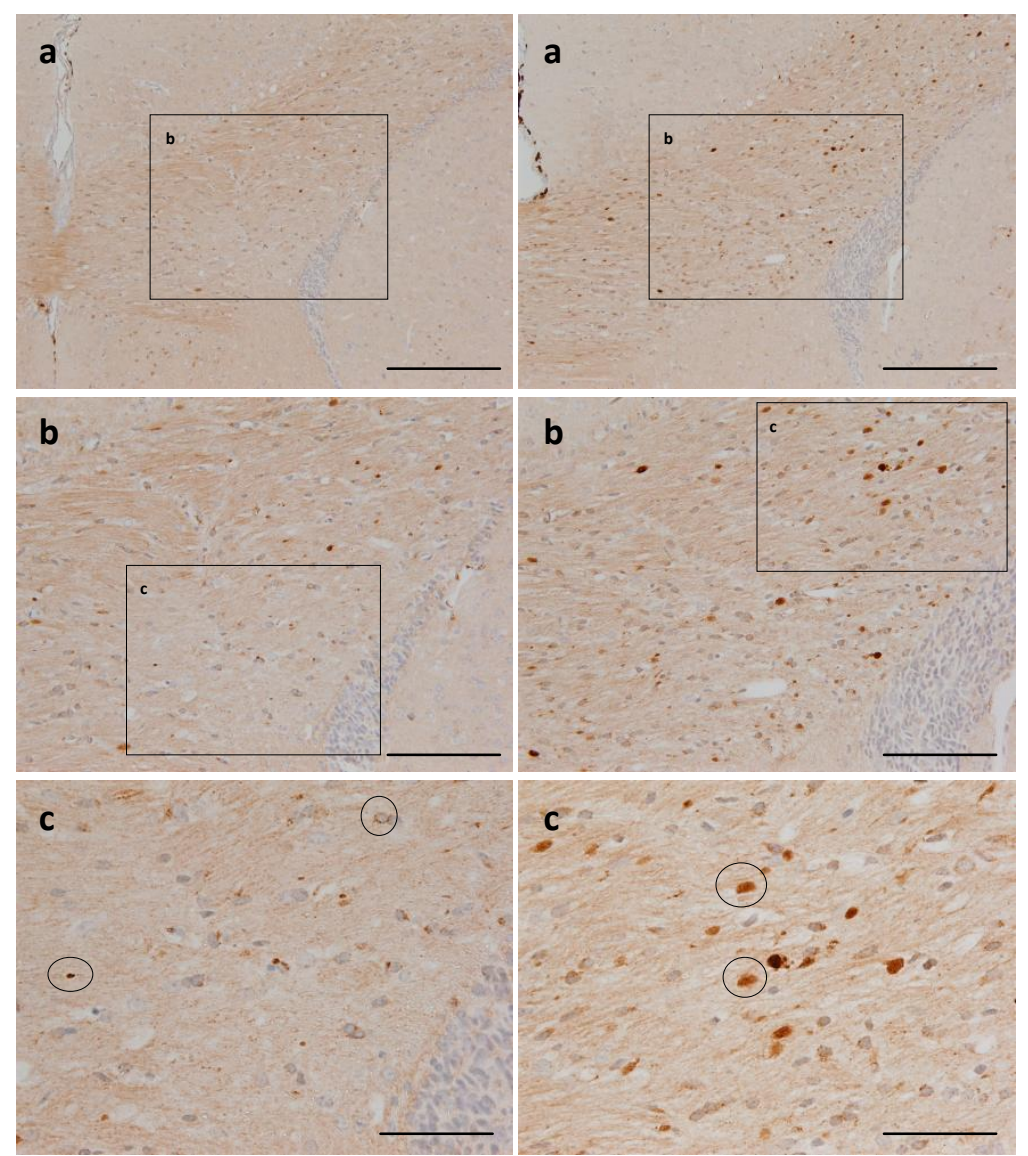

wt

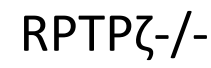

Abbildung 10: Morphologie und Verteilung axonaler Schädigung (schwarze Ellipsen) in der immunhistochemischen Färbung mit Antikörpern gegen APP nach Cuprizon-induzierter

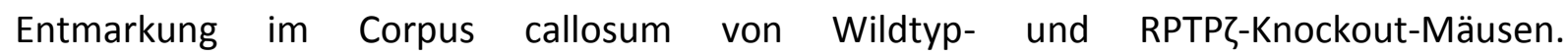
Originalvergrößerung und Balkengröße: 100-fach bzw. $200 \mu \mathrm{m}$ (obere Reihe), 200-fach bzw. $100 \mu \mathrm{m}$ (mittlere Reihe), 400-fach bzw. $50 \mu \mathrm{m}$ (untere Reihe). 


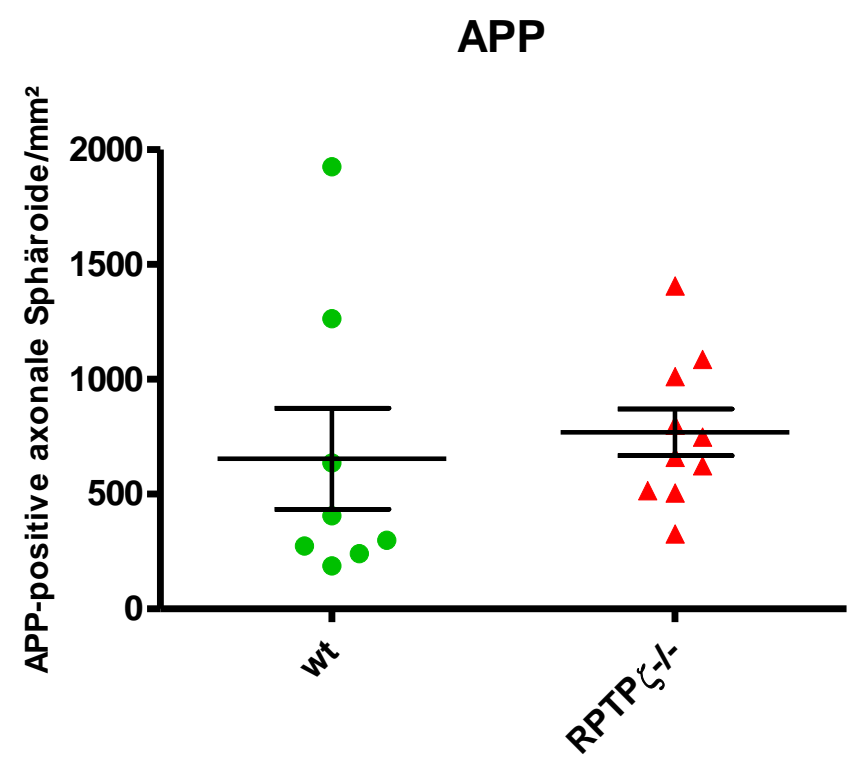

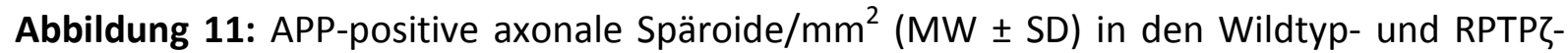
Knockout-Mäusen nach Cuprizon-induzierter Entmarkung. Immunhistochemische Färbung mit Antikörpern gegen APP. Bezüglich der Dichte akut geschädigter Axone $/ \mathrm{mm}^{2}$ zeigte sich kein signifikanter Unterschied ( $p=0,6177$ ) zwischen den beiden Genotypen (ungepaarter tTest).

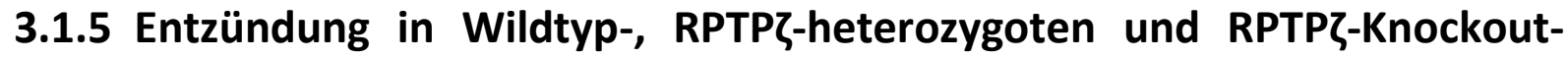 Mäusen}

Die Dichte der T-Lymphozyten bzw. aktivierten Mikroglia in den medialen Arealen des Balkens der drei Genotypen nach 6-wöchiger CuprizonVerfütterung (Stadium der Entmarkung) wurde immunhistochemisch mithilfe von Antikörpern gegen CD3 bzw. Mac-3 bestimmt. Die CD3-positiven TLymphozyten bzw. Mac-3-positiven aktivierten Mikroglia stellten sich jeweils als braun angefärbte Zellkörper dar.

Dabei ergab sich bei der Bestimmung der CD3-positiven Zellen für die WildtypMäuse (wt) ein Wert von 1,3 $\pm 1,9(\mathrm{MW} \pm \mathrm{SD}) \mathrm{CD} 3$-positiven Zellen $/ \mathrm{mm}^{2}$, für

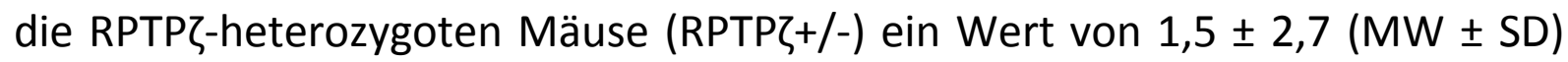

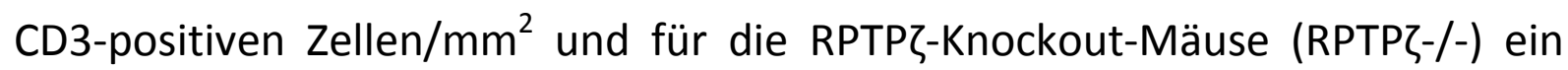
Wert von 0,4 $\pm 0,8\left(\mathrm{MW} \pm \mathrm{SD}\right.$ ) CD3-positiven Zellen/ $/ \mathrm{mm}^{2}$ (vgl. Abb. 13).

Bei der Quantifizierung der Mac-3-positiven Zellen ergab sich für die WildtypMäuse (wt) ein Wert von $357 \pm 200$ (MW \pm SD) Mac-3-positiven Zellen/mm², 


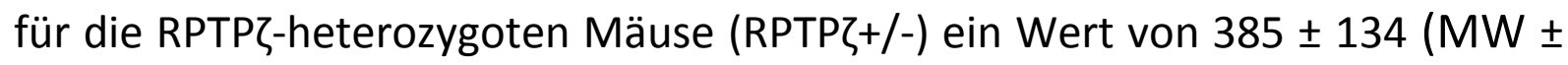

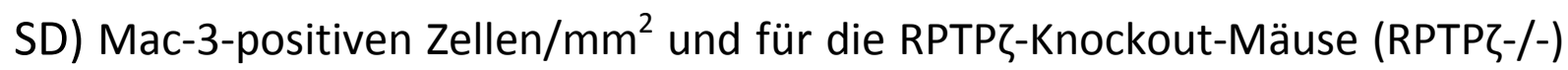
ein Wert von $444 \pm 210$ (MW \pm SD) Mac-3-positiven Zellen $/ \mathrm{mm}^{2}$ (vgl. Abb. 15).

Die Durchführung der Varianzanalyse nach ANOVA ergab für die Dichte der CD3-positiven T-Lymphozyten/mm $\mathrm{mm}^{2}$ einen $\mathrm{p}$-Wert von $\mathrm{p}=0,3991$ und für die Dichte der Mac-3-positiven aktivierten Mikroglia/ $\mathrm{mm}^{2}$ einen $\mathrm{p}$-Wert von $\mathrm{p}=$ 0,4956. Die drei Genotypen unterschieden sich voneinander somit nicht signifikant bei der Dichte der T-Lymphozyten und aktivierten Mikroglia. Auch bei der Post-Test-Analyse nach Tukey zeigte sich kein signifikanter Unterschied bezüglich der Dichte dieser Zelltypen $/ \mathrm{mm}^{2}$. Folglich ließ sich bei den drei Genotypen kein Unterschied bezüglich des Ausmaßes der Entzündung ermitteln. 


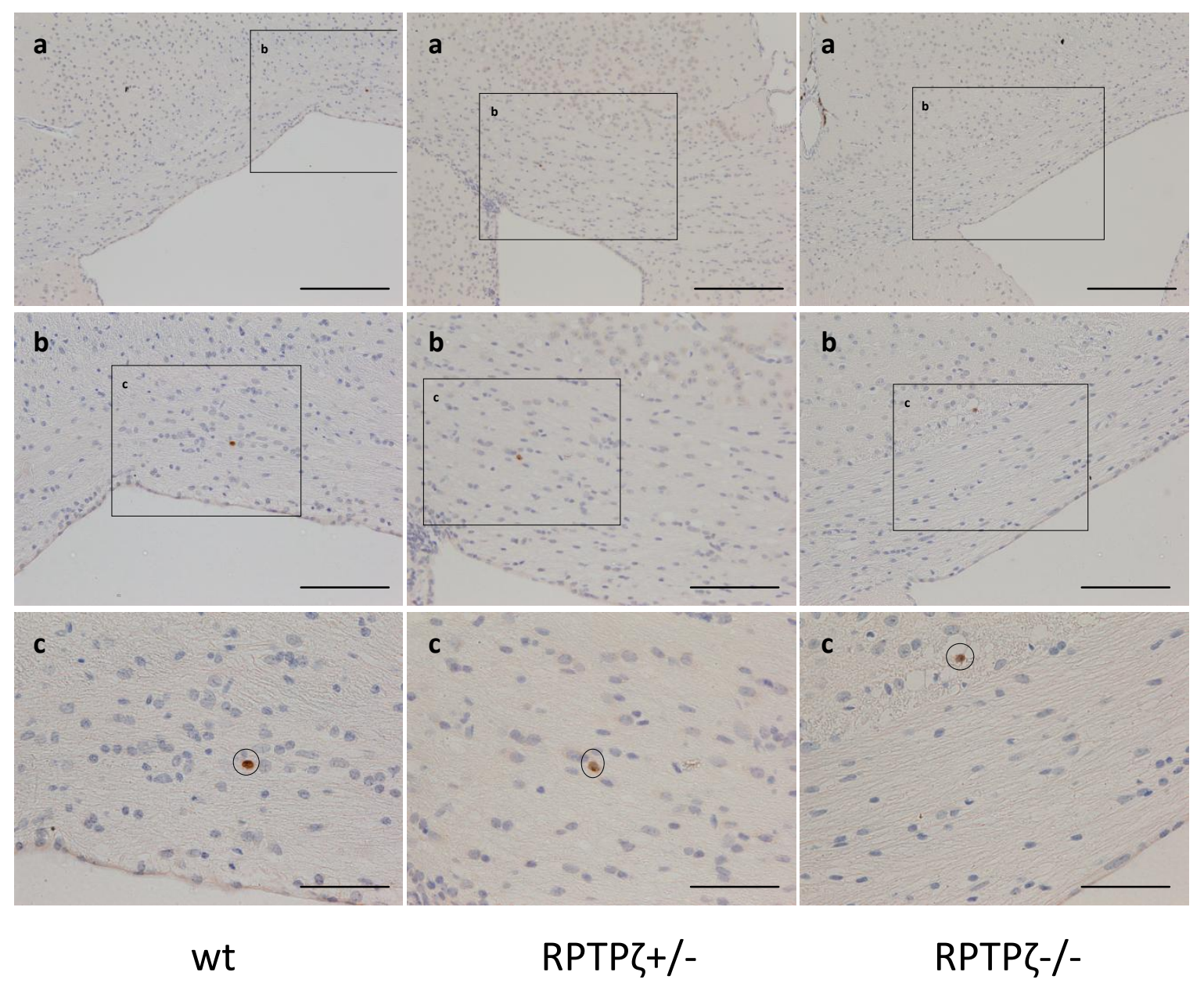

Abbildung 12: Morphologie und Verteilung der T-Lymphozyten (schwarze Ellipsen) in der immunhistochemischen Färbung mit Antikörpern gegen CD3 nach Cuprizon-induzierter

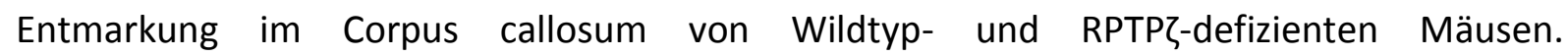
Originalvergrößerung und Balkengröße: 100-fach bzw. $200 \mu \mathrm{m}$ (obere Reihe), 200-fach bzw. $100 \mu \mathrm{m}$ (mittlere Reihe), 400-fach bzw. $50 \mu \mathrm{m}$ (untere Reihe). 


\section{CD3}

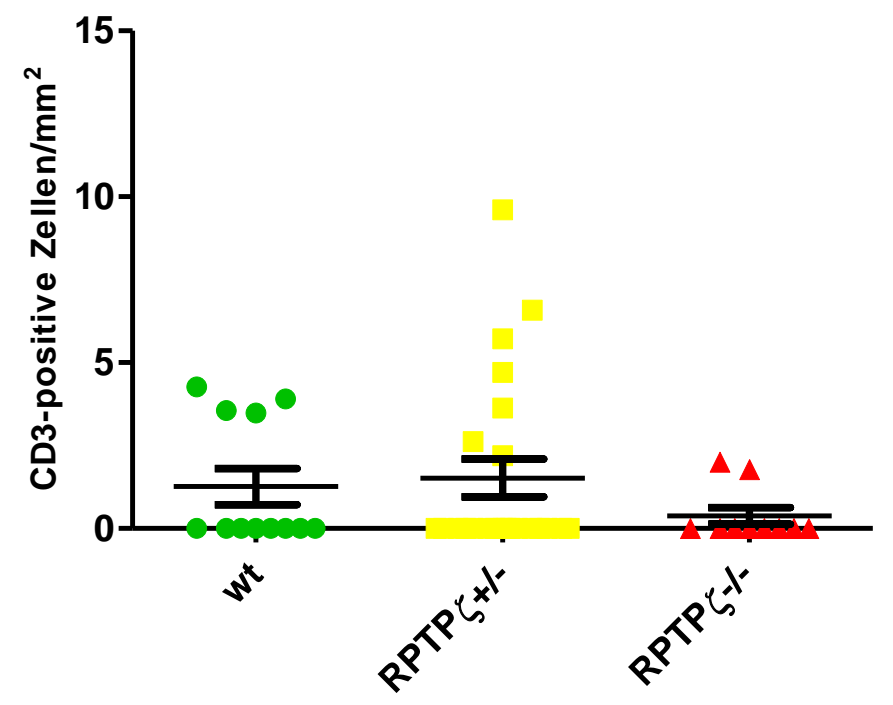

Abbildung 13: CD3-positive T-Lymphozyten $/ \mathrm{mm}^{2}(\mathrm{MW} \pm \mathrm{SD}$ ) in den drei untersuchten Genotypen nach Cuprizon-induzierter Entmarkung. Immunhistochemische Färbung mit Antikörpern gegen CD3. Es zeigte sich kein signifikanter Unterschied ( $p=0,3991)$ bezüglich der Dichte der T-Lymphozyten bei den verschiedenen Genotypen (ANOVA mit Tukey PostTest-Analyse). 


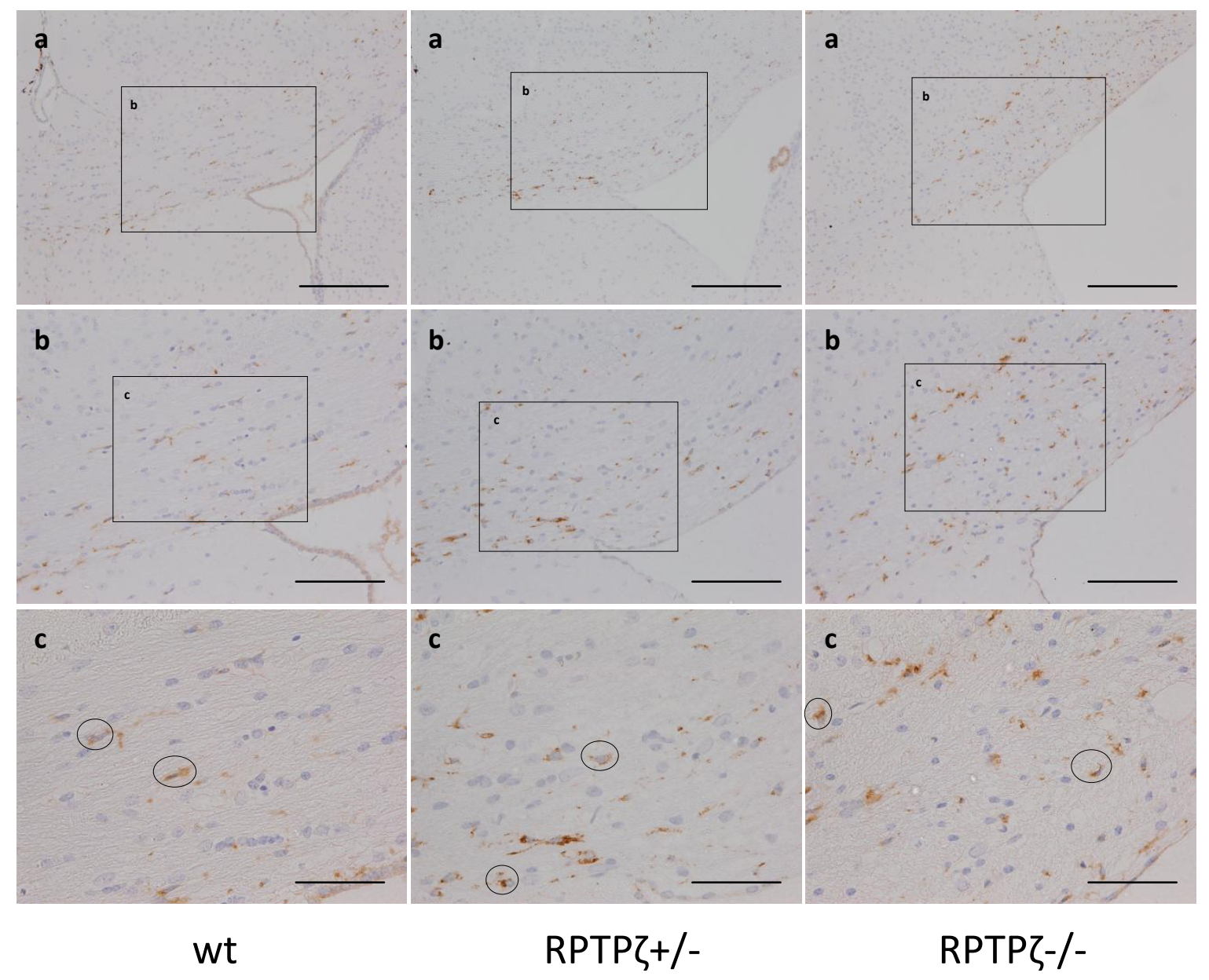

Abbildung 14: Morphologie und Verteilung aktivierter Mikroglia (schwarze Ellipsen) in der immunhistochemischen Färbung mit Antikörpern gegen Mac-3 nach Cuprizon-induzierter Entmarkung im Corpus callosum von Wildtyp- und RPTPל-defizienten Mäusen. Originalvergrößerung und Balkengröße: 100-fach bzw. $200 \mu \mathrm{m}$ (obere Reihe), 200-fach bzw. $100 \mu \mathrm{m}$ (mittlere Reihe), 400-fach bzw. $50 \mu \mathrm{m}$ (untere Reihe). 


\section{Mac-3}

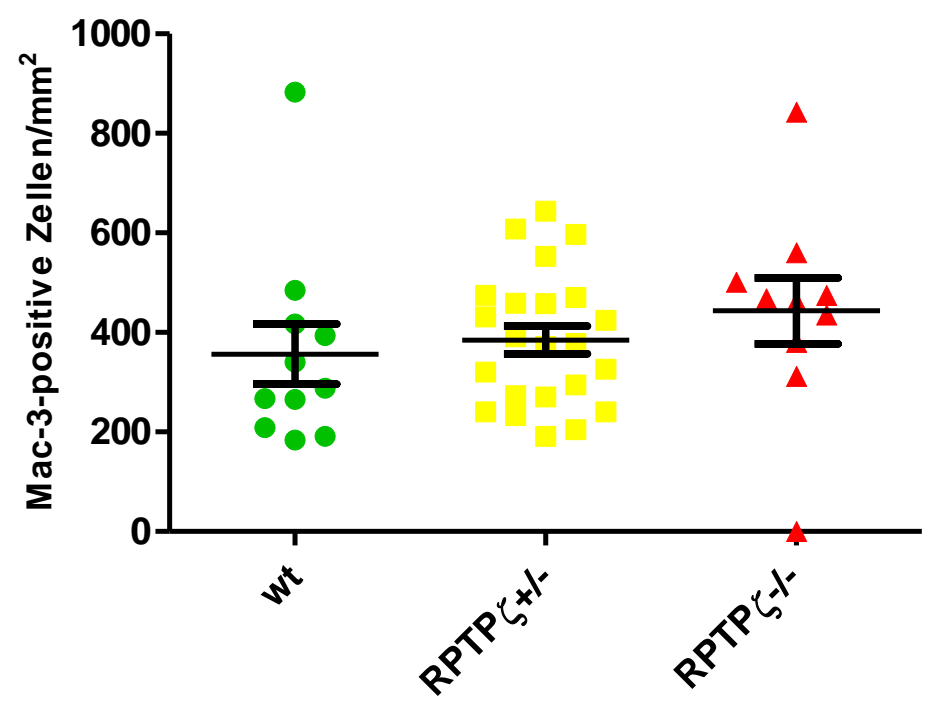

Abbildung 15: Mac-3-positive aktivierte Mikroglia/mm² $(\mathrm{MW} \pm \mathrm{SD})$ in den drei untersuchten Genotypen nach Cuprizon-induzierter Entmarkung. Immunhistochemische Färbung mit Antikörpern gegen Mac-3. Die Dichte der aktivierten Mikroglia unterschied sich bei den verschiedenen Genotypen nicht signifikant $(p=0,4956)$ voneinander (ANOVA mit Tukey Post-Test-Analyse). 


\section{Diskussion}

Das Cuprizon-Modell ist ein experimentelles Tiermodell der MS, welches sehr gut zur Untersuchung der direkt an der De- und Remyelinisierung beteiligten zellulären Prozesse geeignet ist (Ludwin 1978).

Hierbei wird die Demyelinisierung auf toxischem Wege durch Cuprizon (Biscyclohexanon Oxalyldihydrazon), einem Kupferchelator, mit dessen Hilfe Kupfer quantitativ bestimmt werden kann (Peterson und Bollier 1955) und der erstmals in den 1960er Jahren als toxisches Agens bei Tierexperimenten mit Mäusen genutzt wurde (Carlton 1966), hervorgerufen (Blakemore 1973). Die Demyelinisierung wird dabei wohl eher durch den Untergang von Oligodendrozyten verursacht als durch eine direkte Zerstörung der Myelinscheiden. Darüber hinaus hat es den Anschein, als ob die Schädigung von Zellen im ZNS sich auf die Oligodendrozyten beschränke (Blakemore 1972). Auf welche Art und Weise Cuprizon seine toxische Wirkung genau entfaltet, ist noch nicht vollständig geklärt. Es gibt aber Hinweise, dass Cuprizon durch die Bindung von Kupfer einen Kupfermangel im Gehirn verursacht, welcher wiederum zu einer Funktionsstörung von Mitochondrien mit nachfolgendem Energiemangel glialer Zellen führt (Venturini 1973). Der Grund dafür, dass dieser Energiemangel wohl nur bei den Oligodendrozyten zum Zelluntergang führt, könnte darin liegen, dass sie große Mengen von Myelin aufrechterhalten müssen und dies mit einem hohen Energiebedarf verbunden ist (Matsushima und Morell 2001).

Ein wesentlicher Vorteil des Cuprizon-Modells gegenüber anderen experimentellen Tiermodellen der MS, wie z. B. der experimentellen autoimmunen Enzephalomyelitis (EAE), ist die hohe Reproduzierbarkeit des Musters des Oligodendrozytenunterganges und der Demyelinisierung im Corpus callosum bei Verwendung bestimmter Mausstämme. Es kommt weder zu einer Schädigung der Blut-Hirn-Schranke (Bakker und Ludwin 1987) noch zu einer wesentlichen Infiltration von Lymphozyten (Komoly 2005). Das Immunsystem in den Läsionen wird ausschließlich durch aktivierte Mikroglia repräsentiert (Hiremath et al. 1998; Remington et al. 2007). Hierdurch kann unter anderem die Bedeutung der Mikroglia für die Stimulation von Proliferation und Differenzierung der Oligodendrozyten-Progenitorzellen 
(Diemel et al. 1998; Matsushima und Morell 2001), welche die Voraussetzung für eine Remyelinisierung sind, unabhängig von weiteren immunologischen Prozessen analysiert werden.

Ziel dieser Studie war es, die Rolle der Rezeptor-Protein-Tyrosin-Phosphatase $\zeta$

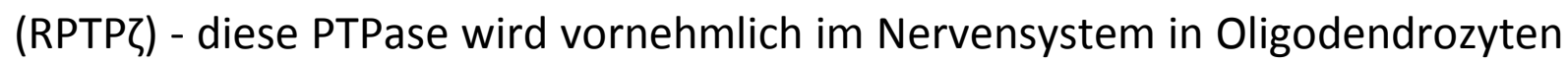
(Canoll et al. 1996; Ranjan und Hudson 1996), Astrozyten und Neuronen (Shintani et al. 1998) exprimiert - bei der De- und Remyelinisierung zu erforschen. Zu diesem Zweck untersuchten wir den Einfluss von RPTP $\zeta$ auf das Ausmaß der Demyelinisierung, den Untergang von Oligodendrozyten bzw. die Rekrutierung und Differenzierung von Oligodendrozyten-Progenitorzellen, die axonale Schädigung sowie die Entzündung im Corpus callosum von Wildtypund RPTPל-defizienten Mäusen nach 6-wöchiger Verfütterung von 0,25\%-igem Cuprizon.

\subsection{Die Bedeutung von RPTP für das Ausmaß der Entmarkung unter Cuprizon-Verfütterung}

Diverse Studien deuten darauf hin, dass Tyrosin-Phosphorylierung bzw.

-Dephosphorylierung durch Protein-Tyrosin-Kinasen (PTKs) bzw. ProteinTyrosin-Phosphatasen (PTPs) eine wesentliche Rolle beim Prozess der Myelinsynthese spielen (Umemori et al. 1999; Peretz et al. 2000). Inwieweit dies auch für die Rezeptor-Protein-Tyrosin-Phosphatase $\zeta$ zutrifft, geht nicht eindeutig aus der Fachliteratur hervor. Während einige Untersuchungen die Bedeutung von RPTP für diverse Reifungsprozesse des ZNS zu bestätigen scheinen (Levy et al. 1993; Canoll et al. 1996; Nishiwaki et al. 1998), wird dies in anderen Quellen (Harroch et al. 2000) in dieser Form nicht bestätigt, wenngleich es jedoch auch hier Hinweise dafür gibt, dass RPTP $\zeta$ an Prozessen der Myelinsynthese und/oder Remyelinisierung beteiligt sein könnte. Spätere Untersuchungen von Harroch et al. (2002) an Mäusen und Menschen scheinen

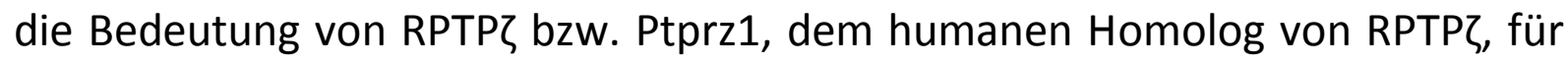
die Genesung von demyelinisierenden Erkrankungen bei Mäusen bzw. Menschen zu untermauern. 
Bei unseren Untersuchungen wurde das Ausmaß der Entmarkung im Corpus

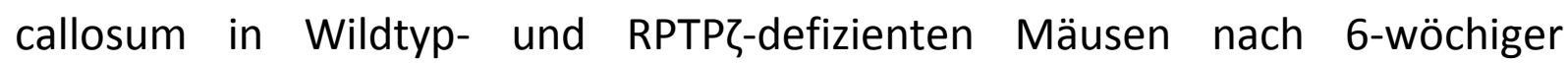
Verfütterung von 0,25\%-igem Cuprizon bestimmt. Dies erfolgte anhand von histologischen Präparaten in der LFB/PAS-Färbung unter Verwendung des semiquantitativen Scores nach Hiremath et al. (1998).

Bei der Auswertung der erhobenen Daten konnten wir keinen signifikanten Unterschied bezüglich des Ausmaßes der Entmarkung zwischen den Wildtypund RPTPל-defizienten Mäusen feststellen. Signifikante Unterschiede bei der Entmarkung zeigten sich lediglich zwischen den medialen und lateralen Arealen des Corpus callosum, dies jedoch bei allen drei Mausgruppen gleichermaßen.

Dementsprechend kam der Rezeptor-Protein-Tyrosin-Phosphatase $\zeta$ bei unseren Untersuchungen offensichtlich keine tragende Rolle beim Schutz des Corpus callosum vor Cuprizon-induzierter Entmarkung zu.

\subsection{Die Bedeutung von RPTP\ für das Ausmaß Cuprizon-induzierter Apoptosen von Oligodendrozyten}

Diverse Studien konnten bereits belegen, dass das Ausmaß der Remyelinisierung in MS-Plaques von der Anzahl der Oligodendrozyten, also jener Zellen, die im ZNS verantwortlich für die Myelinsynthese sind, abhängig zu sein scheint (Brück et al. 1994; Ozawa et al. 1994). Darüber hinaus ist bekannt, dass die Dichte von Oligodendrozyten in chronischen MS-Läsionen meist sehr gering ausfällt (Mews et al. 1998), während sie hingegen in akuten MS-Läsionen stark variiert (Lucchinetti et al. 1999). Die Verkleinerung der Oligodendrozytenpopulation ist dabei vermutlich maßgeblich auf Apoptose zurückzuführen (Mason JL et al. 2000 b). Wenngleich es in aktiv demyelinisierenden Läsionen generell zu einer starken Abnahme der Oligodendrozytendichte kommt, so fällt dennoch auf, dass auch nach Tagen bzw. Wochen demyelinisierender Aktivität teilweise noch funktionstüchtige Oligodendrozyten auffindbar sind, sodass wohl davon ausgegangen werden muss, dass innerhalb demyelinisierter Läsionen Faktoren existieren, welche auf 
Oligodendrozyten stimulierend bzw. protektiv wirken (Raine und Wu 1993). Die Überprüfung dieser These scheint insbesondere bei der Betrachtung der Studien von Ludwin (1984) sowie Ludwin und Bakker (1988) an Relevanz zu gewinnen, in denen die Beobachtung gemacht wurde, dass dem Anschein nach ausgereifte Oligodendrozyten, welche während der Demyelinisierung nicht apoptotisch geworden sind, proliferieren und zur Remyelinisierung beitragen können.

Unterschiedliche Arbeitsgruppen konnten bei ihren Untersuchungen Daten sammeln, die darauf hindeuten, dass Protein-Tyrosin-Phosphatasen (PTPs) bzw. Protein-Tyrosin-Kinasen (PTKs) in den Prozess der Oligodendrozytenprotektion eingebunden sind. Dell' Albani et al. beobachteten 1998, dass sich die beiden Zytokine PDGF (platelet-derived growth factor), ein aus Blutplättchen stammender Wachstumsfaktor, und CNTF (ciliary neurotrophic factor), ein Wachstumsfaktor für Neurone, positiv auf das Überleben von Oligodendrozyten-Progenitorzellen auswirken und sie eben diese Wirkung durch Tyrosin-Phosphorylierung in Oligodendrogliazellen vermitteln. CasacciaBonnefil et al. (1999) schlussfolgerten aus ihren Untersuchungen, dass das Überleben von Oligodendrozyten durch Prozesse gefördert wird, in die auch oligodendrogliale Tyrosin-Kinasen eingebunden sind.

Auch RPTP $\zeta$ - ebenfalls in Oligodendrozyten exprimiert (Canoll et al. 1996; Ranjan und Hudson 1996) - scheint Oligodendrozyten vor Apoptose schützen zu können (Harroch et al. 2002). Unklar ist bis heute jedoch, über welchen

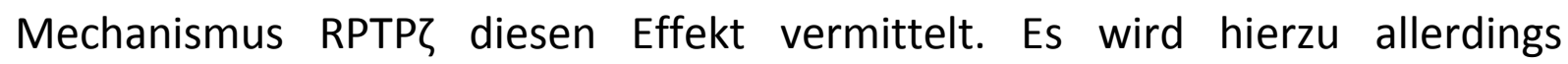
postuliert, dass Astrozyten - auch in diesen Zellen wird RPTP $\zeta$ exprimiert (Shintani et al. 1998) - während Cuprizon-induzierter Entmarkung im Corpus callosum von Mäusen IGF-1 (insulin-like growth factor-1) synthetisieren (Komoly et al. 1992) und dass IGF-1 Cuprizon-induzierte Apoptose von ausgereiften Oligodendrozyten mindern und auf diese Weise eine schnellere Reparatur der Demyelinisierung bewirken kann (Mason JL et al. 2000 a).

Huang et al. (2012) hingegen konnten bei ihren Untersuchungen, im Rahmen derer sie mittels Lysolecithin-induzierter Toxizität eine akute Entmarkung im

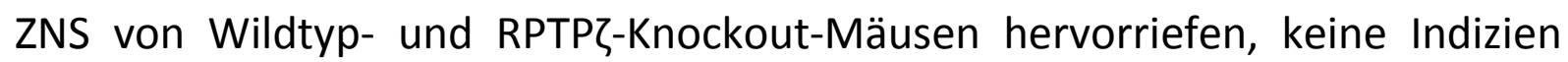


dafür sammeln, dass RPTP $\zeta$ für den Schutz von Oligodendrozyten vor Apoptose durch Lysolecithin essentiell ist.

Ziel unserer Untersuchungen war es, zu untersuchen, inwiefern die Expression von RPTP $\zeta$ Einfluss auf das Überleben bzw. die Apoptose von Oligodendrozyten im Rahmen der Cuprizon-Toxizität hat.

Vor diesem Hintergrund untersuchten wir das Corpus callosum von Wildtypund RPTPל-defizienten Mäusen im Hinblick auf die Dichte der reifen Oligodendrozyten nach 6-wöchiger Verfütterung von 0,25\%-igem Cuprizon mit

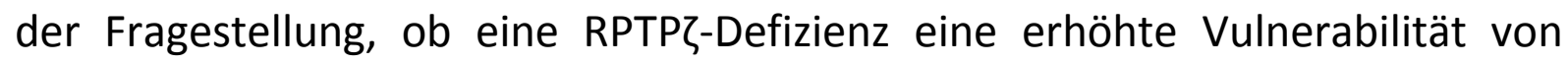
Oligodendrozyten gegenüber Cuprizon-induzierter Toxizität bedingt.

Bei der statistischen Auswertung unserer Daten fiel auf, dass die Dichte der reifen Oligodendrozyten bei den Wildtyp- und RPTPZ-heterozygoten Mäusen

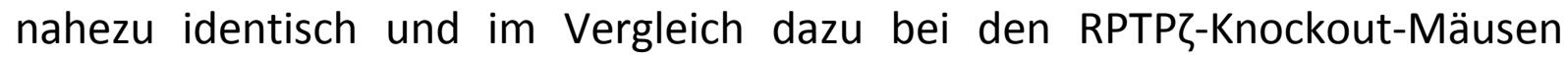
geringer war. Statistisch signifikant war dieser Unterschied der Oligodendrozytendichte zwischen den Mausgruppen jedoch nicht.

Unsere Daten lassen demnach nicht darauf schließen, dass RPTP 3 an der Protektion von Oligodendrozyten vor Cuprizon-bedingter Apoptose wesentlich beteiligt ist.

\subsection{Die Bedeutung von RPTP für das Ausmaß der Rekrutierung und Differenzierung von Oligodendrozyten-Progenitorzellen bei Cuprizon-induzierter Entmarkung}

Beim Cuprizon-Tiermodell fällt unter anderem auf, dass es etwa ab der 6 . Woche der Cuprizon-Verfütterung zu Remyelinisierung im Corpus callosum sowie zu einer Zunahme der Oligodendrozytendichte kommt, nachdem zuvor Demyelinisierung stattgefunden hat und die Oligodendrozytenpopulation nahezu vollständig verschwunden ist (Matsushima und Morell 2001). 
Bis heute ist nicht sicher geklärt, woher diese neuen Oligodendrozyten im Corpus callosum stammen.

Mason JL et al. (2000 b) stellten bei ihren Untersuchungen an Mäusen im Rahmen des Cuprizon-Tiermodells fest, dass ab der 2. Woche der CuprizonVerfütterung Oligodendrozyten-Progenitorzellen in Nachbarregionen des Corpus callosum zu proliferieren und in das Corpus callosum einzuwandern scheinen, dort dann in der 3. bzw. 4. Woche akkumulieren und sich zu differenzieren beginnen, bevor die Dichte der reifen Oligodendrozyten im Corpus callosum deutlich ansteigt. Daraus leiteten sie ab, dass die neue Oligodendrozytenpopulation vermutlich von den zuvor eingewanderten Oligodendrozyten-Progenitorzellen abstammt. Diese Annahme scheint durch eine Studie von Gensert und Goldman (1997) gestützt zu werden, bei der auch sie bereits zuvor beobachten konnten, dass Oligodendrozyten-Progenitorzellen in demyelinisierten Plaques zu myelinisierenden Oligodendrozyten differenzieren.

Für uns stellte sich die Frage, inwiefern RPTP $\zeta$ sich auf den Prozess der Rekrutierung bzw. Differenzierung der Oligodendrozyten-Progenitorzellen auszuwirken vermag. Es wird vermutet, dass die Akkumulation von Oligodendrozyten-Progenitorzellen im Corpus callosum im Zusammenhang mit dem zeitgleich beobachteten starken Anstieg des Spiegels von IGF-1 (insulinlike growth factor-1) stehen bzw. durch ihn bedingt sein könnte (Mason JL et al. 2000 b). IGF-1 wird während Cuprizon-induzierter Demyelinisierung in Mäusen unter anderem von Astrozyten sezerniert (Komoly et al. 1992). Astrozyten gehören zu den Zellen des ZNS, welche RPTP exprimieren (Shintani et al. 1998). Somit scheint ein Zusammenhang zwischen RPTP $\zeta$ und der Rekrutierung bzw. Differenzierung der Oligodendrozyten-Progenitorzellen im Corpus callosum denkbar. Andererseits scheinen die Forschungsergebnisse von Huang et al. (2012), die bei ihren Untersuchungen von Rückenmarksgewebe aus

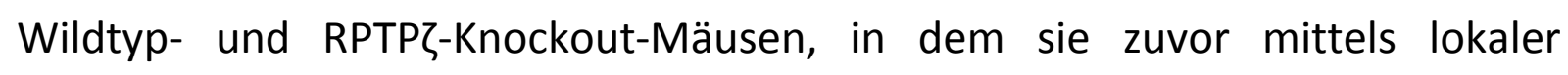
Lysolecithin-Injektion eine fokale Demyelinisierung hervorgerufen hatten, dagegen zu sprechen, dass RPTP $\zeta$ für die Rekrutierung oder Differenzierung von Oligodendrozyten-Progenitorzellen von Bedeutung ist, da sich die beiden experimentellen Gruppen weder bzgl. der Anzahl rekrutierter 
Oligodendrozyten-Progenitorzellen noch bzgl. der Anzahl reifer Oligodendrozyten in den Läsionen signifikant voneinander unterschieden.

Durch unsere Untersuchungen wollten wir überprüfen, ob die Expression von RPTP $\zeta$ für die Rekrutierung bzw. Differenzierung von OligodendrozytenProgenitorzellen im Corpus callosum relevant ist. $\mathrm{Zu}$ diesem Zweck untersuchten wir das Corpus callosum von Wildtyp- und RPTPל-defizienten Mäusen im Hinblick auf die Dichte der Oligodendrozyten und Oligodendrozyten-Progenitorzellen nach 6-wöchiger Verfütterung von 0,25\%igem Cuprizon mit der Fragestellung, ob eine RPTPל-Defizienz zu einer verminderten Rekrutierung bzw. Differenzierung von OligodendrozytenProgenitorzellen führt.

Wir stellten fest, dass die Dichte der Oligodendrozyten bzw. Oligodendrozyten-

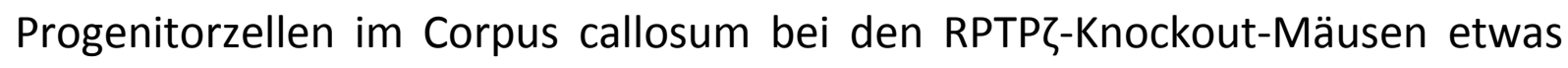
geringer war als in den Wildtyp-Mäusen. Statistisch signifikant war dieser Unterschied allerdings nicht.

Unseren Untersuchungsergebnissen zufolge scheint eine RPTPל-Defizienz also nicht zu einer verminderten Rekrutierung bzw. Differenzierung von Oligodendrozyten-Progenitorzellen im Corpus callosum von Mäusen während Cuprizon-induzierter Demyelinisierung zu führen.

\subsection{Die Bedeutung von RPTP für das Ausmaß der axonalen Schädigung bei Cuprizon-induzierter Entmarkung}

Neuronen gehören ebenfalls zu jenen Zellen, welche RPTP $\zeta$ exprimieren. Wie in Kapitel 1.4.1 dargestellt, bindet RPTP $\zeta$ mit seiner extrazellulären Domäne an diverse Zelladhäsionsmoleküle, Matrixmoleküle und Wachstumsfaktoren, wodurch allem Anschein nach für die Entwicklung des Nervensystems grundlegende Prozesse, wie Wachstum, Migration oder auch Differenzierung von Nervenzellen, reguliert werden. Welche intrazellulären Prozesse hiermit gekoppelt sind, ist bisher nicht abschließend geklärt. 
Huang et al. (2012) stellten bei ihren Untersuchungen fest, dass RPTP $\zeta$ defiziente Mäuse nach Lysolecithin-induzierter akuter Entmarkung des ZNS einen signifikant höheren Verlust von Axonen entwickelten als Wildtyp-Mäuse. Davon leiteten sie ab, dass die Intaktheit bzw. das Überleben von Axonen im Rahmen demyelinisierender Erkrankungen des ZNS anscheinend von der Expression von RPTP $\zeta$ abhängen.

Snyder et al. (1996) konnten im Rahmen ihrer Untersuchungen außerdem beobachten, dass es bei Ratten im Anschluss an eine Verletzung des ZNS unter anderem in Arealen, in denen sie Aussprossung von Axonen verzeichnen konnten, zu einer deutlich gesteigerten Expression von RPTP $\zeta$ kam. Daraus schlussfolgerten sie, dass RPTP $\zeta$ im ZNS womöglich einen Beitrag zum Nachwachsen von Axonen und zur Erholung von Verletzungen leistet.

Angesichts dieser Untersuchungsergebnisse sowie vor dem Hintergrund, dass bei der MS das Ausmaß der Schädigung bzw. des Funktionsverlustes der Axone mit dem Schweregrad der chronischen Behinderung einhergeht (Dutta u. Trapp 2007), die Abnahme der Axonendichte als einer der möglichen Gründe für den letzten Endes meist doch frustranen Verlauf der Remyelinisierung bei der MS diskutiert wird (Wood und Bunge 1986) und es auch deutliche Hinweise dafür gibt, dass das Überleben von Oligodendrozyten von der Präsenz von Axonen abzuhängen scheint (Barres et al. 1993), untersuchten wir das Corpus callosum von Wildtyp- und RPTP\}-defizienten Mäusen hinsichtlich des Ausmaßes der axonalen Schädigung nach 6-wöchiger Verfütterung von 0,25\%-igem Cuprizon. Als Indikator diente dabei APP (amyloid precursor protein, AmyloidVorläuferprotein), welches sich bei einer axonalen Schädigung im proximal (und in geringerem Ausmaß auch distal) der Verletzung gelegenen Bereich des Axons anhäuft (Ferguson et al. 1997). Führt eine RPTPל-Defizienz zu verstärkter axonaler Schädigung bzw. zu einem herabgesetzten Regenerationspotential der im Rahmen der Cuprizon-Verfütterung geschädigten Axone?

Wir stellten fest, dass die Dichte von APP und damit das Ausmaß der axonalen

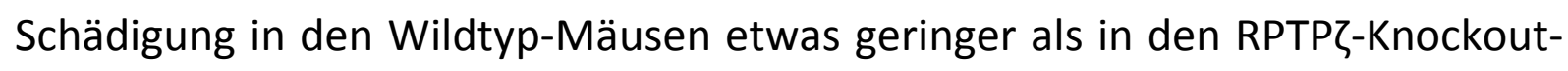
Mäusen ausfiel. Ein signifikanter Unterschied lag dabei allerdings nicht vor. 
Unseren Ergebnissen zufolge scheint ein Fehlen von RPTP $\zeta$ also nicht zu einer erhöhten axonalen Schädigung während Cuprizon-induzierter Toxizität zu führen.

\subsection{Die Bedeutung von RPTP\ für das Ausmaß der Entzündung bei Cuprizon-induzierter Entmarkung}

Bis heute konnte noch nicht abschließend geklärt werden, welche pathophysiologischen Prozesse der MS zugrunde liegen (Trebst et al. 2006) und welche Funktion die Entzündung bzw. die beteiligten Immunzellen dabei im Einzelnen erfüllen. Wie in den Abschnitten 1.1.3.1, 1.2.1 und 1.3 ausführlich dargelegt, werden diesbezüglich neben destruktiven auch neuroprotektive bzw. zum Prozess der Remyelinisierung beitragende Effekte diskutiert:

Wahrscheinlich kommt es bei der MS zur Aktivierung autoreaktiver T-Zellen gegen Myelinbestandteile und im Anschluss hieran zur Migration der T-Zellen ins ZNS, wo sie durch den Kontakt mit Autoantigenen reaktiviert werden und dann im weiteren Verlauf als Typ1- und Typ2-Helferzellen sowie als zytotoxische, CD8-positive T-Zellen eine Entzündung verursachen und dabei teils direkt, teils indirekt mittels Aktivierung von Makrophagen/Mikroglia, BLymphozyten bzw. des Komplementsystems die für die MS charakteristische Zerstörung der Myelinscheiden bewirken.

Andererseits scheinen die Entzündung bzw. die beteiligten Immunzellen auch neuroprotektiv wirken bzw. den Prozess der Remyelinisierung begünstigen zu können. Dies erreichen die Immunzellen allem Anschein nach durch Sekretion bestimmter Zytokine und Wachstumsfaktoren. Hier sind beispielsweise die Sekretion von BDNF (brain-derived neurotrophic factor) durch T-Zellen (Hohlfeld et al. 2000) sowie die Sekretion von IL-1 (Interleukin-1) und IGF-1 (insulin-like growth factor-1) durch Makrophagen zu nennen (Scheibenbogen und Andreesen 1991; Mason JL et al. 2000 a, 2000 b).

Im Rahmen der vorliegenden Arbeit versuchten wir zu ergründen, ob eine

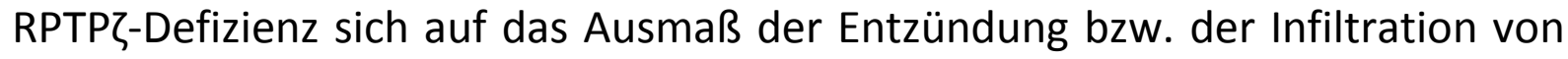


Immunzellen auswirkt. Dazu untersuchten wir das Corpus callosum von Wildtyp- und RPTPל-defizienten Mäusen im Hinblick auf die Dichte der TLymphozyten und aktivierten Mikroglia nach 6-wöchiger Verfütterung von 0,25\%-igem Cuprizon.

Für die Dichte der T-Lymphozyten wie auch für die Dichte der aktivierten Mikroglia ergaben sich bei den Wildtyp- und RPTP $\zeta$-heterozygoten Mäusen jeweils sehr ähnliche Werte. Damit verglichen stellten wir bei den RPTP\}Knockout-Mäusen eine geringere Dichte der T-Lymphozyten und eine eher gesteigerte Dichte der aktivierten Mikroglia fest. Signifikant waren diese Unterschiede allerdings nicht.

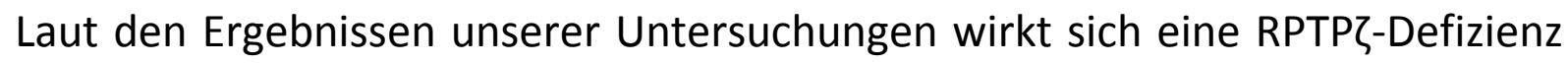
also weder auf das Ausmaß der Infiltration von T-Lymphozyten noch auf das Ausmaß der Infiltration von aktivierten Mikroglia während Cuprizon-bedingter Entmarkung aus. 


\section{$5 \quad$ Zusammenfassung}

Die MS ist eine chronisch entzündliche Erkrankung des ZNS und tritt am häufigsten bei der weißen Bevölkerung Nordeuropas und Nordamerikas auf. Es handelt sich bei ihr um eine komplexe Autoimmunerkrankung mit weiterhin nicht abschließend geklärter Ätiologie und Pathophysiologie. Eine kausale Therapie steht nach wie vor nicht zur Verfügung. Entzündung, Demyelinisierung, Schädigung von Axonen, eine Störung der Blut-HirnSchranke, der Untergang von Oligodendrozyten sowie eine reaktive Gliose sind die Wesensmerkmale der MS. Histopathologisch und klinisch stellt sie sich als eine heterogene Erkrankung mit unterschiedlichen histopathologischen Mustern in den Läsionen und unterschiedlichen Krankheitsverläufen dar.

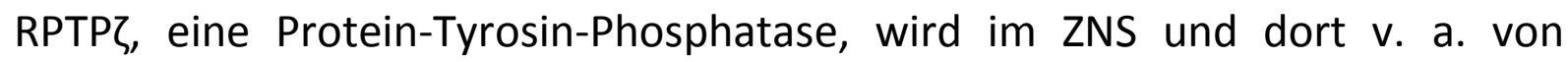
Oligodendrozyten, Astrozyten und Neuronen exprimiert. Sie ist mutmaßlich an diversen Reifungsprozessen des ZNS beteiligt. Untersuchungen von Harroch et al. (2000) zufolge scheint RPTP $\zeta$ auch für die Myelinsynthese und/oder für an der Remyelinisierung beteiligte Prozesse bedeutsam zu sein. Zusätzlich konnten Harroch et al. (2002) belegen, dass RPTP $\zeta$ bzw. Ptprz1 - hierbei handelt es sich um das humane Homolog von RPTP $\zeta$ - allem Anschein nach für die Erholung von demyelinisierenden Erkrankungen bei Mäusen bzw. Menschen, wie beispielsweise der MS, relevant sind.

In der vorliegenden Arbeit untersuchte ich anhand des Cuprizon-Tiermodells, eines etablierten Tiermodells der MS, die Rolle von RPTP $\zeta$ bei der De- und Remyelinisierung.

Unsere Hypothese war es, dass RPTPZ-defiziente Mäuse während Cuprizonbedingter toxischer Entmarkung im Vergleich zu Wildtyp-Mäusen ein erhöhtes Ausmaß an Entmarkung zeigen. Darüber hinaus wollten wir untersuchen, ob bzw. in welchem Ausmaß RPTP $\zeta$ Einfluss auf an der De- bzw. Remyelinisierung beteiligte zelluläre Prozesse zu nehmen vermag.

Wir konnten belegen, dass RPTP $\zeta$ bzw. eine RPTP -Defizienz keinen wesentlichen Einfluss auf das Ausmaß der Entmarkung oder die von uns 
untersuchten und an der De- bzw. Remyelinisierung beteiligten zellulären Prozesse nahmen.

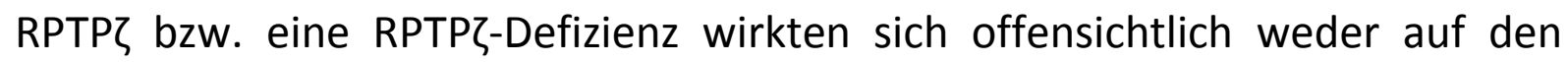
Verlust von Oligodendrozyten durch Apoptose noch auf die Schädigung von Axonen aus. Auch den Prozess der Rekrutierung bzw. Differenzierung von Oligodendrozyten-Progenitorzellen und das Ausmaß der Entzündung bzw. das Ausmaß der Infiltration von Immunzellen - bei unseren Untersuchungen namentlich T-Lymphozyten und aktivierte Mikroglia - hatten RPTP $\zeta$ bzw. eine RPTPS-Defizienz nicht beeinflusst.

Somit bleibt festzuhalten, dass RPTP unseren Untersuchungen zufolge weder bei der De- und Remyelinisierung während Cuprizon-bedingter toxischer Entmarkung im ZNS von Mäusen noch bei den zusätzlich von uns untersuchten an der De- und Remyelinisierung beteiligten zellulären Prozessen eine maßgebliche Rolle zu spielen scheint. 
6 Anhang: Übersichtstabelle der Ergebnisse der statistischen Auswertung

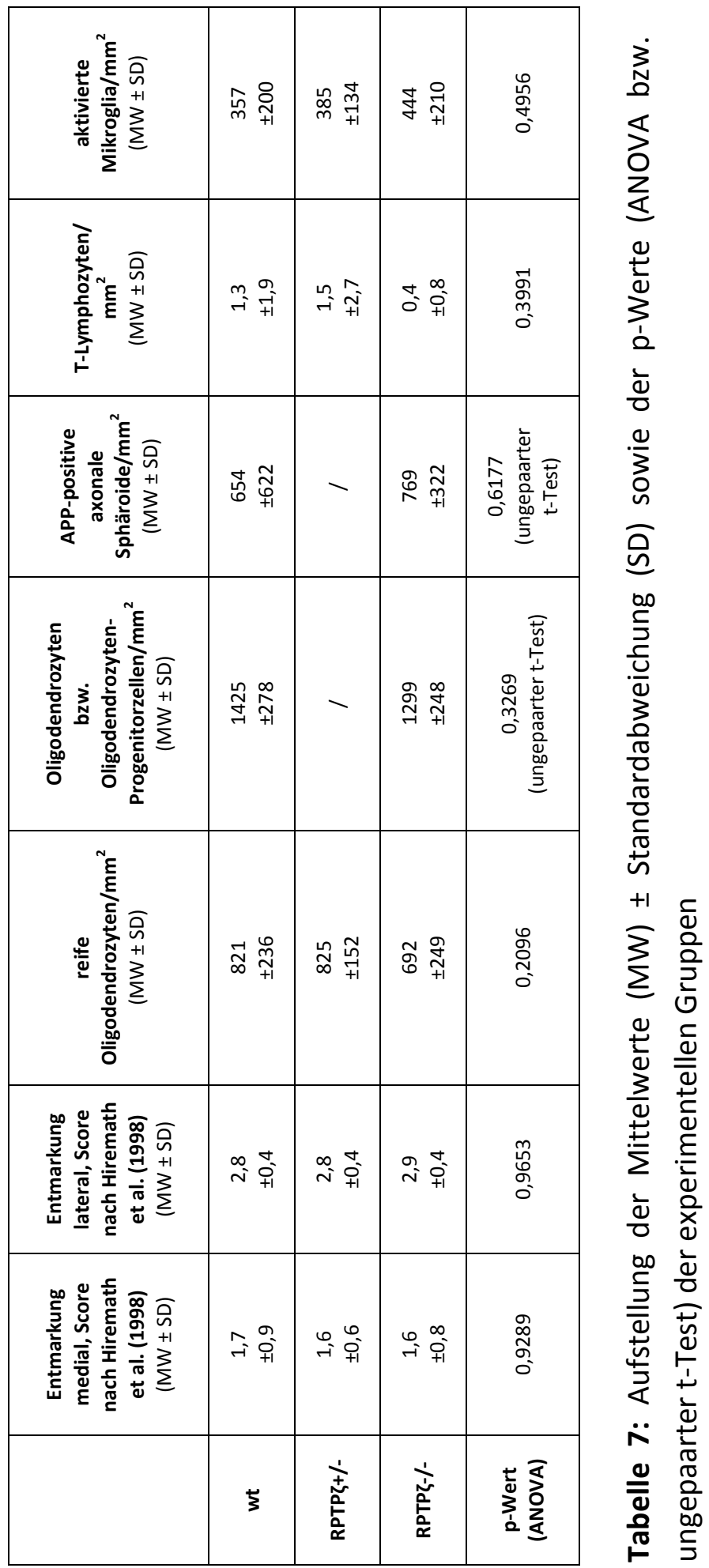




\section{$7 \quad$ Literaturverzeichnis}

Abbas AK, Murphy KM, Sher A (1996): Functional diversity of helper T lymphocytes. Nature $\underline{383}, 787-793$

Acheson ED (1977): Epidemiology of multiple sclerosis. Br Med Bull 33 (1), 9-14

Ahmad F, Considine RV, Goldstein BJ (1995): Increased abundance of the receptor-type protein-tyrosine phosphatase LAR accounts for the elevated insulin receptor dephosphorylating activity in adipose tissue of obese human subjects. J Clin Invest 95 (6), 2806-2812

Armstrong RC, Le TQ, Flint NC, Vana AC, Zhou YX (2006): Endogenous cell repair of chronic demyelination. J Neuropathol Exp Neurol 65 (3), 245-256

Bakker DA, Ludwin SK (1987): Blood-brain barrier permeability during cuprizone-induced demyelination: implications for the pathogenesis of immune-mediated demyelinating diseases. J Neurol Sci 78 (2), 125-137

Barnea G, Silvennoinen O, Shaanan B, Honegger AM, Canoll PD, D'Eustachio P, Morse B, Levy JB, Laforgia S, Huebner K, et al. (1993): Identification of a carbonic anhydrase-like domain in the extracellular region of RPTPY defines a new subfamily of receptor tyrosine phosphatases. Mol Cell Biol 13 (3), 14971506

Barnea G, Grumet M, Milev P, Silvennoinen O, Levy JB, Sap J, Schlessinger J (1994): Receptor tyrosine phosphatase $\beta$ is expressed in the form of proteoglycan and binds to the extracellular matrix protein tenascin. $J$ Biol Chem $\underline{269(20)}, 14349-14352$

Barres BA, Jacobson MD, Schmid R, Sendtner M, Raff MC (1993): Does oligodendrocyte survival depend on axons? Curr Biol 3 (8), 489-497

Benoist C, Mathis D (2001): Autoimmunity provoked by infection: how good is the case for T cell epitope mimicry? Nat Immunol 2 (9), 797-801

Blakemore WF (1972): Observations on oligodendrocyte degeneration, the resolution of status spongiosus and remyelination in cuprizone intoxication in mice. J Neurol 1 (4), 413-426

Blakemore WF (1973): Demyelination of the superior cerebellar peduncle in the mouse induced by cuprizone. J Neurol Sci 20 (1), 63-72 
Blakemore WF, Franklin RJM (1991): Transplantation of glial cells into the CNS. Trends Neurosci 14 (8), 323-327

B $\varnothing$ L, Vedeler CA, Nyland HI, Trapp BD, Mørk SJ (2003): Subpial Demyelination in the cerebral cortex of multiple sclerosis patients. J Neuropathol Exp Neurol $\underline{62(7)}, 723-732$

Brod SA, Marshall GD, Henninger EM, Sriram S, Khan M, Wolinsky JS (1996): Interferon- $\beta_{1 b}$ treatment decreases tumor necrosis factor- $\alpha$ and increases interleukin-6 production in multiple sclerosis. Neurology 46 (6), 1633-1638

Brück W, Schmied M, Suchanek G, Brück Y, Breitschopf H, Poser S, Piddlesden $S$, Lassmann H (1994): Oligodendrocytes in the early course of multiple sclerosis. Ann Neurol 35 (1), 65-73

Brück W, Porada P, Poser S, Rieckmann P, Hanefeld F, Kretzschmar HA, Lassmann $H$ (1995): Monocyte/macrophage differentiation in early multiple sclerosis lesions. Ann Neurol 38 (5), 788-796

Campana D, Thompson JS, Amlot P, Brown S, Janossy G (1987): The cytoplasmic expression of CD3 antigens in normal and malignant cells of the T lymphoid lineage. J Immunol 138, 648-655

Canoll PD, Petanceska S, Schlessinger J, Musacchio JM (1996): Three forms of RPTP- $\beta$ are differentially expressed during gliogenesis in the developing rat brain and during glial cell differentiation in culture. J Neurosci Res 44 (3), 199215

Capello E, Mancardi GL (2004): Marburg type and Balò’s concentric sclerosis: rare and acute variants of multiple sclerosis. Neurol Sci 25 (Suppl4), S361-S363

Carlton WW (1966): Response of mice to the chelating agents sodium diethyldithiocarbamate, $\alpha$-benzoinoxime, and biscyclohexanone oxaldihydrazone. Toxicol Appl Pharmacol 8 (3), 512-521

Carlton WW (1967): Studies on the induction of hydrocephalus and spongy degeneration by cuprizone feeding and attempts to antidote the toxicity. Life Sci 6 (1), 11-19

Casaccia-Bonnefil P, Gu C, Chao MV (1999): Neurotrophins in cell survival/death decisions. Adv Exp Med Biol 468, 275-282

Cermelli C, Jacobson S (2000): Viruses and multiple sclerosis. Viral Immunol $\underline{13}$ (3), 255-267 
Charbonneau H, Tonks NK, Walsh KA, Fischer EH (1988): The leukocyte common antigen (CD45): a putative receptor-linked protein tyrosine phosphatase. Proc Natl Acad Sci U S A 85 (19), 7182-7186

Chen MS, Huber $A B$, van der Haar ME, Frank M, Schnell L, Spillmann AA, Christ F, Schwab ME (2000): Nogo-A is a myelin-associated neurite outgrowth inhibitor and an antigen for monoclonal antibody IN-1. Nature $\underline{403}, 434-439$

Coleman JE (1984): Carbonic anhydrase: zinc and the mechanism of catalysis. Ann N Y Acad Sci $\underline{429}$ (1), 26-48

Comi G, Filippi M, Barkhof F, Durelli L, Edan G, Fernández O, Hartung HP, Seeldrayers P, Soelberg Sørensen P, Rovaris M, et al. (2001): Effect of early interferon treatment on conversion to definite multiple sclerosis: a randomised study. Lancet 357 (9268), 1576-1582

Cree BAC, Goodin DS, Hauser SL (2002): Neuromyelitis optica. Semin Neurol 22 (2), 105-122

Currier RD, Haerer AF, Meydrech EF (1993): Low dose oral methotrexate treatment of multiple sclerosis: a pilot study. J Neurol Neurosurg Psychiatry $\underline{56}$ (11), 1217-1218

Daniels JB, Pappenheimer AW, Richardson S (1952): Observations on encephalomyelitis of mice (da strain). J Exp Med $\underline{96}$, 517-530

Dell Albani P, Kahn MA, Cole R, Condorelli DF, Giuffrida-Stella AM, de Vellis J (1998): Oligodendroglial survival factors, PDGF-AA and CNTF, activate similar JAK/STAT signaling pathways. J Neurosci Res 54 (2), 191-205

Denu JM, Dixon JE (1998): Protein tyrosin phosphatases: mechanisms of catalysis and regulation. Curr Opin Chem Biol 2 (5), 633-641

de Rosbo NK, Milo R, Lees MB, Burger D, Bernard CCA, Ben-Nun A (1993): Reactivity to myelin antigens in multiple sclerosis. J Clin Invest 92 (6), 26022608

Detels R, Visscher BR, Malmgren RM, Coulson AH, Lucia MV, Dudley JP (1977): Evidence for lower susceptibility to multiple sclerosis in japanese-americans. Am J Epidemiol 105 (4), 303-310 
de Vos AF, van Meurs M, Brok HP, Boven LA, Hintzen RQ, van der Valk $P$, Ravid $R$, Rensing S, Boon L, 't Hart BA, et al. (2002): Transfer of central nervous system autoantigens and presentation in secondary lymphoid organs. J Immunol 169 (10), 5415-5423

Diemel LT, Copelman CA, Cuzner ML (1998): Macrophages in CNS remyelination: friend or foe? Neurochem Res 23 (3), 341-347

D'Souza SD, Alinauskas KA, Antel JP (1996): Ciliary neurotrophic factor selectively protects human oligodendrocytes from tumor necrosis factormediated injury. J Neurosci Res 43 (3), 289-298

Dutta R, Trapp B (2007): Pathogenesis of axonal and neuronal damage in multiple sclerosis. Neurology 68 (Suppl 3), S22-S31

Ebers GC, Sadovnick AD (1994): The role of genetic factors in multiple sclerosis susceptibility. J Neuroimmunol $\underline{54}$ (1-2), 1-17

Elian M, Nightingale S, Dean G (1990): Multiple sclerosis among united kingdom-born children of immigrants from the indian subcontinent, afrika and the west indies. J Neurol Neurosurg Psychiatry 53, 906-911

European Study Group on Interferon $\beta-1 b$ in Secondary Progressive MS (1998): Placebo-controlled multicentre randomised trial of interferon $\beta-1 b$ in treatment of secondary progressive multiple sclerosis. Lancet 352 (9139), 14911497

Faissner A, Heck N, Dobbertin A, Garwood J (2006): DSD-1proteoglycan/phosphacan and receptor protein tyrosine phosphatase-beta isoforms during development and regeneration of neural tissues. Adv Exp Med Biol $\underline{57}, 28$

Ferguson B, Matyszak MK, Esiri MM, Perry VH (1997): Axonal damage in acute

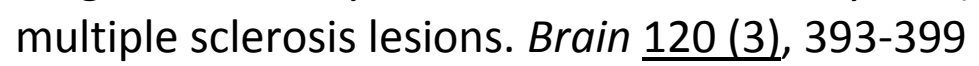

Flachenecker P, Stuke K, Elias W, Freidel M, Haas J, Pitschnau-Michel D, Schimrigk S, Zettl U, Rieckmann P (2008): Multiple-Sklerose-Register in Deutschland: Ausweitung des Projektes 2005/2006. Dtsch Arztebl 105 (7), 113119

Franklin RJM (2002): Why does remyelination fail in multiple sclerosis? Nat Rev Neurosci $\underline{3}, 705-714$ 
Gaillard PJ, van der Meide PH, de Boer AG, Breimer DD (2001): Glucocorticoid and type I interferon interactions at the blood-brain barrier: relevance for drug therapies for multiple sclerosis. Neuroreport 12 (10), 2189-2193

Gebbink MFBG, van Etten I, Hateboer G, Suijkerbuijk R, Beijersbergen RL, van Kessel AG, Moolenaar WH (1991): Cloning, expression and chromosomal localization of a new putative receptor-like protein tyrosine phosphatase. FEBS Lett 290 (1-2), 123-130

Gensert JM, Goldman JE (1997): Endogenous progenitors remyelinate demyelinated axons in the adult CNS. Neuron 19 (1), 197-203

Gieffers J, Pohl D, Treib J, Dittmann R, Stephan C, Klotz K, Hanefeld F, Solbach W, Haass A, Maass M (2001): Presence of Chlamydia pneumoniae DNA in the cerebral spinal fluid is a common phenomenon in a variety of neurological diseases and not restricted to multiple sclerosis. Ann Neurol 49 (5), 585-589

Giulian D, Baker TJ, Shih LCH, Lachman LB (1986): Interleukin 1 of the central nervous system is produced by ameboid microglia. J Exp Med 164 (2), 594-604

Gleixner C: Multiple Sklerose; in: Neurologie und Psychiatrie. Für Studium und Praxis, 6. Auflage; hrsg. v. Müller $M$; Medizinische Verlags- und Informationsdienste, Breisach 2007/2008, 69-74

Gold R, Linington C, Lassmann H (2006): Understanding pathogenesis and therapy of multiple sclerosis via animal models: 70 years of merits and culprits in experimental autoimmune encephalomyelitis research. Brain $\underline{129}$ (8), 19531971

Golde S, Coles A, Lindquist JA, Compston A (2003): Decreased iNOS synthesis mediates dexamethasone-induced protection of neurons from inflammatory injury in vitro. Eur J Neurosci 18 (9), 2527-2537

Grauer O, Offenhäusser M, Schmidt J, Toyka KV, Gold R (2001): Glukokortikosteroid-Therapie bei Optikusneuritis und Multipler Sklerose. Nervenarzt 72 (8), 577-589

Grumet M, Flaccus A, Margolis RU (1993): Functional characterization of chondroitin sulfate proteoglycans of brain: interactions with neurons and neural cell adhesion molecules. J Cell Biol 120 (3), 815-824 
Haas J, Maass-Enriquez M, Hartung HP (2005): Intravenous immunoglobulins in the treatment of relapsing remitting multiple sclerosis - results of a retrospective multicenter observational study over five years. Mult Scler $\underline{11(5)}$, 562-567

Hafler DA, Compston A, Sawcer S, Lander ES, Daly MJ, De Jager PL, de Bakker PIW, Gabriel SB, Mirel DB, Ivinson AJ, et al. (2007): Risk alleles for multiple sclerosis identified by a genomewide study. N Engl J Med 357 (9), 851-862

Hall SM (1972): The effect of injections of lysophosphatidyl choline into white matter of the adult mouse spinal cord. J Cell Sci 10 (2), 535-546

Harroch S, Palmeri M, Rosenbluth J, Custer A, Okigaki M, Shrager P, Blum M, Buxbaum JD, Schlessinger J (2000): No obvious abnormality in mice deficient in receptor protein tyrosine phosphatase $\beta$. Mol Cell Biol 20 (20), 7706-7715

Harroch S, Furtado GC, Brück W, Rosenbluth J, Lafaille J, Chao M, Buxbaum JD, Schlessinger J (2002): A critical role for the protein tyrosine phosphatase receptor type $Z$ in functional recovery from demyelinating lesions. Nat Genet $\underline{32}, 411-414$

Hartung HP, Grossman RI (2001): ADEM: distinct disease or part of the MS spectrum? Neurology $\underline{56(10)}, 1257-1260$

Hartung HP, Gonsette R, König N, Kwiecinski H, Guseo A, Morrissey SP, Krapf H, Zwingers T, Mitoxantrone in Multiple Sclerosis Study Group (M1MS) (2002): Mitoxantrone in progressive multiple sclerosis: a placebo-controlled, doubleblind, randomised, multicentre trial. Lancet 360 (9350), 2018-2025

Hawkins SA, McDonnell GV (1999): Benign multiple sclerosis? Clinical course, long term follow up, and assessment of prognostic factors. J Neurol Neurosurg Psychiatry $\underline{67}$ (2), 148-152

Hein T, Hopfenmüller W (2000): Hochrechnung der Zahl an Multipler Sklerose erkrankten Patienten in Deutschland. Nervenarzt 71 (4),288-294

Henze T (2004): Symptomatische Therapie der Multiple Sklerose. Psychoneuro 30 (7), 393-400

Hermiston ML, Xu Z, Weiss A (2003): CD45: a critical regulator of signaling thresholds immune cells. Annu Rev Immunol 21, 107-137 
Hiremath MM, Saito Y, Knapp GW, Ting JPY, Suzuki K, Matsushima GK (1998): Microglial/macrophage accumulation during cuprizone-induced demyelination in C57BL/6 mice. J Neuroimmunol 92 (1-2), 38-49

Ho MK, Springer TA (1983): Tissue distribution, structural characterization, and biosynthesis of Mac-3, a macrophage surface glycoprotein exhibiting molecular weight heterogeneity. J Biol Chem 258 (1), 636-642

Hogancamp WE, Rodriguez M, Weinshenker BG (1997): The epidemiology of multiple sclerosis. Mayo Clin Proc 72 (9), 871-878

Hohlfeld R, Kerschensteiner M, Stadelmann C, Lassmann H, Wekerle H (2000): The neuroprotective effect of inflammation: implications for the therapy of multiple sclerosis. J Neuroimmunol 107 (2), 161-166

Hoppel CL, Tandler B (1973): Biochemical effects of cuprizone on mouse liver and heart mitochondria. Biochem Pharmacol 22 (18), 2311-2318

Hotamisligil GS, Budavari A, Murray D, Spiegelman BM (1994): Reduced tyrosine kinase activity of the insulin receptor in obesity-diabetes: central role of tumor necrosis factor- $\alpha$. J Clin Invest 94 (4), 1543-1549

Huang JK, Ferrari CC, de Castro GM, Lafont D, Zhao C, Zaratin P, Pouly S, Greco B, Franklin RJM (2012): Accelerated axonal loss following acute CNS demyelination in mice lacking protein tyrosine phosphatase receptor type $z$. Am J Pathol 181 (5), 1518-1523

Hunter T (1995): Protein kinases and phosphatases: the yin and yang of protein phosphorylation and signaling. Cell $\underline{80}$ (2), 225-236

Jiang YP, Wang H, D’Eustachio P, Musacchio JM, Schlessinger J, Sap J (1993): Cloning and characterization of R-PTP-K, a new member of the receptor protein tyrosine phosphatase family with a proteolytically cleaved cellular adhesion molecule-like extracellular region. Mol Cell Biol 13 (5), 2942-2951

Johnson KP, Brooks BR, Cohen JA, Ford CC, Goldstein J, Lisak RP, Myers LW, Panitch HS, Rose JW, Schiffer RB, et al. (1995): Copolymer 1 reduces relapse rate and improves disability in relapsing-remitting multiple sclerosis: results of a phase III multicenter, double-blind, placebo-controlled trial. Neurology 45 (7), 1268-1276

Kabat EA, Wolf A, Bezer AE (1947): The rapid production of acute disseminated encephalomyelitis in rhesus monkeys by injection of heterologous and homologous brain tissue with adjuvants. J Exp Med $\underline{85}$, 117-130 
Kawachi H, Tamura H, Watakabe I, Shintani T, Maeda N, Noda M (1999): Protein tyrosine phosphatase $/$ /RPTP $\beta$ interacts with PSD-95/SAP90 family. Brain Res Mol Brain Res 72 (1), 47-54

Keirstead HS, Blakemore WF (1997): Identification of post-mitotic oligodendrocytes incapable of remyelination within the demyelinated adult spinal cord. J Neuropathol Exp Neurol 56 (11), 1191-1201

Kida E, Palminiello S, Golabek AA, Walus M, Wierzba-Bobrowicz T, Rabe A, Albertini G, Wisniewski KE (2006): Carbonic anhydrase II in the developing and adult human brain. J Neuropathol Exp Neurol 65 (7), 664-674

Komoly S (2005): Experimental demyelination caused by primary oligodendrocyte dystrophy. Regional distribution of the lesions in the nervous system of mice. Ideggyogy Sz $\underline{58(1-2)}, 40-43$

Komoly S, Jeyasingham MD, Pratt OE, Lantos PL (1987): Decrease in oligodendrocyte carbonic anhydrase activity preceding myelin degeneration in cuprizone induced demyelination. J Neurol Sci 79 (1-2), 141-148

Komoly S, Hudson LD, Webster HD, Bondy CA (1992): Insulin-like growth factor I gene expression is induced in astrocytes during experimental demyelination. Proc Natl Acad Sci U S A 89 (5), 1894-1898

Koo EH, Sisodia SS, Archer DR, Martin L, Weidemann A, Beyreuther K, Fischer P, Masters CL, Price DL (1990): Precursor of amyloid protein in Alzheimer disease undergoes fast anterograde axonal transport. Proc Natl Acad Sci U S A 87 (4), 1561-1565

Krueger NX, Saito H (1992): A human transmembrane protein-tyrosine-

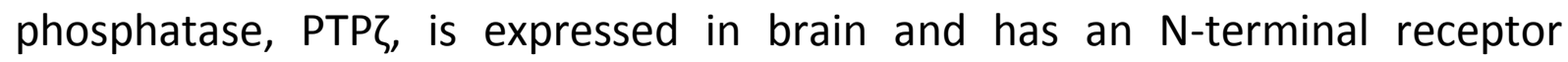
domain homologous to carbonic anhydrases. Proc Natl Acad Sci U S A 89 (16), 7417-7421

Krueger NX, Streuli M, Saito H (1990): Structural diversity and evolution of human receptor-like protein tyrosine phosphatases. EMBO J 9 (10), 3241-3252

Krupp LB, Christodoulou C (2001): Fatigue in multiple sclerosis. Curr Neurol Neurosci Rep 1 (3), 294-298

Kuhlmann T, Remington L, Maruschak B, Owens T, Brück W (2007): Nogo-A is a reliable oligodendroglial marker in adult human and mouse CNS and in demyelinated lesions. J Neuropathol Exp Neurol 66 (3) 238-246 
Kuhlmann T, Miron V, Cuo Q, Wegner C, Antel J, Brück W (2008): Differentiation block of oligodendroglial progenitor cells as a cause for remyelination failure in chronic multiple sclerosis. Brain $\underline{131}$ (7), 1749-1758

Kurtzke JF (1983): Rating neurologic impairment in multiple sclerosis: an expanded disability status scale (EDSS). Neurology 33 (11), 1444-1452

Lang G: Histotechnik. Praxislehrbuch für die Biomedizinische Analytik. 1.Auflage; Springer-Verlag, Wien 2006, 183-189, 207-210, 226-227 und 258-268

Lassmann H, Brück W, Lucchinetti C, Rodriguez M (1997): Remyelination in multiple sclerosis. Mult Scler $\underline{3}$ (2), 133-136

Lassmann H, Brück W, Lucchinetti C (2001): Heterogeneity of multiple sclerosis pathogenesis: implications for diagnosis and therapy. Trends Mol Med 7 (3), $115-121$

Leary SM, Thompson AJ (2005): Primary progressive multiple sclerosis: current and future treatment options. CNS Drugs 19 (5), 369-376

Lennon VA, Kryzer TJ, Pittock SJ, Verkman AS, Hinson SR (2005): IgG marker of optic-spinal multiple sclerosis binds to the aquaporin-4 water channel. $J$ Exp Med 202 (4), 473-477

Levy JB, Canoll PD, Silvennoinen O, Barnea G, Morse B, Honegger AM, Huang JT, Cannizzaro LA, Park SH, Druck T, et al. (1993): The cloning of a receptor-type protein tyrosine phosphatase expressed in the central nervous system. J Biol Chem 268 (14), 10573-10581

Li L, Dixon JE (2000): Form, function, and regulation of protein tyrosine phosphatases and their involvement in human diseases. Semin Immunol 12 (1), 75-84

Lipton HL (1975): Theiler's virus infection in mice: an unusual biphasic disease process leading to demyelination. Infect Immun 11 (5), 1147-1155

Lu QR, Yuk D, Alberta JA, Zhu Z, Pawlitzky I, Chan J, McMahon AP, Stiles CD, Rowitch DH (2000): Sonic hedgehog-regulated oligodendrocyte lineage genes encoding bHLH proteins in the mammalian central nervous system. Neuron $\underline{25}$ (2), 317-329

Lublin FD (1992): Susceptibility to experimental allergic encephalomyelitis in animal models of autoimmunity. Curr Opin Neurol 5 (2), 182-187 
Lublin FD, Reingold SC (1996): Defining the clinical course of multiple sclerosis: results of an international survey. Neurology 46 (4), 907-911

Lucchinetti C, Brück W, Parisi J, Scheithauer B, Rodriguez M, Lassmann H (1999): A quantitative analysis of oligodendrocytes in multiple sclerosis lesions. Brain 122 (12), 2279-2295

Lucchinetti C, Brück W, Parisi J, Scheithauer B, Rodriguez M, Lassmann H (2000): Heterogeneity of multiple sclerosis lesions: implications for the pathogenesis of demyelination. Ann Neurol 4 7 (6), 707-717

Ludwin SK (1978): Central nervous system demyelination and remyelination in the mouse: an ultrastructural study of cuprizone toxicity. Lab Invest 39 (6), 597612

Ludwin SK (1984): Proliferation of mature oligodendrocytes after trauma to the central nervous system. Nature $\underline{308}, 274-275$

Ludwin SK, Bakker DA (1988): Can oligodendrocytes attached to myelin proliferate? J Neurosci 8 (4), 1239-1244

Lutton JD, Winston R, Rodman TC (2004): Multiple sclerosis: ethiological mechanisms and future directions. Exp Biol Med 229, 12-20

Maeda N, Nishiwaki T, Shintani T, Hamanaka H, Noda M (1996): 6B4 proteoglycan/phosphacan, an extracellular variant of receptor-like proteintyrosine phosphatase $\zeta / R P T P \beta$, binds pleiotrophin/heparin-binding growthassociated molecule (HB-GAM). J Biol Chem 271 (35), 21446-21452

Maeda N, Ichihara-Tanakas K, Kimura T, Kadomatsu K, Muramatsu T, Noda M (1999): A receptor-like protein-tyrosine phosphatase PTPC/RPTP $\beta$ binds a heparin-binding growth factor midkine. J Biol Chem $\underline{274}$ (18), 12474-12479

Marburg O (1906): Die sogenannte "akute multiple Sklerose" (Encephalomyelitis periaxialis scleroticans). Jahrb Psych Neurol 27, 211-312

Martin R, McFarland HF (1995): Immunological aspects of experimental allergic encephalomyelitis and multiple sclerosis. Crit Rev Clin Lab Sci 32 (2), 121-182

Martin R, Schippling S, Heesen C (2008): Zukünftige Therapien der multiplen Sklerose. Aktuelle Neurol 35, 169-176 
Mason DY, Krissansen GW, Davey FR, Crumpton MJ, Gatter KC (1988): Antisera against epitopes resistant to denaturation on T3 (CD3) antigen can detect reactive and neoplastic $T$ cells in paraffin embedded tissue biopsy specimens. $J$ Clin Pathol 41 (2), 121-127

Mason JL, Ye P, Suzuki K, D’Ercole AJ, Matsushima GK (2000 a): Insulin-like growth factor-1 inhibits mature oligodendrocyte apoptosis during primary demyelination. J Neurosci 20 (15), 5703-5708

Mason JL, Jones JJ, Taniike M, Morell P, Suzuki K, Matsushima GK (2000 b): Mature oligodendrocyte apoptosis precedes IGF-1 production and oligodendrocyte progenitor accumulation and differentiation during demyelination/remyelination. J Neurosci Res $\underline{61}$ (3), 251-262

Matozaki T, Suzuki T, Uchida T, Inazawa J, Ariyama T, Matsuda K, Horita K, Noguchi H, Mizuno H, Sakamoto C, et al. (1994): Molekular cloning of a human transmembrane-type protein tyrosine phosphatase and its expression in gastrointestinal cancers. J Biol Chem 269 (3), 2075-2081

Matsushima GK, Morell P (2001): The neurotoxicant, cuprizone, as a model to study demyelination and remyelination in the central nervous system. Brain Pathol 11 (1), 107-116

Maurel P, Rauch U, Flad M, Margolis RK, Margolis RU (1994): Phosphacan, a chondroitin sulfate proteoglycan of brain that interacts with neurons and neural cell-adhesion molecules, is an extracellular variant of a receptor-type protein tyrosine phosphatase. Proc Natl Acad Sci U S A 91 (7), 2512-2516

McDonald WI, Compston A, Edan G, Goodkin D, Hartung HP, Lublin FD, McFarland HF, Paty DW, Polman CH, Reingold SC, et al. (2001): Recommended diagnostic criteria for multiple sclerosis: guidelines from the international panel on the diagnosis of multiple sclerosis. Ann Neurol $\underline{50}$ (1), 121-127

Melcangi RC, Cavarretta I, Magnaghi V, Ciusani E, Salmaggi A (2000): Corticosteroids protect oligodendrocytes from cytokine-induced cell death. Neuroreport 11 (18), 3969-3972

Mews I, Bergmann M, Bunkowski S, Gullotta F, Brück W (1998): Oligodendrocyte and axon pathology in clinically silent multiple sclerosis lesions. Mult Scler $\underline{4}$ (2), 55-62

Miller DJ, Rodriguez M (1995): Spontaneous and induced remyelination in multiple sclerosis and the Theiler's virus model of central nervous system Demyelination. Microsc Res Tech 32 (3), 230-245 
Minagar A, Alexander JS (2003): Blood-brain barrier disruption in multiple sclerosis. Mult Scler 9 (6), 540-549

Mizuno K, Hasegawa K, Katagiri T, Ogimoto M, Ichikawa T, Yakura H (1993): MPTPS, a putative murine homolog of HPTPS, is expressed in specialized regions of the brain and in the B-cell lineage. Mol Cell Biol 13 (9), 5513-5523

Morell P, Barrett CV, Mason JL, Toews AD, Hostettler JD, Knapp GW, Matsushima GK (1998): Gene expression in brain during cuprizone-induced demyelination and remyelination. Mol Cell Neurosci 12 (4-5), 220-227

Mourey RJ, Dixon JE (1994): Protein tyrosine phosphatases: characterization of extracellular and intracellular domains. Curr Opin Genet Dev 4 (1), 31-39

Nishiwaki T, Maeda N, Noda M (1998): Characterization and developmental regulation of proteoglycan-type protein tyrosine phosphatase $3 / R P T P \beta$ isoforms. J Biochem 123 (3), 458-467

Noronha A, Toscas A, Jensen MA (1993): Interferon $\beta$ decreases T cell activation and interferon $\gamma$ production in multiple sclerosis. J Neuroimmunol 46 (1-2), 145153

Norton WT, Aquino DA, Hozumi I, Chiu FC, Brosnan CF (1992): Quantitative aspects of reactive gliosis: a review. Neurochem Res 17 (9), 877-885

Östman A, Yang Q, Tonks NK (1994): Expression of DEP-1, a receptor-like protein-tyrosine-phosphatase, is enhanced with increasing cell density. Proc Natl Acad Sci U S A 91 (21), 9680-9684

Ohyama K, Kawano H, Asou H, Fukuda T, Oohira A, Uyemura K, Kawamura K (1998): Coordinate expression of L1 and 6B4 proteoglycan/phosphacan is correlated with the migration of mesencephalic dopaminergic neurons in mice. Brain Res Dev Brain Res 107 (2), 219-226

Oldstone MBA (1998): Molecular mimicry and immune-mediated diseases. FASEB J 12, 1255-1265

Ozawa K, Suchanek G, Breitschopf H, Brück W, Budka H, Jellinger K, Lassmann H (1994): Patterns of oligodendroglia pathology in multiple sclerosis. Brain $\underline{117}$ (6), 1311-1322

Pallen CJ (1993): The receptor-like protein tyrosine phosphatase $\alpha$ : a role in cell proliferation and oncogenesis. Semin Cell Biol $\underline{4(6)}$, 403-408 
Park HC, Mehta A, Richardson JS, Appel B (2002): Olig2 is required for zebrafish primary motor neuron and oligodendrocyte development. Dev Biol 248 (2), 356-368

Patrikios P, Stadelmann C, Kutzelnigg A, Rauschka H, Schmidbauer M, Laursen H, Soelberg Sorensen P, Brück W, Lucchinetti C, Lassmann H (2006): Remyelination is extensive in a subset of multiple sclerosis patients. Brain $\underline{129}$ (12), 3165-3172

Peles E, Nativ M, Campbell PL, Sakurai T, Martinez R, Lev S, Clary DO, Schilling J, Barnea G, Plowman GD, et al. (1995): The carbonic anhydrase domain of receptor tyrosine phosphatase $\beta$ is a functional ligand for the axonal cell recognition molecule contactin. Cell $\underline{82}$ (2), 251-260

Peles E, Nativ M, Lustig M, Grumet M, Schilling J, Martinez R, Plowman GD, Schlessinger J (1997): Identification of a novel contactin-associated transmembrane receptor with multiple domains implicated in protein-protein interactions. $E M B O J \underline{16(5)}, 978-988$

Peretz A, Gil-Henn H, Sobko A, Shinder V, Attali B, Elson A (2000): Hypomyelination and increased activity of voltage-gated $\mathrm{K}^{+}$channels in mice lacking protein tyrosine phosphatase $\varepsilon$. EMBO J 19 (15), 4036-4045

Périer O, Grégoire A (1965): Electron microscopic features of multiple sclerosis lesions. Brain $\underline{88(5)}$, 937-952

Peterson RE, Bollier ME (1955): Spectrophotometric determination of serum copper with biscyclohexanoneoxalyldihydrazone. Anal Chem 27 (7), 1195-1197

Pitt D, Werner P, Raine CS (2000): Glutamate excitotoxicity in a model of multiple sclerosis. Nat Med $\underline{6}$ (1), 67-70

Pöhlau D, Aktas O, Epplen C, Hartung HP, Hoffmann V, Przuntek H (1998): Remyelinisierungsförderung als zukünftiges Therapiekonzept der Multiplen Sklerose? Nervenarzt 69 (10), 841-850

Polman CH, Reingold SC, Edan G, Filippi M, Hartung HP, Kappos L, Lublin FD, Metz LM, McFarland HF, O'Connor PW, et al. (2005): Diagnostic criteria for

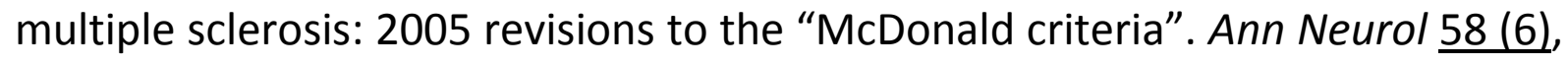
840-846 
Polman CH, Reingold SC, Banwell B, Clanet M, Cohen JA, Filippi M, Fujihara K, Havrdova E, Hutchinson M, Kappos L, et al. (2011): Diagnostic criteria for multiple sclerosis: 2010 revisions to the McDonald criteria. Ann Neurol 69 (2), 292-302

Poser CM (1994): The epidemiology of multiple sclerosis: a general overview. Ann Neurol 36 (S2), S180-S193

Poser CM, Brinar VV (2000): Diagnostic criteria for multiple sclerosis. Clin Neurol Neurosurg 103 (4), 1-11

Poser CM, Paty DW, Scheinberg L, McDonald WI, Davis FA, Ebers GC, Johnson KP, Sibley WA, Silberberg DH, Tourtellotte WW (1983): New diagnostic criteria for multiple sclerosis: guidelines for research protocols. Ann Neurol 13 (3), 227231

Poser CM, Goutières F, Carpentier MA, Aicardi J (1986): Schilder's myelinoclastic diffuse sclerosis. Pediatrics $\underline{77(1)}, 107-112$

Prineas JW, Barnard RO, Revesz T, Kwon EE, Sharer L, Cho ES (1993): Multiple sclerosis: pathology of recurrent lesions. Brain 116 (3), 681-693

Raine CS, WU E (1993): Multiple sclerosis: remyelination in acute lesions. J Neuropathol Exp Neurol 52 (3), 199-204

Ranjan M, Hudson LD (1996): Regulation of tyrosine phosphorylation and protein tyrosine phosphatases during oligodendrocyte differentiation. Mol Cell Neurosci 7 (5), 404-418

Remington LT, Babcock AA, Zehntner SP, Owens T (2007): Microglial recruitment, activation, and proliferation in response to primary demyelination. Am J Pathol 170 (5), 1713-1724

Rieckmann P, Toyka KV (2002): Immunmodulatorische Stufentherapie der Multiplen Sklerose. Neue Aspekte und praktische Umsetzung, März 2002. Nervenarzt 73 (6), 556-563

Risau W, Engelhardt B, Wekerle H (1990): Immune function of the blood-brain barrier: incomplete presentation of protein (auto-)antigens by rat brain microvascular endothelium in vitro. J Cell Biol $\underline{110}$, 1757-1766

Rivers TM, Sprunt DH, Berry GP (1933): Observations on attempts to produce acute disseminated encephalomyelitis in monkeys. J Exp Med 58 (1), 39-53 
Rodriguez M, Miller DJ, Lennon VA (1996): Immunoglobulins reactive with myelin basic protein promote CNS remyelination. Neurology 46 (2), 538-545

Ropper AH (2006): Selective treatment of multiple sclerosis. N Engl J Med $\underline{354}$, 965-967

Rudick RA, Ransohoff RM, Peppler R, VanderBrug Medendorp S, Lehmann P, Alam J (1996): Interferon beta induces interleukin-10 expression: relevance to multiple sclerosis. Ann Neurol 40 (4), 618-627

Sadovnick AD (2002): The genetics of multiple sclerosis. Clin Neurol Neurosurg 104, 199-202

Sakurai T, Lustig M, Nativ M, Hemperly JJ, Schlessinger J, Peles E, Grumet M (1997): Induction of neurite outgrowth through contactin and $\mathrm{Nr}$-CAM by extracellular regions of glial receptor tyrosine phosphatase $\beta$. J Cell Biol $\underline{136}$ (4), 907-918

Scheibenbogen C, Andreesen R (1991): Developmental regulation of the cytokine repertoire in human macrophages: IL-1, IL-6, TNF- $\alpha$, and M-CSF. J Leukoc Biol 50, 35-42

Schlesinger H (1909): Zur Frage der akuten multiplen Sklerose und der Encephalomyelitis disseminata im Kindesalter. Arb Neurol Inst Wien 17, 410433

Schönrock LM, Kuhlmann T, Adler S, Bitsch A, Brück W (1998): Identification of glial cell proliferation in early multiple sclerosis lesions. Neuropathol Appl Neurobiol 24 (4), 320-330

Seo Y, Matozaki T, Tsuda M, Hayashi Y, Itoh H, Kasuga M (1997): Overexpression of SAP-1, a transmembrane-type protein tyrosine phosphatase, in human colorectal cancers. Biochem Biophys Res Commun 231 (3), 705-711

Shapiro IP, Masliah E, Saitoh T (1991): Altered protein tyrosine phosphorylation in Alzheimer`s disease. J Neurochem 56 (4), 1154-1162

Shintani T, Watanabe E, Maeda N, Noda M (1998): Neurons as well as astrocytes express proteoglycan-type protein tyrosine phosphatase Z/RPTP $\beta$ : analysis of mice in which the PTPC/RPTP $\beta$ gene was replaced with the LacZ gene. Neurosci Lett 247 (2-3), 135-138 
Sim FJ, Zhao C, Penderis J, Franklin RJM (2002): The age-related decrease in CNS remyelination efficiency is attributable to an impairment of both oligodendrocyte progenitor recruitment and differentiation. J Neurosci 22 (7), 2451-2459

Simić D, Budić I (2003): Trace elements. Acta Fac Med Naiss 20 (4), 189-202

Smith ME (1999): Phagocytosis of myelin in demyelinative disease: a review. Neurochem Res 24 (2), 261-268

Snyder SE, Li J, Schauwecker PE, McNeill TH, Salto SRJ (1996): Comparison of RPTP $/ \beta$, phosphacan, and trk B mRNA expression in the developing and adult rat nervous system and induction of RPTP $/ \beta$ and phosphacan mRNA following brain injury. Brain Res Mol Brain Res 40 (1), 79-96

Sriram S, Rodriguez M (1997): Indictment of the microglia as the villain in multiple sclerosis. Neurology 48 (2), 464-470

Steinman L (2001): Multiple sclerosis: a two-stage disease. Nat Immunol 2 (9), 762-764

Streuli M, Krueger NX, Tsai AYM, Saito H (1989): A family of receptor-linked protein tyrosine phosphatases in humans and drosophila. Proc Natl Acad Sci U SA $\underline{86(22)}, 8698-8702$

Streuli M, Krueger NX, Thai T, Tang M, Saito H (1990): Distinct functional roles of the two intracellular phosphatase like domains of the receptor-linked

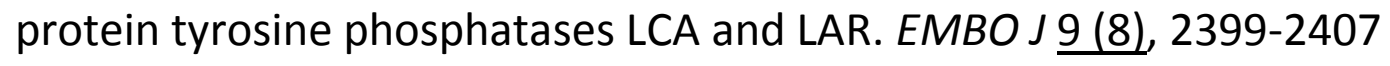

Streuli M, Krueger NX, Ariniello PD, Tang M, Munro JM, Blattler WA, Adler DA, Disteche CM, Saito $H$ (1992): Expression of the receptor-linked protein tyrosine phosphatase LAR: proteolytic cleavage and shedding of the CAM-like

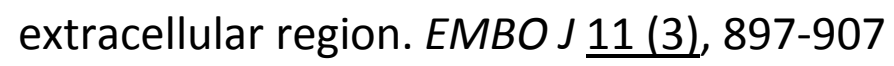

Stüve O, Dooley NP, Uhm JH, Antel JP, Francis GS, Williams G, Yong VW (1996): Interferon $\beta-1 b$ decreases the migration of $T$ lymphocytes in vitro: effects on matrix metalloproteinase-9. Ann Neurol $\underline{40}$ (6), 853-863

Suzuki K, Andrews JM, Waltz JM, Terry RD (1969): Ultrastructural studies of multiple sclerosis. Lab Invest 20 (5), 444-454

The IFNB Multiple Sclerosis Study Group (1993): Interferon beta-1b is effective in relapsing-remitting multiple sclerosis: I. clinical results of a multicenter, randomized, double-blind, placebo-controlled trial. Neurology 43 (4), 655-661 
Theiler M (1937): Spontaneous encephalomyelitis of mice, a new virus disease. J Exp Med 65 (5), 705-719

Thompson AJ, Polmann CH, Miller DH, McDonald WI, Brochet B, Philippi M, Montalban X, De Sá J (1997): Primary progressive multiple sclerosis. Brain $\underline{120}$ (6), 1085-1096

Toshniwal PK, Zarling EJ (1992): Evidence for increased lipid peroxidation in multiple sclerosis. Neurochem Res 17 (2), 205-207

Trebst C, Wiendl H, Stangel M (2006): Konzepte zur Läsionsentstehung bei Multipler Sklerose: Aktueller Diskussionsstand und klinisch-therapeutische

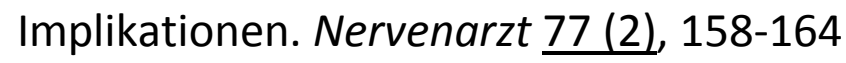

Umemori H, Kadowaki Y, Hirosawa K, Yoshida Y, Hironaka K, Okano H, Yamamoto $T$ (1999): Stimulation of myelin basic protein gene transcription by fyn tyrosine kinase for Myelination. J Neurosci 19 (4), 1393-1397

van Noort JM, van Sechel AC, Bajramovic JJ, El Ouagmiri M, Polman CH, Lassmann H, Ravid R (1995): The small heat-shock protein $\alpha$ B-crystallin as candidate autoantigen in multiple sclerosis. Nature $\underline{375}, 798-801$

Venturini G (1973): Enzymic activities and sodium, potassium and copper concentrations in mouse brain and liver after cuprizone treatment in vivo. $J$ Neurochem 22 (5), 1147-1151

Wakabayashi T, Green DE (1974): On the mechanism of cuprizone-induced

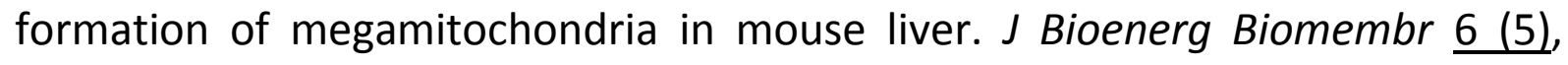
179-192

Wang H, Lian Z, Lerch MM, Chen Z, Xie W, Ullrich A (1996): Characterization of PCP-2, a novel receptor protein tyrosine phosphatase of the MAM domain family. Oncogene 12 (12), 2555-2562

Weiner HL, Cohen JA (2002): Treatment of multiple sclerosis with cyclophosphamide: critical review of clinical and immunologic effects. Mult Scler 8 (2), 142-154

Wiggins RC, Wiggins JE, Goyal M, Wharram BL, Thomas PE (1995): Molecular cloning of cDNAs encoding human GLEPP1, a membrane protein tyrosine phosphatase: characterization of the GLEPP1 protein distribution in human kidney and assignment of the GLEPP1 gene to human chromosome 12p12-p13. Genomics 27 (1), 174-181 
Wingerchuk DM, Lucchinetti CF, Noseworthy JH (2001): Multiple sclerosis:

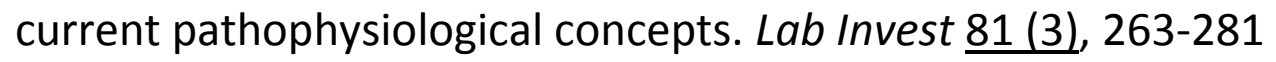

Wood PM, Bunge RP (1986): Myelination of cultured dorsal root ganglion neurons by oligodendrocytes obtained from adult rats. J Neurol Sci $\underline{74}$ (2-3), 153-169

Yajima K, Suzuki K (1979): Demyelination and remyelination in the rat central nervous system following ethidium bromide injection. Lab Invest 41 (5), 385392

Yan H, Grossman A, Wang H, D`Eustachio P, Mossie K, Musacchio JM, Silvennoinen O, Schlessinger J (1993): A novel receptor tyrosine phosphatase- $\sigma$ that is highly expressed in the nervous system. J Biol Chem 268 (33), 2488024886

Yudkin PL, Ellison GW (1991): Overview of azathioprine treatment in multiple sclerosis. Lancet 338 (8774), 1051-1055

Zhou Q, Wang S, Anderson DJ (2000): Identification of a novel family of oligodendrocyte lineage-specific basic helix-loop-helix transcription factors. Neuron 25 (2), 331-343 


\section{Danksagung}

Ich danke Herrn Prof. Dr. med. Wolfgang Brück für die Ermöglichung dieser Dissertation in seiner Abteilung.

Mein ganz besonderer Dank gilt meiner Betreuerin Frau Prof. Dr. med. Christine Stadelmann-Nessler, die mir mein Dissertationsthema vorschlug und mich bei der Fertigstellung meiner Arbeit stets überaus freundlich und engagiert mit kompetenten Ratschlägen unterstützt hat.

Mein Dank gilt auch Frau Dr. Claudia Wrzos für die Anleitung bei der praktischen Durchführung meiner Arbeit. 